Louisiana State University

LSU Digital Commons

1982

\title{
The Effects of Training, Goal Setting, and Knowledge of Results on Safe Behavior: a Component Analysis.
}

Robert Allen Reber

Louisiana State University and Agricultural \& Mechanical College

Follow this and additional works at: https://digitalcommons.Isu.edu/gradschool_disstheses

\section{Recommended Citation}

Reber, Robert Allen, "The Effects of Training, Goal Setting, and Knowledge of Results on Safe Behavior: a Component Analysis." (1982). LSU Historical Dissertations and Theses. 3737.

https://digitalcommons.Isu.edu/gradschool_disstheses/3737

This Dissertation is brought to you for free and open access by the Graduate School at LSU Digital Commons. It has been accepted for inclusion in LSU Historical Dissertations and Theses by an authorized administrator of LSU Digital Commons. For more information, please contact gradetd@lsu.edu. 


\section{INFORMATION TO USERS}

This was produced from a copy of a document sent to us for microfilming. While the most advanced technological means to photograph and reproduce this document have been used, the quality is heavily dependent upon the quality of the material submitted.

The following explanation of techniques is provided to help you understand markings or notations which may appear on this reproduction.

1. The sign or "target" for pages apparently lacking from the document photographed is "Missing Page(5)". If it was possible to obtain the missing page(s) or section, they are spliced into the film along with adjacent pages. This may have necessitated cutting through an image and duplicating adjacent pages to assure you of complete continuity.

2. When an image on the film is obliterated with a round black mark it is an indication that the film inspector noticed either blurred copy because of movement during exposure, or duplicate copy. Unless we meant to delete copyrighted materials that should not have been filmed, you will find a good image of the page in the adjacent frame. If copyrighted materials were deleted you will find a target note listing the pages in the adjacent frame.

3. When a map, drawing or chart, etc., is part of the material being photographed the photographer has followed a definite method in "sectioning" the material. It is customary to begin filming at the upper left hand corner of a large sheet and to continue from left to right in equal sections with small overlaps. If necessary, sectioning is continued again-beginning below the first row and continuing on until complete.

4. For any illustrations that cannot be reproduced satisfactorily by xerography, photographic prints can be purchased at additional cost and tipped into your xerographic copy. Requests can be made to our Dissertations Customer Services Department.

5. Some pages in any document may have indistinct print. In all cases we have filmed the best available copy.

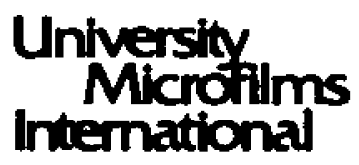

$300 N$. ZEEB RD. ANN ARBOR, MI 48106 


\section{6}

Reber, Robert Allen

THE EFFECTS OF TRAINING, GOAL SETTING, AND KNOWLEDGE OF RESULTS ON SAFE BEHAVIOR: A COMPONENT ANALYSIS

The Lowisiona State University and Agricultural and Mechanical CoL PH.D. 1982

University

Microfilms

International 300 N. Zeeb Roes, Ann Arbor, MI 48106 
PLeAse NOTE:

In all cases thls materlal has been filmed in the beet poseible way from the avaliable copy. Problems encountered with thls document have been identified here with a check mark

1. Glosey photographs or pagea

2. Colored Ilfustrations, paper or print

3. Photographs with dark background

4. Illustrations are poor copy

5. Pages with black marks, not original copy

B. Print shows through as there is text on both sides of page

7. Indiatinct, broken or amall print on several pages

8. Print exceeds margin requirements

9. Tightly bound copy with print lost in apine

10. Computer printout pages with indistinct print

11. Page(s) author. lacking when material received, and not avaifable from school or

12. Pago(s) soem to be missing in numbering only as text follows.

13. Two pages numbered . Text follows.

14. Curling and wrinkled pagee

15. Other

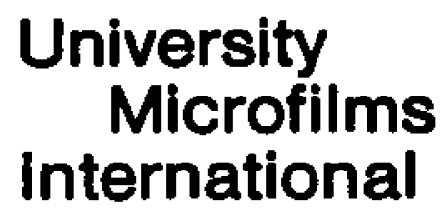


THE EFFECTS OF TRAINING, GOAL SETTING, AND KNOWLEDGE OF RESULTS ON SAFE BEHAVIOR:

\title{
A COMPONENT ANALYSIS
}

\author{
A Dissertation \\ Submitted to the Graduate Faculty of the \\ Louisiana State University and \\ Agricultural and Mechanical College \\ in partial fulfillment of the \\ requirements for the degree of \\ Doctor of Philosophy \\ in
}

The Department of Psychology

by

Robert A. Reber

B.A., West Virginia University, 1977

M.A., Louisiana State University, 1979

May 1982 


\section{ACKNOW LEDGEMENTS}

There are number of individuals who deserve recognition for their contributions toward the completion of this dissertation. First, I would like to thank Dr. Irving Lane for the autonomy, guidance, and support which he exhibited throughout my graduate career and especially as chairman of my comnittee. Special thanks goes to Dr. Jerry wallin for his encouragement and continuous efforts which were fundamental for the success of the project. I an obliged to Dr. Donald Willianson for his worthy suggestions, particularly concerning the design of the investigation. Appreciation is also extended to Drs. Laurence Siegel and Robert Mathews who made several constructive conments which proved to be quite useful.

In addition, I owe a debt of gratitude to Dr. Steven Buco for his invaluable assistance with the statistical analysis of the data. Further, I an grateful for the knowledgeable recommendations made by Dr. Judi Komaki of Georgia Tech in the early stages of the study.

Thanks should also be tendered to Mr. William Hadaway and Mr. Mel Hoskins for their time and efforts regarding the data collection. Acknowledgment with gratitude goes to the management and elployees of Cane Machinery and Engineering Company of Thibodaux, Louisiana for their cooperation as well.

I would like to express my appreciation to Mrs. Janice Walker for her patience, flexibility, and expediency in the typing of the final draft of this manuscript. 
Finally, I dedicate this dissertation to the people who were responsible for making it possible. To my parents, whose love and support throughout my life is the foundation for all that I have or aspire to accomplish. I especially dedicate this achievenent to my loving wife, Debbie, who provided the supportive environment, patience, encouragement, and hard work necessary to complete the task. 
Page

ACKNOWLEDGEMENTS . . . . . . . . . . . . . . . . . . . . . . ii

LIST OF TABLES . . . . . . . . . . . . . . . . . . . . . . vi

LIST OF FIGURES. . . . . . . . . . . . . . . . . . . . . . . . . vii

ABSTRACT . . . . . . . . . . . . . . . . . . . . . vii

I. INTRODUCTION, . . . . . . . . . . . . . . . . . . . 1

II. SAFETY RESEARCH . . . . . . . . . . . . . . . . . . 1

A. Introduction. . . . . . . . . . . . . . . . . . . . 1

B. The Human Side of Accident Prevention . . . . . . . . . 3

C. Applied Behavior Analysis in Safety Research. . . . . . 5

1. Rationale . . . . . . . . . . . . . . . . . . . 6

2. Measurement of Safety . . . . . . . . . . . . . 7

3. Methodological Contributions. . . . . . . . . . . 10

D. Summary and Comment . . . . . . . . . . . . . . . . 14

III. GOAL SETTING AND MNOWLEDGE OF RESULTS . . . . . . . . . . . 16

A. Introduction. . . . . . . . . . . . . . . . . . . 16

B. Goals as Mediators of Incentives. . . . . . . . . . . . 17

C. Goals as Mediators of KR. . . . . . . . . . . . . . . . 19

1. Rationale.................... 19

2. Empirical Evidence. . . . . . . . . . . . . . . 20

3. Necessity of KR..................... 25

D. Summary and Comment . . . . . . . . . . . . . . . 29

IV. RESEARCH OBJECTIVES . . . . . . . . . . . . . . . . . 30

V. METHOD. . . . . . . . . . . . . . . . . . . 33

A. Setting and Subjects. . . . . . . . . . . . . . . . 33

1. Setting....................... 33

2. Subjects. . . . . . . . . . . . . . . . . 34

B. Criteria Measures. . . . . . . . . . . . . . . . 35

1. Instrument. . . . . . . . . . . . . . . . 35

2. Observation Procedure ......... . . . . . 36

3. Computing the Safety Score. . . . . . . . . . . 38

C. Design and procedure. . . . . . . . . . . . . . . . . 40

1. Training only ................... 40

2. Goal Setting and Training . . . . . . . . . . . . . 43

3. Feedback (KR), Goal Setting, and Training . . . . . 46

VI. RESULTS . . . . . . . . . . . . . . . . . . . 50

A. Observational Reliability and Validity. . . . . . . . 50

B. Manipulation Checks . . . . . . . . . . . . . . . . 51

1. Training. . . . . . . . . . . . . . . . . 51

2. Goals....................... 51 
TABLE OF CONTENTS (continued)

Page

VI. RESULTS (continued)

C. Observational Data Analysis . . . . . . . . . 52

1. ARIMA Analysis. . . . . . . . . . . . . 52

2. Repeated Measures ANOVA . . . . . . . . . . 54

D. Accident Data .............. 54

VII. DIscussion. . . . . . . . . . . . . . . . . 55

A. Theoretical Implications. . . . . . . . . 55

B. Practical Implications. ............. 58

c. Conclusions................ 59

VIII. REFERENCE NOTES ................... 61

IX. REFERENCES. . . . . . . . . . . . . 63

X. APPENDICES. . . . . . . . . . . . . 78

A. Description of Departments. . . . . . . . . . 79

B. Location of Departments . . . . . . . . . . . . . . 84

C. Company Safety Manual . . . . . . . . . . . . 86

D. Observation Form. . . . . . . . . . . . . . 112

E. Observational Code. . . . . . . . . . . . . . 114

F. Multiple-Baseline Design of the Study . . . . . . . 121

G. Description of Training slides. . . . . . . . . 123

H. Safety Goal Sign. . . . . . . . . . . . . . . . . 129

I. Safety Goal Reminder. . . . . . . . . . . . . . . 131

J. Questionnaire for Manipulation Checks . . . . . . . 133

K. Feedback Sign ................. 140

L. Results of Departmental Data Analysis . . . . . . 142

VITA ...................... 160 


\section{LIST OF TABLES}

Page

1. Mean Group Response for Each Questionnaire Factor . . . . . . . 75

2. Mean Group Safety Performance for Each Period . . . . . . . . . 76

3. Mean Departmental Response for Each Questionnaire Factor. . . . 146

4. Mean Goal for Each Department After Receiving Feedback (KR) ** 147

5. Mean Departmental Safety Performance for Each Period. . . . . . 148 


\section{LIST OF FIGURES}

Figure

Page

1. Average weekly safety performance for each group . . . . . . . 77

2. a. Average weekly safety performance for final essembly . . . 149

b. Average weekly safety performance for hydraulics . . . . . 150

c. Average weekly safety performance for mechanics. . . . . . 151

d. Average weekly safety performance for painting/ sandblasting .. . . . . . . . . . . . . . . . . . . 152

e. Average weekly safety performance for heavy equipment. . . 153

f. Average weekly safety performance for raw material prep. . 154

g. Average weekly safety performance for sub-assenbly . . . . 155

h. Average weekly safoty performance for welding . . . . . . . 156

i. Average week1y safety performance for crating. . . . . . . 157

j. Average weekly safety performance for machine shop . . . . 158

k. Average weekly safety performance for parts. . . . . . . . 159 


\section{ABSTRACT}

The present research investigated the effects of training, goal setting, and knowledge of results (KR) on safe behavior in a field setting. As a result, it addressed both a theoretical issue and a practical problem. Of theoretical importance is ascertaining the effects of $K R$ when combined with goal setting. Of practical significance is assessing the utility of a behavioral approach to occupational safety.

Eleven departments ( $\underline{n}=105$ employees) of a farm machinery manufacturing plant were divided into three groups. A multiplebaseline, across-groups design was utilized for the four phases: a) baseline, b) Training Only, c) Goal Setting and Training, and d) Feedback (KR), Goal Setting, and Training. The primary dependent variable was the percentage of employees observed to be working in complete accordance with the behavioral safety rules.

An ARIMA analysis suggested that a white noise model best described the time series data. A repeated measures ANOVA revealed that, as hypothesized, behavioral safety performance was significantly better than baseline $(\bar{X}=62.208)$ after the employees were trained via explanation and visual presentation of the safety rules $(X=70.858)$. The ANOVA also indicated that, as prodicted, assigning a specific, difficult but acceptable departmental goal further significantly enhanced performance $(\bar{X}=77.544)$. When $K R$ was provided in relation to the goal, performance again significantly increased $(\bar{X}=95.39 \%)$. In addition, the overall and lost-time injury rates for the plant decreased considerably. 
It was concluded that feedback (KR) was a beneficial condition for the effects of goal setting to be maximally realized. Of practical significance is the finding that non-monetary incentives could be used to increase the frequency of safe behaviors. Future research was recommended to assess the function of $K R$ in relation to goals and to determine the generalizability of these results to other types of organizations and behaviors. 


\section{INTRODUCTION}

The present study attempts to make both a theoretical and practical contribution to the existing literature in the field of safety research. First, from a theoretical perspective it will provide an analysis of the relative effects of goal setting and knowledge of results on safety performance. Second, of practical importance, the study will systematically measure the effectiveness of a behavioral safety program through the use of a multiple-baseline design. As a result, this study will endeavor to bridge the gap between theory and the application of psychological principles (Dubin, 1976; Hale \& Hale, 1970) by at tempting to resolve current theoretical controversy in an actual organizational setting. The following literature revi ow sumarizes the two research areas relevant to the present investigation. The review presents literature concerning 1) the applied behavior analysis approach to safety, and 2) the effects of goal setting and knowledge of results.

\section{SAFETY RESEARCH}

\section{Introduction}

Occupational safety has been an issue of concern since about 2000 years before the Christian period when Hammurabi ordered a body of laws concerned with indemifying the injurod. From the early days of Christianity until the end of the 15 th century, information about industrial work situations is scanty. In the 17th and 18 th centuries, however, there was a succession of statutes governing working conditions in the textile and mining industries in Germany and Great 
Britain. The first safety regulations in the United States appeared in 1876, and the first workmen's compensation laws came in 1902 (Grimaldi Simonds, 1975). Perhaps "the most pervasive safety law" ever passed in the United States was the Williams-Steiger Act (1970), more popularly known as the Occupational Safety and Health Act. This act authorizes the federal govermment to set and enforce safety and health standards for all places of employment affecting interstate comerce, and to enforce the standards with criminal and civil penalties for violations (U.S. Department of Labor, 1976; Grimaldi Simonds, 1975) . To establish and enforce the federal occupational safety and health standards, a new agency, the Occupational Safety and Health Administration (OSHA) was created under the auspices of the Department of Labor. In conjunction with OSHA, a new agency in the Department of Health, Education and Welfare (HEW) was authorized. The duties of the HEW agency, the National Institute for Occupational Safety and Health (NIOSH), include conducting research and demonstrations relating to occupational safety and health, developing OSHA criteria, conducting inspections, and publishing data on occupational illness.

In addition to these government agencies, several 20th century private organizations have been established for the purpose of promoting safety. These include the National Safety Council (established in 1915); the American Society of Safety Engineers (1947); and the Center for Safety at New York University (1938); to name but a few. Numerous insurance companies and industrial organizations have also contributed to the developient of safety ideals and wethodology (Grimaldi Simonds, 1975). 
Associated with such continuing safety efforts was a 71 percent reduction in accidental work deaths per 100,000 population between 1912 and 1979. In 1912, an estimated 18,000 to 21,000 workers lost their lives. In 1979, with a work force more than twice the size, there were 13,200 work deaths (National Safety Council, 1980). Nevertheless it has been estimated that in the United States every 8 minutes there is 1 work related fatality, 148 disabling injuries, and over 500 less serious on-the-job injuries (Shafai-Sahrai, 1973). These figures highlight a continuing need for the development of methods to improve occupational safety and reduce accidents and injuries.

The Human Side of Accident Prevention

Several reviews of safety literature have noted that the bulk of existing accident prevention research and legislation has concentrated on making the work environment less hazardous (e.g., Ellis, 1975; Fitch, Hermann, \& Hopkins, 1976; Grimaldi \& Simonds, 1975;

Heinrich, 1959), However, safety researchers generally accept that the occurrence of an injury-producing accident requires both a behaving human being and hazardous physical environment capable of producing injury to the human being (Fitch et a1., 1976; Grimaldi 5 simonds, 1975; Hale \& Hale, 1970). Thus, while it is vitally important to continue the safety engineering approach for the latter causal factor, there is a need for a more effective approach to the behavioral half of the safety equation (Fitch et al., 1976).

Several early investigations concerned with the human-side of accident provention focused on identifying personal characteristics of employees that may be correlated with accident rates. Such reports 
have generally been non-supportive of "accident-proneness" theory (Crawford, 1960; Davids \& Mahoney, 1957; Harris, 1950; Kerr, 1957; Mintz B (um, 1949). However, there does seem to be an inverse relationship between both age and experience on the job and the frequency of injuries (Cohen, Smith, \& Cohen, 1975; Van Zelst, 1954). Other correlation studies have attempted to evaluate the effectiveness of employee-directed safety programs by comparing the various safety efforts of high- and low-accident rate companies (e.g., Cohen et al., 1975; Ellis, 1975; Shafai-Sahrai, 1973).

Although these studies are important initial steps, the conclusions that can be drawn from them are limited. For example, Fitch et al. (1976) recognized that there were many difficulties with these correlational studies, not the least of which is that correlation is a measure of association rather than causation. Frequently, the statistically significant correlations obtained in safety research are so low that little of the total variation is accounted for by the variables in question (Fitch et al., 1976). Further, the variables found to be related to occupational accidents and injuries may not be directly controllable by management (e.g., Sherman, Korr, \& Kosinar, 1957). As Fitch et al. (1976) noted, knowledge of the influence of uncontrollable variables may be potentially valuable to the scientist, but is of limited value to the manager who needs to know about variables which he can manipulate inexpensively.

There have been efforts to assess the effectiveness of safety campaigns in actual organizations. Such reseacch has generally focused on evaluating the benefits of informational caupaigns (lectures, 
posters, booklets, etc.) and/or promotional campaigns involving departmental competitions accompanied by rewards of disciplinary actions (Haskins, 1969, 1970; Laner Se11, 1960). It has been noted. however, that much of the existing safety research often reported in trade journals, is primarily descriptive and/or anecdotal (E1lis, 1975; Fitch et al., 1976; Haskins, 1969, 1970; Komaki, Barwick, \& Scott, 1978). Thus, there appears to be a faucity of well-controlled studies demonstrating the effectiveness of safety programs in actual work settings (Grimaldi, 1970; Haskins, 1969, 1970; Komaki et al, 1978). As Ellis (1975) concluded after his review of the literature, "the quality and intensity of research necessary to draw firm conclusions - . were found to be remarkably inadequate" (p. 180). He further warned that "unless much better evaluative research begins to be undertaken, all the innovative work safety programs in the future may well result in a waste of time and money" (p. 187).

The next section reviews several recent studies which have employed an applied behavior analysis approach to occupational safety for the purpose of filling this void in safety research.

Applied Behavior Analysis in Safety Research

Applied behavior analysis, more comonly known as behavior modification, can be broadly defined as the collection of research methods and strategies used to evaluate scientifically the effects of any management program or procedure on any socially important behavior(s) (Fitch ot al, 1976). Utilizing technology derived largely from the principles of operant conditioning, applied behavior management attempts systematically to modify precisely defined target behaviors. 
Such an approach has al ready shown considerable promise for industrial-organizational applications (Jablonsky \& DeVries, 1972; Luthans \& Kreitner, 1975; Nord, 1969; Schneier, 1974). Nuwerous successful studies have been reported. For example, reward contingencies have been arranged to improve productivity (e.g., "At Emory Air Freight", 1973; Yuk1, Wexley, S Seymore, 1972; Yuk1 \& Latham, 1975), reduce absenteeism (Pendalino \& Gamboa, 1974; Wallin \& Johnson, Note 1), reduce tardiness (Herman, deMontes, Dominguez, Montes, \& Hopkins, 1973), improve individual omployee performance (Komaki, Wadde11, \& Pearce, 1977), and reduce residential energy consumption (Hayes \& Cone, 1977).

Similarly, several researchers have advocated the use of behavior modification (b-mod) techniques for increasing safe behaviors (Fitch et al., 1976; Goldstein, 1975; MeIntire \& White, 1975; Smith, Anger, Uslan, 1978; Tuttle, Dachler, \& Scheider, 1975).

Rationale: The primery premise supporting the utilization of applied behavior analysis in safety research is that most safety experts agree that the majority of occupational accidents and injuries are the results of an unsafe act performed by an employee (Fitch et $a 1$, 1976; Grimaldi Simonds, 1975; Heinrich, 1959; Schenkelback, 1975 ). Heinrich (1959) has estimated that 888 of all industrial accidents are caused by unsafe acts; 10 by equipment failure of the working envi ronment; and 24 by Acts of cod. Unsafe acts would include both direct and indirect behavioral actions. An indirect action would include failure to act, as in the case where an exployee uses an unsafe tool without checking its condition first, or not performing preventive maintenance on equipment. 
Heinrich (1959) also noted that one reason for the frequency of unsafe acts is that such actions rarely result in a disabling injury and may save time and energy expended. Ho estimeted that for nost fobs, of every 330 unsafe acts, 300 would result in no infury; 29 would result in only minor injuries; and 1 would result in a disabling injury. This ratio could be much higher (or lower) depending on the demands of a particular job. Thus, employees working unsafely may actually be reinforced for doing so, and rarely punished. Arranging reward contingencies so that workers are reinforced for safe behaviors should increase the frequency of safe acts and decrease competing unsafe behaviors. As the potential behavioral causes of injuries are eliminated, it only follows that the frequency of accidents will also diminish.

In sum, applied behavior analysis enables one to direct safety promotional efforts at the major cause of occupational accidents and injuries.

Measurement of Safety: A second advantage of using applied behavior analysis is that it can provide a reliable measure of safety. Safety research has often been plagued by a lack of consensus on how to measure safety performance (Grimaldi, 1970; Komaki, et a1., 1978; Smith, 1976). Typical criterion measures include disabling injuries (lost-time accidents) and injuries requiring medical treatment (Grimaldi, 1970; Jacobs, 1970; Tarrants, 1970). It has been noted that lost-time accidents, which include deaths, permanent total disabilities, permanent partial disabilities, and tomporary total disabilities, are considered "rare events" (Jacobs, 1970; Komaki et al, 
1978). Since these events are infrequent and unpredictable, it is difficult to reflect the effect of a safety progran using lost-time accidents as a primary index. Further, medical treatment injuries, those requiring first-aid treatment but not disabling, are an unreliable measure due to large-scale reporting and recording inaccuracies (Grimaldi, 1970; Komaki et al, 1978; Smith, 1976). Both of these measures are after-the-fact and offer little in the way of suggesting preventive procedures. In addition, accidents are expensive teaching devices (Kerr, 1957). In other words, taking steps to correct unsafe behaviors after an accident nay prevent future problems; but post hoc action cannot repair the physical and financial damages al ready incurred by the organization and/or its employees.

A behaviorally specific observation and recording system, however, provides a sensitive and reliable measure of the safety level of the organization (Fitch et al., 1976; Konaki et al., 1978; Smith, 1976). Frequent repeated measurement of a behavioral criteria not only makes it possible to objectively assess safety performance, but also allows one to assess more readily whether a program is having its desired effect or whether new strategies need to be introduced (Komaki et al., 1978).

The measurement and modification of the behavioral causes of accidents not only has a logical rationale, but several recent studies provide emplrical support as well. For example, Zohar (1980) reviewed two studies in which various tokens were made contingent upon the use of earplugs by employees in textile plants. As a result earplug usage was increased from an average baseline of 354 to a level of 85 - 908. 
Similar results were found in a metal fabrication plant where more employees began wearing earplugs after recelving feedback concerning the amount of their hearing loss (Zohar, Cohen, Azar, 1980).

In the area of coal mine safety, a combined program of periodic inspections, contingent punitive control, praise, and graphic feedback was successful in reducing the number of ventilation violations to zero for ten months at a mine with four coal-producing sections (Rhoton, 1980).

Smith, Anger, and Uslan (1978) employed a social roinforcer (supervisory praise) to increase the use of eye protection equipment anong shipyard employees. They had found that over $60 \%$ of the on-thejob injuries were eye injuries, and therefore trained firstine supervisors to observe, record, and appropriately praise worker behavior. In yet another fiel l study, Larson and her colleagues used a tachograph recorder attached to patrol cars to monitor such vehicle functions as speed, distance traveled, non-movement, and the use of emergency equipment (Larson, Schnelle, Kirchner, Carr, Domash, \& Risley, 1980). They found that appropriate use of the patrol cars improved after the police officers received monitored supervisory feedback in conjunction with the tachograph records. Further, there was a large reduction in repair costs and virtual elimination of personal injury for the 224 vehicles involved, which drove over 4 million miles per year.

In addition to the previous field studies, support for the use of applied behavior analysis has also been found with well-controlled laboratory investigations in which the frequency of unsafe acts was 
reduced with the use of accident simulation and other contingent negative consequences (Mckelvey, Engen, \& Peck, 1973; Rubinsky f Smith, 1973).

Methodological Contributions: A third advantage of the applied behavior analysis approach is that it offers nethodological as well as substantive contributions to the area of safety research (Bouchard, 1976; Fitch et al., 1976; Hersen \& Barlow, 1975; Kazdin, 1973; Konaki, 1977; Komaki et a1., 1978). As Komaki (1977) has noted, the use of control groups or randomization of subjects is often difficult in field settings. It is still possible to draw conclusions about the efficacy of an intervention procedure with a within-subject, multiplebaseline design (Baer, Wolf, G Risely, 1968). This entails collecting concurrent baseline data repeatedly over a period of time on multiple behaviors, groups, persons, or settings. A second feature of the design involves staggering the introduction of the intervention across the various behaviors, groups, etc. (Hersen \& Bar1ow, 1976; Komaki, 1977). This procedure allows one to rule out history, maturation, statistical regression, and instrumentation (Campbell Stanley, 1963) as alternative explanations for the results (Komaki, 1977). To be more specific, if changes in behavior (e.g., safe behavior) occur only after the intervention has been introduced and only for those groups or behaviors receiving the treatment, then it is unlikely that an extraneous event (history) and/or process operating as a function of time (maturation) were responsible for the change (Komak1, 1977). Similarly, regression effects would be seen in any series of repeated measurements of the behaviors and not only after the introduction of a 
treatment. Instrumentation, i.e., observer bias or a faulty measuring device, can be eliminated as a plausible alternative hypothesis if the assessment of interrater realiability (common in behavioral studies) shows substantial agreement (Komaki, 1977).

Several recent studies exemplify the use of applied behavior analysis with a multiple-baseline design to evaluate the effectiveness of a safety campaign. For example, Zohar (1980) reports one study in which a token economy system designed to increase earplug usage was introduced at staggered intervals across three shifts of a textile plant's weaving department. The results showed that an increase in earplug usage occurred in each shift only after the treatment was employed in that shift.

Another across-subjects-multiple-baseline experimental design study is reported by Sulzer-Azaroff (1978). In the study, corrective feedback to ameliorate hazards was given to university laboratories assigned to either an early, middle, or late feedback condition. The results demonstrated that following the delivery of feedback there was generally a substantial reduction in safety hazards. A similar study employing a "feedback package" in several departments of a manufacturing firm yielded comparable results (Sulzer-Azaroff \& Santamaria, 1980).

Two we1l-controlled studies by Komaki and her colleauges are particularly worth noting since the present investigation will attemt to replicate several features of these studies. The first study (Komak1, Barwick, Scott, 1978) was done with the wrapping and make-up departments of a large wholesale bakery. The bakery had been 
experiencing an unusually high injury rate with previous safety efforts consisting of posting comercial safety posters and irregularly posting accident information.

A behavioral observation code was tailored for each department and fiold tested to eliminate ambiguities in interpretation. The non-participant observers would observe each area of each department and check the respective code items as safe, unsafe or not observed. The level of safety performance was the percentage of items performed safely by the group with respect to the total observed. The instrument used to measure safety was found to be very reliable as evidenced by the high level of interrater agreement (over 96.74).

The investigation employed a multiple-baseline design with a reversal component. After the baseline observation period, the wrapping department employees were exposed to the intervention which had three salient features. First the employees went through a training session consisting of viewing pairs of 35 wn slides depicting safe and unsafe acts in accordance with the safety observational code. Next they were shown a graph depicting their baseline performance and asked to try to improve their safety to achieve a 908 goal. The graph was then posted in the departments and updated after each observation period. In addition to the feedback and training, supervisors were asked to coment and recognize workers performing safely. After 8 weeks of baseline, the second departmont was also exposed to the intervention procedure. Later the observers discontinued providing feedback via the graph data. Unlike previous studies (Sulzer-Azaroff, 1978; Sulzer-Azaroff Santamaria, 1980), Komaki et al. (1978) did not 
provide the departments with any feedback concerning how they could improve their safety performance.

Visual inspection of the data showed considerable improvement in the performance of safe behaviors only after the intervention was introduced. The effectiveness of the training-goal setting-feedback treatment is further noted by the fact that safety performance returned to baseline levels during the reversal phase. The accident rate continued to decline for at least 10 months after the ond of the study.

A second study (Komaki, Heinzman, Lawson, 1980) was conducted in 4 departments of a city's vehicle maintenance division. The investigation essentially followed the same format as the first. Safety performance was measured by the behavioral chocklist of safe and unsafe acts that were identified for each department based on their previous accident reports; and the training session consisted of a presentation of slides depicting the target behaviors. A multiplebaseline design across departments with a reversal couponent was again employed.

The latter study (Komaki et al., 1980) was designed to perform a component analysis of the relative effects of training and supervisory feedback. After baseline, the training was presented alone; then the feedback (and goal setting) was added; then feedback was removed; and finally it was reintroduced.

The results revealed that significant improvement in safety performance occurred only after feedback was given. The level of safety in each department decreased when supervisory feedbeck was withdrawn but the effects of treining remained. Interestingly, 
performance did not increase when feedback was reintroduced. Komaki et a1. (1980) noted, however, that the supervisors provided feedback quite irregularly and infrequently the second time around. In addition to behavioral changes, there was also a reduction of lost-time accidents during the 8 month period of the program.

It was concluded that training alone was not sufficient in improving safety performance, i.e., increasing the frequency of safe behaviors. Frequent feedback seems to be a necessary condition. In this experiment, as in the first, there were two types of feedback given--strictly knowledge of results (KR) and a more extrinsically evaluative type of feedback in the form of praise and recognition. Komaki et al. (1980) noted that the effects of the latter type were probably weak due to a lack of supervisory participation.

\section{Sumary and Comment}

The review of the literature in this section has tried to illustrate the contributions that applied behavior analysis can make to safety research. To recapitulate, by pimpointing safe and unsafe behaviors and manipulating consequence contingencies to modify these acts, one is directly treating a major cause of accidents and thus preventing injuries. Furthermore, frequent observation and recording of operationally defined target behaviors allows one to measure safety performance without relying on infrequent and costly accidents and injuries. By using a behavioral measure of safety, the effectiveness of an intervention can be assessed more readily and action can be taken to prevent possible mishaps. Finally, methodological advantages associated with applied behavior analysis also makes it appealing for 
evaluating components of a safety program. That is, a within-subject, across-group, multiple-baseline design enables one to test the efficacy of an intervention without the need for a control group or randomization of subjects, both of which are difficult to obtain in actual field settings. As in the studies by Komaki and her colleagues (Komaki et al., 1978; Komaki et a1., 1980), a reversal in addition to the multiple-baseline design can even more convincingly demonstrate the effectiveness of an intervention or interventions. If performance substantially decreases and perhaps returns to a prior level after removal of treatment, then one may say that improvements were a function of the intervention and not other extraneous variables (Hersen \& Barlow, 1976; Komaki, 1977). However, one may question the removal of an effective intervention procedure in occupational safety research. To quote Hersen and Barlow (1976):

Ethical considerations are of paramount importance when the treatment variable is effective in reducing self- or otherdestructive behaviors in subjects. Here the withdrawal of treatment is obviously unwarranted, even for brief periods of time. (p. 225)

Therefore, when removal of treatment is unfeasible for either ethical or practical reasons, a multiple-baseline design is sufficient (Baer et al., 1968; Hersen E Barlow, 1976; Kazdin, 1973; Komaki, 1977). In addition to exemplifying the criteria and experimental design advantages of an applied behavior analysis approach to safety research, several of the studies reviewed also demonstrated the utility of non-monetary consequences such as performance feedback in enhancing safety performance. These studies typically exployed knowledge of performance in conjunction with other extrinsic conditions such as 
praise and recognition, training, goal setting, corrective feedback, disciplinary action, accident simulation, and equiprent stoppage (Komaki et al., 1978; Komaki et al., 1980; Larson ot al., 1980; McKelvey et al. 1973; Rhoton, 1980; Rubinsky \&mith, 1973; Smith ot a1., 1978; Sulzer-Azaroff, 1980; Sulzer-Azaroff \& Santamaria, 1980; Zohar, 1980; Zohar et al., 1980). It has been noted however, that future research is needed to determine the relative contributions of each of these components as procedures for enhancing safe performance (Komaki et a1., 1980; Sulzer-Azaroff \& Santamaria, 1980),

If the reader will recall, Komaki et al. (1980) demonstrated how a component analysis of the effects of training and feedback could be done with applied behavior analysis and a multiple-baseline design. A similar design would be useful for conducting future research separating the effects of the other procedures. For example, one current controversy concerns the relative importance of goal setting versus knowledge of results (KR) or knowledge of performance. Resolution of this controversy may not only benefit safety research, but may also have general theoretical significance as well. The next section will discuss this controversial issue in more detail.

\section{GOAL SETTING AND KNOWLEDGE OF RESULTS}

\section{Introduction}

The use of knowledge of performance to enhance learning and task performance has been reported to be one of the best established findings in psychology (Ammons, 1956; Annett, 1969; Bilodeau Bilodeau, 1961). Support for the use of knowledge of results to 
enhance performance is found in both laboratory (e.g., Church \& Camp, 1965; Leamon, 1974; Pritchard \& Montagno, Note 2; Pritchard, Montagno, 8 Moore, Note 3) and field studies (e.g., Adan, 1972; Braunstein, Klein, G Pachla, 1973; Catano, 1976; Hundal, 1969; Panyan, Boozer, \& Morris, 1970; Payne \& Hauty, 1955; Quilitch, 1975; Seligman \& Darley, 1977). It has been suggested that in discussing the effects of feedback, a distinction between informational KR and motivational KR needs to be made (Payne Hauty, 1955). The former type of KR provides the individual with information about the correctness of a response and/or a way to achieve the desired response. Motivational KR refers to simply providing information concerning one's performance score. The latter type of $K R$ indicates an incentive value when it is given in relation to a standard. The latter $K R$ may also serve a reinforcement function especially when it signifies achievement of a desired level of performance (Bilodeau \& Bilodeau, 1961; Campbell \& Pritchard, 1976; Chapanis, 1964; Hundal, 1969; Pritchard 4 Montagno, Note 2; Pritchard, Montagno, \& Moore, Note 3). The controversial issue to be discussed in this review concerns only the motivational or incentive/reinforcement function of $\mathrm{KR}$. Henceforth, in this review of the literature, the terms knowledge of results (KR), or performance feedback shall refer to motivational type.

\section{Goals as Mediators of Incentives}

The controversy surrounding KR'stems from Locke's (1968) thesis that an incentive (or an external environmental condition) has no effect independent of its offect on the goals set by the individual. Locke (1968), in accord with others (Annett, 1969; Dulany, 1962, 1968; 
Fryer, 1964; Mace, 1935; Ryan, 1958, 1970), contends that the most immediate determinant of an individual's behavior in a specific situation is his/her goal, intention, desire, want, wish, or task in that situation. Therefore, the effects of incentives on performance are dependent on their influence on goals and intentions. Specifically, an incentive such as instructions (e.g., assigning performance goals), will affect behavior only if they are consciously accepted by the individual and translated into specific goals or intentions (Locke, 1968). As Locke (1968) further notes:

This applies equally well to the instruction by an experimenter to 'try for quality in your answers' to the instruction by a shop foreman to 'produce 400 portzeebies an hour'. It is not enough to know that an order or request has been made; one has to know whether or not the individual heard it and understood it, how he appraised it, and what he decided to do about it before its effects on his behavior can be predicted and explained. (p. 174)

It should be noted that the use of instructions, i.e., the assignment of specific and difficult goals to enhance performance, is one of the more durable findings of goal setting research (reviews by Latham Yuk1, 1975a; Locke, 1968, 1975; Miner \& Dachler, 1973;

Mitche11, 1979; Steers \& Porter, 1974). Goal acceptance, however, is a key element (Locke, 1968). Several recent studies have shown that accepted assigned goals which are specific and reasonably difficult can be equally effective as participatively set goals and usually saves time (Dossett, Latham, \& Mitche11, 1979; Ivancevich, 1976; Latham, Mitche11, \& Dossett, 1978; Latham \& Saari, 1979; Latham \& Yuk1, 1975b, 1976; Yuk1 Latham, 1978).

Goals or intentions are also considered to mediate the effects of incentives such as time 1imits (Bryan Locke, 1967; Dossett, Latham, 
G Saari, 1980; Latham \& Locke, 1975; Nevin \& Ford, 1976), supervision (Ronan, Lathan, \& Kinne, 1973), and evaluation apprehension (White, Mitche11, Be11, 1977).

Monetary incentives, according to Locke (1968), serve to comit subjects to tasks which they would not otherwise undertake. In other words, money (if it is valued by the workers), will encourage employees to accept tasks and set goals that they would not accept or set on their own (i.e., for the intrinsic enjoyment of the work itself). The empirical basis for this proposition stems from five laboratory studies by Locke, Bryan, and Kendall (1968) which found no relationship between incentive condition and behavior when goals were controlled or partialed out.

More recent studies using larger monetary incentives than Locke, Bryan, and Kendall (1968) have failed to confirm their findings. Instead, significant main effects for both incentive and goal conditions were often found (Latham, Mitche11, \& Dossett, 1978; London 6 01dham, 1976; Pritchard \& Curts, 1973; Terborg, 1976; Terborg \& Miller, 1978; Yuk1 Latham, 1978). The recent findings suggest that maximum effects can be obtained by combining goal setting with monetary incentives/reinforcements (London \& 01dham, 1976; Pritchard \& Curts, 1973; Terborg, 1976; Terborg Miller, 1978).

\section{Goals as Mediators of $\mathrm{KR}$}

Rationale: As with these previous incentives, Locke (1968) stated that the effects of KR are nediated by goal setting. He further noted that it is not enough to simply provide knowledge of results. In order for it to be effective, $\mathrm{KR}$ has to be interpreted and 
evaluated. Understanding the information implies that cognitive processes are operating (Locke, 1968). Thus the important factor is what an individual does with the $\mathrm{KR}$ that he/she receives.

In concern with this proposition, Latham and Yuk1 (1975a)

reviewed the literature and concluded that performance feedback or KR could lead to an increase in effort and performance in at least four ways: a) KR may induce a person who previously did not have specific goals to set them; b) KR may induce a person to raise his goal level after attaining a previous goal; c) KR may inform the individual that his current level of effort and performance is insufficient to attain his goal or standard, thus greater effort may result; and d) KR may inform the person of ways to improve his method of performing a task (i.e., informational KR). The first three "motivational" aspects of feedback are the primary concern in Locke's (1968) goal setting theory. These three statements indicate that $\mathrm{KR}$ is only effective through its effects on goals or intentions.

Empirical Evidence: The empirical evidence supporting Locke's (1968) contention that goals mediate the effects of KR comes largely from laboratory studies (reviews by Latham \& Yuk1, 1975a; Locke, Cartledge, \& Koeppel, 1968). For example, Locke, Cartledge, and Koeppel (1968) reviewed a number of studies in which the relative effects of goal setting and KR were separated by a) post hoc questionnaire analysis (Locke Bryan, 1966, 1968); b) experimental manipulation (Locke, 1967), or c) comparing the effects of KR alone relative to the effects of KR plus goal setting. The general conclusion reached from these studies was that the effects of KR were vitiated when the effects of goal setting were removed. 
The importance of goal setting was illustrated in a series of experiments by Locke and Bryan (1969a). They found that having the subjects focus their goals on one task parameter resulted in performance improvement for only that parameter. This result occurred even when the subjects received KR for all of the task parameters. For example, one task involved having subjects either minimize the number of errors or maximize the number of correct answers to addition problems. They received KR on both dimensions but improvements were generally seen for the goal-dimension only. These results were also generalized to a vehicle driving task involving five separate dimensions. This experiment required the subjects to set goals for improving their performance on two parameters. Again, despite KR given for al1, improvements were seen only for those parameters for which goals had been set.

In another study, Locke and Bryan (1969b) measured subjects' performance on several series of simple addition problems in an experiment employing a 2 (KR vs. No-KR) X 2 (hard vs. easy goal) factorial design. As in the previous studies, the hard goal group generally performed better than the easy goal group, regardless of the KR condition. Again, KR was found not to account for much of the performance variance when goal setting was partialed out (Locke \& Bryan, 1969b).

Cumings, Schwab, and Rosen (1971) were able to show directly that past performance and $K R$ were determinants of goal setting. They hypothesized and found that a higher level of previous performance would lead to higher goal setting for future performance on simple 
addition problems. Further, with previous performance accounted for, the greater the amount and accuracy of $K R$, then the higher the level of goal setting. They found that 26 of the self-reported goal setting variance was accounted for by past performance. When past performance and $\mathrm{KR}$ were combined, 448 of the variance was accounted for. Interestingly, the study did not report any task performance results. While the previous laboratory studies (i.e., Cunings et al., 1971; Locke, 1966, 1967; Locke \& Bryan, 1966, 1968, 1969a, 1969b) may provide evidence that $K R$ has no effect on performance independent of its effect on goal setting, there has been a paucity of field research in which goal setting and performance feedback have been independently manipulated (Latham Yukl, 1975a). Many studies which have tested the "practical significance" of Locke's (1968) theory have usually provided KR in conjunction with the goal setting procedures. It was often assumed that $K R$ would not have any additional effects over and above the effects of goal setting, nevertheless, it was considered necessary (e.8., Campbel1 I1gen, 1976; Dachler \& Mobley, 1973; Dossett et al., 1979; Latham \& Ba1des, 1975; Lathan \& Kinne, 1974; Latham \& Saari, 1979; Latham \& Yuk1, 1975b; Latham et al., 1978; Umstot, Be11, Mitche11, 1976; Unstot, Mitche11, \& Bel1, 1978; Wexley \& Nemeroff, 1975; Yuk1 \& Latham, 1975b).

One field study which has been noted (Locke, 1980) as demonstrating the necessity of goals in addition to KR was completed by Latham and Baldes (1975). They assigned specific hard goals to truck drivers concerning the size of the load of logs they hauled. The drivers had always been able to determine the welght of their load, 
i.e., receive $\mathrm{KR}$, but it was not until specific goals were set did they begin increasing the amounts hauled. In this case, goal setting may have facilitated an increased awareness of the foedback measures that were already available. Latham and Baldes (1975) also reported that supervisors gave "specific praise to drivers when goals were met." Thus, a possible confound existed. Further, while the goal setting and $K R$ seemed to increase the drivers' sense of achievement, recognition, and commitment to the company, the drivers also modified the trucks and suggested other ways to increase load size.

Locke (1980) found further support for his "goals as mediators of XR" hypothesis by reinterpreting the results of Komaki et al.'s (1978) safety study. Locke (1980) asserted that a cognitive explanation of the results was more plausible as he logically critiqued the claim that feedback acted as a reinforcer in the study and/or whether it played any causal role in the experiment at all. It is not exactly clear whether Locke (1980) is referring only to the praise or recognition "feedback" or the KR-performance foedback found (and confounded) in Komaki et al.'s (1978) experiment. Nevertheless, he proposed a number of arguments against the feedback-as-reinforcement thesis provided post hoc by Konaki et al. (1978).

First, based on previous reviews (Annett, 1969; Locke, Cartledge, 8 Kooppel, 1968), Locke (1980) noted that feedback itself does not automatically improve performance, but serves as a source of information regarding the adequacy of performance in relation to one's goal or standard. Thus, as noted earlier, the primary notivational element is actually the goal, value, or conscious purpose. 
Second, Locke (1980) claimed that foedback in the Komaki ot al. study was not given contingent on good performance, but simply on performance. According to reinforcenent principles, this should have resulted in static performance and not the improvenent that was found. According to Locke (1980), the subjects cognitively chose to improve their performance based on their interpretation of the feedback.

A third criticism with the findings of Komaki et al. (1978) is that there was no learning curve showing gradual improvement as expected in classical reinforcement theory. The dramatic improvement, shown before reinforcers (praise and recognition) were presented, and the sudden drop during the reversal phase suggest that a more parsimonious explanation of this and other behavior mod experiments is that:

$$
\begin{aligned}
& \text { of the job resulting frow the now standards and the more } \\
& \text { accurate feedback regarding performance in relation to those } \\
& \text { standards. (Locke, } 1977, p \text {. 548) }
\end{aligned}
$$

Two other arguments raised by Locke (1980) further suggest that feedback, an external event, must first operate through cognitive processes before having effects. For example, feedback that is "closer" to a standard is considered more positive than feedback that is "farther" from the standard. This would suggest that higher performance would be reinforcing. This would also require a conscious awareness on the part of the exployee of where they stood in relation to their goal. In addition, if foedback is to provide information to someone, that information must be understood. If feedback is given via praise, reproof, or recognition, it is still translated into knowledge of results of prior performance. This is an implicit 
assumption in all feedback research, including that done by behaviorists (Locke, 1980).

In sum, Locke (1980) makes a strong argument that a cognitive explanation is more plausible for the findings of Komaki et al. (1978).

Necessity of KR: The studies reviewed thus far which have tried to separate the effects of goal setting and KR have all provided similar results and conclusions. Whether the relative effects were separated by post hoc manipulation (e.g., Cumings et al., 1971; Locke \& Bryan, 1966, 1968); by experimental manipulation (Locke, 1967; Locke \& Bryan, 1969b); or by comparing the effocts of KR alone relative to KR plus goal setting (Latham \& Baldes, 1975; Locke, 1966b; Locke \& Bryan, 1969a), the general conclusion was that goal sotting was a necessary condition for $K R$ to have any motivational effects on behavior. Another implication of these studies is that successful manipulation of an individual's or group's conscious goal(s) may be a sufficient condition for motivating performance. That is, if assigned, specific, and difficult performance goals are accepted by an individual or group, then task performance will be enhanced without the need for other extrinsic incentives such as KR or monetary contingencies. However, the empirical evidence concerning this implication is not unequivocal. It has already been noted that monetary incentives may have effects over and above the effects of goal setting alone (London \& 01dham, 1976; Pritchard C Curts, 1973; Terbort, 1976; Terborg \& Miller, 1978). The same result may also be true of nonmonetary incentives such as $K R$. Recent evidence has been found to support this conclusion. In another test of Locke's (1968) theory, Erez (1977) 
hypothesized that goals were related to performance only when KR was present. Such a prediction is in accord with the theorem that behavior is a function of the interaction of the envi ronment (KR) and the individual (cognitive intentions).

Erez. (1977) used two forms of a number list comparison section of a clerical aptitude test as the task for the lab study. Performance was measured by the number of correct answers. At the end of the first trial, the experimental (KR) group received information concerning their performance relative to the others (i.e., among the highest 10\%, 25\%, 50\%, 75\%, or 90\%). The control group did not receive any information concerning their performance. Before the second trial, the subjects checked their level of intention on a five point scale.

The results indicated that $K R$ subjects had higher levels of intentions (self-set goals) than those in the No-KR condition. The relationships between self-set goals and performance $(r=.24)$ and between $\mathrm{KR}$ and performance $(r=.25)$ were significant across all subjects. When KR was controlled for, the self-set goal/performance relationship was $I=.60$ with KR but .01 for No-KR. Thus, the effects of goal setting were moderated by KR. However, it was also noted that the interaction of KR and goal setting accounted for $39 t$ of the performance variance while $34 \%$ was accounted for by initial differences, feedback, and goal setting combined. It would appear, therefore, that feedback is a necessary condition for goal setting to be effective (Erez, 1977).

Other laboratory investigations also suggest that feedback may be a necessary complement to assigned goals in facilitating 
performance. Amett (1974), for example, found that KR and competition had significant, albelt weak, correlations with performance on a repetitive construction task, even after the effects of goal indices were removed. The goal indices, measured by a post-experimental questionnaire, remained strongly correlated with performance even after KR and competition effects were separately and jointly removed by partial correlation analysis.

Similar to the study by Erez (1977), Strang, Lawrence, and Fowler (1978) also investigated the necessity of feedback for goal setting. They assigned quantity and quality goals for performance on complex arithmetic computation tasks, and provided KR with respect to each task dimension. The results confirmed Locke's (1968) conclusion that the effects of motivational KR depend upon goal conditions, (i.e., specific, hard goals). Strang t al. (1978) found that computational speed was enhanced only when accompanied by explicit KR coupled with the assignment of a challenging goal. Furthermore, this increase in computational speed was not paralleled by any loss in accuracy. There was, however, no evidence that goal setting alone facilitated performance. In fact, subjects assigned challenging goals but not given KR actually showed a significant increase in errors. Strang et al. (1978) concluded that KR may function not only as a complement but, as Erez (1977) suggested, a necessary partner of goals in determining subsequent performance. Replication of the results in applied settings was also suggested.

Two recent field studies also provide ovidence that KR can increase performance above and beyond goal setting alone. In one study, Becker (1978) used a 2 (high vs. low goal) X 2 (KR vs. No-KR) 
factorial design to determine the joint effect of feedback and goal setting on residential energy consumption. He reasoned that giving a person knowledge of his/her performance in relation to a standard would influence the anount of effort exerted and thereby enhance performance. If one has no information concerning their performance, then one has no way of knowing if a change in effort is required. Likewise, if one has no goal or standard level of performance to achieve, then feedback is irrelevant.

The results of Becker's (1978) study confirmed the proposition that both a difficult goal and $K R$ in relation to that goal were necessary to produce a significant decrease in energy consumption. Residents with easy, low goals and No-KR actually wasted more energy. In the second study, Kim and Hamer (1976) used a quasiexperimental design to determine if goal setting with a contingent extrinsic outcome enhanced performance more than goal setting alone.

The subjects were blue collar unionized workers of four plants of Midwestern Bell. They were not randomly chosen, and, for logistical reasons, each plant served as the group for one experimental condition. Though there were similarities in functions, between plant differences should have been accounted for in the flnal analysis. It is not clear if this was done or not. In such incidences, a within-subject nultiple-baseline design may have been more appropriate (Baer et al., 1968; Hersen Barlow, 1976; Jones et a1., 1977; Kazdin, 1973; Komaki, 1977).

Overall, the results demonstrated that while there was an increase in performance after goal setting, there was an even greater 
increase when feedback or KR was given. There did not appear to be any significant differences between extrinsic or intrinsic feedback; the maximum effects were attained when they were combined. These findings were restricted to cost performance (forecasted costs/actual costs) and safety performance (points subtracted from 100 for various accidents) only.

\section{Summary and Comment}

To recapitulate the findings of these recent lab and field investigations, the evidence indicates that foedback may be a necessary addition for goal setting to be maximally effective (Amett, 1974; Becker, 1978; Erez, 1977; Kim G Hamer, 1976; Strang et al., 1978). Several investigators have noted that KR adds meaning to the task goals (Annett, 1969; Erez, 1977; Latham \& Kinne, 1974; Locke, 1980; Steers G Porter, 1974). Further, the addition of KR in relation to a goal or standard may enable one to obtain a sense of achievenent which may affect future goals and performance (Hall \& Foster, 1977; Hall \& Hall, 1976). The presence of KR may also provide the individual or group with information concerning the anount of effort required to achieve a desired level of performance (Becker, 1978; Latham \& Yuk1, 1975a). While the latest evidence presented here suggests that the effects of KR and goal setting may be additive, much of this evidence comes frow laboratory studies (e.g., Arnett, 1974; Erez, 1977; Strang ot al., 1978), with college students as subjects. One ay question if the results of these studies will generalize to the real world (Campbe11, Dunnette, Lawler, Weick, 1970). The field studies completed have been few but generally supportive of the proposition 
that goal setting and KR should be combined (Becker, 1978; Kim Hamer, 1976). These studies, however, suffered possible methodological problems. For example, one nay question couparing performance across different plants at different locations (e.g., Kim 8 Hamner, 1976). Initial individual differences need to be accounted for as well as other extraneous occurrences taking place at each separate geographical location. Further, since an evaluative type of an incentive, i.e., praise, was present, the effects of "motivational" KR and goal setting may have been confounded in the Kim and Hamer (1976) study. Similarly, Becker's (1978) study on residential energy consumption may have had an inherent extraneous variable confounding the results. As the KR plus difficult goal residents reduced their energy usage, they also reduced their bills, thus a monetary incentive and/or reinforcer may have been operative.

It has been fairly adequately shown, both logically and ompirically, that $K R$ alone is not sufficient for enhancing performance. Implicit or explicit goals or intentions are necessary conditions for KR to be effective (e.g., Annett, 1969; Amett, 1974; Cumings et a1., 1971; Hall Foster, 1977; Latham \& Kinne, 1974; Latham \& Yuk1, 1975a; Locke, 1968; Locke, Cartledge, \& Koeppe1, 1968; Steers \& Porter, 1974). More research is needed however, to determine if goal setting alone is sufficient for enhancing performance in actual industrial/ organizational settings (Mitchell, 1979).

\section{RESEARCH OBJECTIVES}

The purpose of the present study is two-fold. First, for theoretical advancement, it will attempt to correct some of the 
methodological problems of the previous research in evaluating the possible additive effects of $\mathrm{KR}$ and goal setting in an organizational environment. To accomplish this, a within-subject, multiple-baseline across-groups design will be employed. Further, as in the Komaki et al. (1980) study, a component analysis of the two variables will be done in which goal setting will be established and KR later added. Performance (in this study, safe behavior), is expected to improve when specific, difficult, and accepted departmental goals are assigned. Employee performance will be further enhanced, however, when they recelve feedback concerning their department's performance in relation to their goal. The study does not question Locke's (1968) proposition that cognitive processes must operate before KR can be effective. It is concerned with the necessity of an extrinsic incentive such as KR in relation to a conscious goal or standard.

The second objective is of practical importance in that the study will systematically evaluate the effects of a safety program. Specifically, it will attempt to show that the combined effects of goal setting and KR will increase the frequency of safe bohaviors and thereby reduce the frequency and liklihood of an industrial accident and/or injury. Thus, the study will contribute to the growing body of literature utilizing applied behavior analysis in safety research.

The specific hypotheses of this study are:

1. Safety performance after training employees to ongage in safe behaviors will be greater than performance during baseline.

2. Safety performance after the assignment of a specific, difficult, yet acceptable goal will be greater than performance after training only. 
3. Safety performance after the addition of frequent knowledge of results (KR) will be greater than performance after goal-setting and training. 
METHOD

\section{Setting and Subjects}

Setting: The study was conducted in a sugar cane machinery manufacturing plant located in southeast Louisiana. The company's top management expressed a concern over the relatively large number of accidents being reported. This concern was well founded as evidenced by the comparison of the company's accident rate with the national average roported by the National Safety Council (1980). The average occupational injury and illness incidence rates for similar organizations for 1977-1979 were 15.82 total recordable cases and 7.19 lost workday cases per 100 employees. Using the same criteria and computational formula suggested by the National Safety Council and OSHA, the rates for this company for 1979 were 40.0 total cases and 14.32 lost-time cases per 100 employees. The national average number of workdays lost was 90 compared to 383.21 for the organization in question. For 1980, the company's rates were 43.61 total cases; 9.81 lost-time cases; and 159.50 lost workdays per 100 employees. The plant's safety program at this time consisted of posting commercial safety warning signs and assigning the electricalmaintenance supervisor to be in charge of safety. His duties included keeping abreast of current OSHA rules and regulations, and maintaining the equipment and machinery in safe condition. There was no formal company safety policy or training progran for the plant enployees. The investigator was therefore asked to assist the safety supervisor (a.k.a. electrical-naintenance supervisor) in developing a safety 
manual and corresponding safety training session. In addition, the management requested a program for motivating employees to follow the safety rules. They stipulated a preference for a program not utilizing extrinsic incentives such as monetary bonuses, safety prizes, and/or disciplinary action. It should also be added that inproving safety performance was a goal unanimously set by the shop's first-line supervisors when they participated in a recent MBO seminar. Thus, safety was a concern expressed by all the levels of management.

The following proposal was submitted to the executive vicepresident, vice-president in charge of production, safety supervisor, and first-line supervisors for their approval. The research interests of the investigator and the experimental nature and rationale of the design were fully explained to these managers, who in turn gave their complete support for the project. Later, permission to use the data for doctoral dissertation was also given.

Subjects: An analysis of the company's accident reports for the past three years revealed that $95 \%$ of the recorded injuries and illnesses occurred in eleven departments located in the shop area of the plant. It was therefore decided that the 105 full time employees in these departments would serve as subjects for the study. The departments are Crating $(N=6)$; Final Assembly $(N=25)$; Heavy Equipment $(N=10)$; Hydraulics $(N=8)$; Machine Shop $(N=6)$; Mechanics $(N=6)$; Painting/Sandblasting $(N=5)$; Parts $(N=13)$; Raw Material Prep $(N=14)$; Sub-Assembly $(N=8)$; and Welding $(N=5)$. A brief description of each department appears in Appendix $A$. The relative location of each department is shown in Appendix $B$. 
Criteria Moasures

The main dependent variable in this study was the percentage of employees in each department performing their job in complete accordance with the observational checklist and company safety manual.

Instrument: Prior to the study, the investigator assisted the plant's safety supervisor in writing a company safety manual. The rules and regulations stated in the manual were obtained from several sources. First, the accident reports for the last three years were reviewed to identify unsafe acts which resulted in injuries. For each unsafe act found, a behavioral safety rule was written to specify the correct and safe way to perform the task in question. However, many of the accident reports were incomplete and unable to provide information concerning the antecedent conditions of the accidents. Therefore, additional behavioral items were obtained from supervisors' and employees' suggestions; established safety practices advocated by OSHA and the American Standards Institute (ANSI); other related companies' manuals; and the recomendations of the various tool and equipment manufacturers. A copy of the manual appears in Appendix $C$.

An observational checklist based on the manual was also developed (Appendix D). The manual's items were classified as General Safety, Personal Protective Equipment, Housekeeping, Material Handling, and Tool 6 Equipment Use. Sub-categories of items were also identified under the above classifications listed on the observation form. For example, under personal protective equipment, the observer could mark if an eployee was wearing proper eye and face protection or hand and arm protection for the particular task he/she was performing at that time. 
The observational checklist was developed in an abbreviated form in order to allow an observer to carry the form easily and make unobtrusive observations. One of the long term objectives of the company was to have the first-line supervisors trained to make observations; thus, a forw which could be carried on their person at all times was roquested. Further, many of the behavioral items could be grouped or coded for easy scoring, and habitual violations could still be identified. By taking note of the activity the omployeo was engaged in, one could determine which behaviors they wore performing safely or unsafely.

A pretest of the observation form revealed several ambiguties in the scoring form and the safety manual items. For example, the different observers were unable to remember all of the safety rules or agree on which rules applied in which situations. Therefore, a second list of 37 behaviorally specific safety items (Appendix E) was developed for observational and training purposes. This list was not only more precise in the operational definitions of safe and unsafe acts than the safety manual, but it also focused on the behaviors judged by the first line supervisors to be the most problematic and potentially hazardous. The list of actual observational items, how they were scored, and their safety manual reference item appears in Appendix E. Further, the various departments for which the safety items wero applicable are also designated in Appendix E.

Observation Procedure: The observation procedure involved observing each employee in the eleven departments for 15 to 20 seconds. After observing an employee, the observer then recorded the individual's 
department, the date, the time of day (am or $\mathrm{pm}$ ), and his/her current activity or task on the safety check form (Appendix D). Next, the behavioral safety itens (Appendix E) that were applicable for the employee's activity were marked as being performed safely $(\checkmark)$ or unsafely ( $x)$. The observations were made in full view of the employees, but attempts were made to record the scores unobtrusively. The observation session generally lasted about $2 \frac{l}{2}$ hours.

Observations were nade 2 to 4 times $(\bar{X} \approx 3)$ per week depending on the length of the work week. The observations were made at various times of the day and varying days of the week. They were never made twice on one day. A total of 162 observations were made during the 56 week study.

The observations were made by 2 observers: the investigator (primary observer) and the safety supervisor (secondary observer). A tertiary observer (a graduate student in management) made observations through sixteen weeks of the first two phases of the study. Overall, the primary observer made 77.164 of the observations, the secondary observer--11.73\%; and the tertiary observer--11.11\%.

Prior to actual data collection, the secondary observer (and later the tertiary observer) was trained to make the behavioral safety inspections. Training consisted of reviewing the abbreviated observational code and scoring form (Appendices E and D respectively); viewing 35 in slides which depicted the safe and unsafe acts to be observed (Appendix G); and making practice observations while accompanied by the primary observer. By having the primary and secondary observers make concurrent yet independent observations, 
interrater reliability could be assessed as check for observer bias or instrumentation effects. To check reliability, a percentage agreement method was used in which the number of agreenents was divided by the total number of observations and multiplied by 100 . An agreement was tallied when both raters scored an employee's behavior in an identical manner. Data collection began after the two observers reached 908 agreement on the practice observations. This training procedure and reliability criterion was also used for training the third observer who made observations from the 7 th week through the 21 st week of the study.

In addition to assessing interrater reliability prior to data collection, it was also computed throughout the study. Reliability checks were made at the average rate of approximately one every 5 weeks (or 15 observations), with total of 11 checks for the $s$ tudy. The agreement checks always involved the primary observer and one of the other observers. Interrater agreement between the second and third observers was never assessed due to scheduling difficulties of the parties involved.

Computing the Safety Score: As noted earlier, the main dependent variable being measured was the percentage of elployees in each department performing their job in a completely safe manner. In this respect, safe performance of a job was considered to be all or none. It was possible for several of the behavioral safety itens to apply to an eaployee performing any given task at any time. While an exployee may have been working in accordance with most of the applicable rules, if he/she was violating just one of the safety items, 
then there existed a possibility of an injury. Therofore, that employee was considered to be working unsafely.

After each observation session, the safety performance for each department was computed by dividing the number of exployees working completely safe by the total number of departmental employees observed and multiplying by 100 . Weekly departmental safety performance was determined by averaging the results of the observations pade that week. As in other behavioral safety studies (e.g., Komaki et al., 1978; Komaki et al., 1980), this measure of safety accentuated positive behavior, i.e., safe behavior. It was assuned that safe and unsafe behaviors were in competition, therefore an increase in one should have been associated with a decrease in the other.

A second dependent variable of the study was the frequency of on-the-job injuries, as recorded by the personnel director of the plant in accordance with OSHA requirements (Public Law 91-596). A pre- and post-intervention analysis of the whole company's accident frequency was planned. There were problems associated with the reporting and recording of injuries occurring at the plant, however. For example, informal interviews with key personnel revealed a lack of consistency of how injuries were reported and/or who they were reported to. While lost-time injuries had a more objective criteria and thus were recorded more consistently than non-lost time accidents, they occurred too infrequently to permit correlational analysis and/or other statistical tests of significance (Komaki et al., 1978). Since the accident data had deficiencies, a caveat aust be issued concerning any conclusions drawn from it. Any change in the 
accident rate is of practical significance, but such changes must be considered tentatively since they may be a product of measurement varlation and not an intervention procedure.

Design and Procedure

A multiple-baseline design was enployed with a total of 4 phases: baseline, Training Only, Training and Goal Setting, and Training, Goal Setting, and Knowledge of Results. Baseline data were collected in all eleven departments, and the intervention phases were introduced in a staggered sequence across groups of departments (see Appendix F). The departments were divided into three groups based on their proximity to one another (see Appendix B), and perceived amount of interdepartment interaction. The groups were: Group 1--Final Assembly, Hydraulics, Mechanics, and Painting/Sandblasting; Group 2-Heavy Equipment, Raw Material Prep, Sub-Assembly, and Welding; and Group 3--Crating, Machine Shop, and Parts. Combining the departments was also done in order to conduct safety meetings efficiently and to introduce each stage of the program without severely disrupting production. Data, however, was collected on a departmental basis. Training Only: At the beginning of the 14th woek of the study, workers in Group 1 attended a safety training session that lasted from 45 to 60 minutes during their regular workday. Due to production demands, half of the Group 1 employees attended the meeting in the morning while a second session was held in the afternoon for the remaining half. Prior to attending the meeting, the workers in the group were each given a safety manual (Appendix C) and asked to read it before coming to the training session. 
The training session began wtth the company's executive vicepresident and general nanager addressing the workers. He explained to them that the majority of accidents were caused by someone performing an unsafe act. He further added that the responsibility for industrial safety was found at all levels of the organization. Therefore, he asked their (the workers") cooperation in following the regulations stated in the safety manual, in order to reduce the chance of injury by working in a safe manner. The moeting was then turned over to the safety supervisor.

The safety supervisor (with the author's assistance) then reviewed the safety manual with the employees. During this review, he instructed the employees to make certain additions and/or corrections to some of the safety items in their manual. These revised rules provided the employees with the specific behavioral items used for making observations (Appendix E). Next, the employees were shown a series of $35 \mathrm{~mm}$ slides depicting the unsafe and safe behaviors specified by the observational code. The slides were taken after work hours and involved employees of the electrical-maintenance department. The workers attending the training session were told that the actions exemplified in the slides were carefully posed for lllustrational clarity. Further, while the majority of the slides pertained to behaviors for the entire shop in general, a few slides depicted behaviors and situations specific to a certain department or group of departments. A written description of each slide, the observational code items involved, and the departments and/or group which saw the slide (because of special relevance) is found in Appendix G. Each 
viewed a total of 38 slides: 17 pairs of safe and unsafe illustrations, 3 slides depicting actual housekeeping violations, and 1 slide exemplifying "horseplay".

The employees first viewed a slide depicting an individual(s) performing a task unsafely. As a group, the workers were asked to verbally state what they observed to be correct or incorrect ("What's safe or unsafe here?"). Invariably, the employees could recognize the unsafe behaviors exemplified in the slide. After the unsafe behaviors were identified, a slide illustrating an individual doing the same job safely was shown and the corresponding safety rules were restated. For the four unsafe behavior slides, the applicable rules were simply restated.

During this meeting, the employees were also shown the observational form and told how their department's safety performance was being observed and measured. The meeting ended with a question and answer period.

After five weeks, the group held another safety meeting again during regular working hours. During this meeting, employee safety knowledge was assessed by asking each worker in attendance to viow 10 slides ( 5 safe - 5 unsafe) and write down what they observed the individual to be doing safely and/or unsafely. The employee's score on this safoty quiz was the percentage of behavioral items recorded compared with the total number of items shown in the slides. A different set of ten slides was used for each group. The slides used in each quiz and their respective groups are designated in Appendix G. The Training Only phase lasted 10 weeks and ended with the 
introduction of the Goal Setting and Training phase. The second group received the training sequence after 16 weeks of baseline and the third group after the $18 \mathrm{th}$ week of baseline. The Training Only phase continued through the 26 th and 28 th weeks of the study for these two groups respectively. Since the effects of training were considered to be irreversible, it remained a factor in each of the subsequent phases. Goal Setting and Training: At the beginning of the 24th, 27th, and 29 th weeks of the study, a safety performance goal was assigned to Groups 1 through 3 respectively. The safety goal was based on three considerations. First, in accordance with previous goal setting research (e.g., Latham \& Yuk1, 1975a; Locke, 1968; Mitche11, 1979; Steers \& Porter, 1974), the goal had to be specific. Second, the goal had to be perceived as difficult but attainable. The third goal criterion for this particular study was that the safety goal had to be the same for each department. Differing department safety goals may have suggested a difference in previous performance, i.e., the employees may have received implicit KR from different goals being assigned. It was recognized that assigning a constant goal for the entire plant may have varied the difficulty of the goal for departments performing at different lovels of safety. Prior to assigning the goal, however, the supervisors from each of the departments agreed that the goal was specific and difficult but attainable by their employees. Therefore, possible differences in perceived goal difficulty across departments was considered to be less disturbing than possibly allowing implict $K R$ to confound the results of this phase of the study. 
The goal setting phase was introduced (at staggered intervals across groups) by posting a 12" $X 12^{\prime \prime}$ sign which read "SAFETY GOAL-904" (Appendix H). The level at which the goal was set was estimated by conputing two standard errors above the mean performance for all the departments after they received the training session. As previousiy mentioned, this goal level was approved by the supervisors of the shop area.

Two days after the signs were posted, the employees attended another safety meeting during working hours. During this thirty minute meeting, the safety supervisor and the investigator reviewed the safety items covered by the observational code with the workers. Next, it was again explained exactly how the observations were being made and how safety performance was being measured on a departmental basis. The employees were then told that the safety goal was related to their department's woekly safety performance. Weekly performance was determined by averaging the results of the observations made that week. It was also mentioned that 100 weekly safety performance was unrealistically high and therefore not expected. It was noted that if 904 of all the shop employees performed their jobs completely safe, then not only would the goal be attained, but the frequency of injuries would be decreased as well.

After employees' questions concerning the neasure of safety or the safety goal were answered, the workers were asked to raise their hand if they thought their departwont could reach the goal. They were also requested to indicate in a sinllar manner if they would try to he1p their department achieve the safety goal by working safety in 
accordance with the observational code and safety manual. The overall response to these queries was always positive, i.e., an across-group average of 95.79 of the employees gave an affirmative response to each question. The workers were then thanked for their cooperation and dismissed.

After this initial goal setting meeting, the department supervisors were asked to remind their employees each week to try to achieve the safety performance goal. Five weoks after the goals were set, the safety supervisor issued a witten reminder to encourage the departments to achieve the goal (Appendix I). This reminder was posted near the safety goal sign in each department.

Since goal comitment and acceptance was considered to be vital to the success of goal setting in enhancing performance (Latham \& Yuk1, 1975a; Locke, 1968; Steers \& Porter, 1974), a manipulation check of these conditions was planned. Though a verbal commitment to the goal was Indicated at the initial goal setting meeting, a follow-up questionnaire was administered immediately before the KR phase was introduced in each group of departments.

The questionnaire was an opinion survey used as a measure of job satisfaction (Scott, 1967; Scott \& Rowland, 1970; Reitz, Note 4). It consisted of three parts: a bipolar adjectives section, a section with Likert-type scale statements, and an open-ended comment section. The questionnaire was belng used as part of an MBO program evaluation. of concern in this study wore responses to the bipolar adjectives concerning the assigned goal that were incorporated in the first section of the questionnaire. In the second section, 10 statenents 
concerning goal comitment, perceived goal difficulty, perceived departmental safety, and supervisory feedback were also added (see Appendix J).

The original plan was for the Goal Setting and Training phase to last 12 weoks. Unfortunately, production demands dictated the postponement of the safety meetings in which the next intervention phase was to be introduced. Therefore, the goal setting and training phase lasted 16 weeks for each group.

Feedback (KR), Goal Setting, and Training: Employees in Group 1 began receiving feedback, i.e., knowledge of results, concerning their department's safety performance during the 40th week of the study. Three weeks later (43rd week), Group 2 employees began receiving KR. The third group of departments received KR starting the 45th week of the study. The goal setting sign (Appendix H) and goal reminder (Appendix I) remained posted during this fourth phase of the study. The procedural sequence for the feedback phase was as follows:

A sixty-minute safety meeting was scheduled for the group during regular work hours. The first half of this meeting was devoted to the employees completing the job satisfaction questionnaire (Appendix J). As previously mentioned, included in this questionnaire were manipulation checks for goal acceptance/goal commitment, perceived goal difficulty, goal clarity, curront supervisory feedbeck, and perceived current departmental safety performance. After completing the questionnaires, the observational code items were discussed along with any new items that the employees suggested. The mothod for measuring safety for each department was also briefly explained again 
at this time. Next, the employees were asked to write down that they thought their department's average safety performance was. In other words, they were asked to estimate their department's current weekly safety performance based on the average percentage of employees working in a completely safe manner according to the safety rules.

The next step involved showing the employees in each department their respective average performance as recorded by the observers. To do this, a 12" $\times 15^{\prime \prime}$ sign was made for each individual dopartment. The sign depicted an incomplete line graph with the abscissa labeled "WEEK" and the ordinate labeled "AVERAGE SAFETY PERFORMANCE ( $($ )" (see Appendix $\mathrm{K}$ ). The 908 mark on the vertical axis was highlighted in reference to the goal level. In addition, the goal level was designated by a horizontal red line drawn at 90\%. For each department, the average level of performance observed and recorded for the Goal Setting and Training phase was marked on the vertical axis of the graph and thus provided the employees with their first KR in relation to the goal or standard. These features of the graph were explained to the emp loy ees.

The workers were then told that the two observers would continue to make safety observations approximately 3 times a week at various times and on various days. The graphs were posted in their respective departments, and after each observation session, the observer recorded the results on the sign. The observer recorded the date the observation was made and the percentage of employees observed working completely safe in each department. This information was written in the spaces provided after the statement found below the graph (see Appendix $K$ ). At the end of each week, the investigator 
wrote the beginning and ending dates of the work week at the intervals marked on the abscissa. He then recorded the department's average performance for that weok on the graph. Thus, the departments received KR 2 to 4 times per week depending on the length of the work week. After this procedure was explained to the employees, and their questions answered, they were dismissed to return to their work. At their next regularly scheduled safety meeting ( 6 weeks later) the safety goal was reemphasized, and any questions the enployees had concerning the KR being provided were answered. This meeting did not focus on the goal or performance levels; but mainly involved discussing new safety procedures and/or suggestions the employees might have for improving safety.

During the feedback intervention phase, neither of the observers provided any explicit evaluative feedback concerning the departments' progress (or regress) in relation to the goal. Attempts were made to provide only information regarding the level of performance in relation to the standard. While such KR may have produced implicit evaluation of performance, this evaluation had to have been intrinsically derived, i.e., the employees themselves being the source. The supervisors of the departments were asked to continue mentioning the safety goal on a weekly basis. They were not asked to provide any priase or reproof based on their departments' performance during this phase. Though such action on the part of the supervisor could not be sufficiently controlled, any observances of stpervisory personnel making evaluative coments were noted. Similarly, the observers tried to be aware of and 
record incidences of informal competition which may heve developed between departments according to Komaki et al. (1978, 1980).

The Knowledge of Results, Goal Setting, and Training phase lasted at least 12 weeks for each group of departments. 


\section{RESULTS}

In order to present the findings of the study succinctly, this section reports the results of the data analysis for the three groups (of departments) which the interventions were staggered across. The results of data analysis performed on a departmental basis is presented in Appendix $L$. The latter essentially substantiates the results presented here.

Observational Reliability and Validity

In an effort to estimate the roliability of the observational procedure, interrater reliability employing the percentage agreement method was assessed eleven times throughout the course of the study. The mean agreenent between the primary observer and the secondary observer (assessed 7 times) was 87.684 . The average agreement between the primary and tertiary observers (assessed 4 times) was 89.718. Overa11, the average interrater reliability was 88.414 .

To estimate the validity of the behavioral measure of safety, rank-order correlations between the departments' injury rates and their mean behavioral performance during the study were to be conputed. However, the accident rates (computed per 100 employees as described by the National Safety Council, 1980) for the departments were too low to permit meaningful correlations. Since the baseline performance is assumed to be an extrapolation of previous performance, then correlating baseline levels with provious accident rates may provide an ostimate of the validity of the observational procedure.

The Spearman correlation coefficient for the departments' 
overall-injury rate and mean baseline performance was -.85 (p<.001). The corrolation between departmental lost-time injury rate and mean baseline performance was tho $=-.69(\mathrm{p}<.01)$. These figures indicate that the higher the behavioral performance, the lower the accident rates. While this provides at least an indirect indication of the validity of the measure, it must be reiterated that the results should be interpreted cautiously since accident records tend to be unreliable.

\section{Manipulation Checks}

Training: The results of the quiz administered midway through the Training Only period Indicated that overall, the enployees $(N=87)$ could identify 81.77 of the safe and unsafe behaviors exhibited in the slides (see Appendix E).

Goals: As previously noted, several bipolar adjectives and contingency statements were incorporated in a job satisfaction questionnaire completed by the employees prior to the introduction of the KR phase (see Appendix J). Specifically, 11 items were included to assess goal acceptance; 3 items were for perceived goal difficulty, and 1 item for goal clarity. Three separate items were included to estimate the perceived probability that the supervisors would give their employees positive (praise), negative (reprinand), or corrective feedback to their employees for performing safe or unsafe behaviors. All the items (footnoted in Appendix $J$ ) were scored on a 7 point scale with seven being the desired response. Eighty-six of the 96 enployees who had been through each phase of the study responded. The mean response for each factor measured appears in Table 1. 
Insert Table 1 about here

Overall, the employees considered the goal to be acceptable $(\bar{X}=5.78)$ and clear $(\bar{X}=5.82)$. They also perceived the goal to be slightly difficult $(\bar{X}=4.54)$. The probability that the supervisors would praise the employees for working safely was low $(\bar{X}=3.28)$. On the other hand, elmployees expected to receive corrective feedback $(\bar{X}=4.76)$ and/or be reprimanded $(\bar{X}=4.49)$ for performing an unsafe act. The employees also indicated that they and their fellow workers generally worked in a safe manner $(\bar{X}=5.12)$.

The employees involved in the study were also asked (prior to receiving $K R$ ) to estimate their department's behavioral safety performance. In general, they estimated their performance to be lower $(\bar{X}=79.438)$ than the goal of 908 which they had been assigned and apparently accepted.

At the end of the KR phase of the study, the employees were asked to write what they perceived their current department goal to be. The mean goal of the 77 employees responding was 95.758. All three groups had mean goals of 946 or higher. Thus, there is some indication that they were trying to achieve a level which was higher than assigned or expected of them.

Observational Data Analysis

ARIMA Aralysis: The first step in the analysis of the observational data was to estimate the model that appeared to best fit the time-series. This was accomplished with the use of the 
autoregressive integrated moving average (ARIMA) modeling technique developed by Box and Jenkins (1976) and recommended by McCain and McCleary (1979) for interrupted, time-series analysis.

Visual inspection of the weekly average performance (shown graphically in Figure 1) indicated that there appeared to be marked intervention effects. Therefore, it was decided to perform the ARIMA analysis on the observational data for each period within each group to estimate the model which appeared to fit the entire time-series.

Insert Figure 1 about here

The resulting autocorrelations and partial autocorrelations exhibited a stationary process for each period. Differencing of the data did not appear to be warranted since there was no indication of a statistically significant secular trend for any of the periods. Further, the analysis did not reveal any significant autoregressive or moving average component. In other words, the autocorrelation function and the partial autocorrelation function were interpreted as identifying an ARIMA $(0,0,0)$ model. Further evidence supporting the assumption that the data reflected a stochastic component or "white noise" model was found with the autocorrelation check of residuals. Since the Q-statistic (essentially a chi-square goodness-of-fit test for the autocorrelations) was not significant for any of the periods or groups, then it could be concluded that the estimated autocorrelation of the non-adjusted time-series data depicted a white noise process (McCain \& McCleary, 1979). 
Repeated Measures ANOVA: Given that the raw data within each period for each group resembled random fluctuations (i.e., a stationary process), a repeated measures analysis of variance with blocking on groups was considered appropriate for testing the hypothesis. The result was a highly significant main effect for the period or phase of the study ( $F=103.68, \mathrm{~d} f=3, \mathrm{p}<.0001$ ). A Duncan's multiple range test was then performed on the period means. As expected, the means for each period were significantly different. Inspection of the means for each period (Table 2) revealed that they were in the hypothesized direction. Briefly, the mean performance after KR was introduced $(\bar{X}=95.398)$ was substantially higher than after a goal was set without KR $(\bar{X}=77.548)$. Performance during the goal setting phase was higher than the Training Only phase $(\bar{X}=70.85 \%)$; which in tum was better than baseline performance $(\bar{X}=62.20 \%)$. Inspection of the means for each group (presented in Table 2) and the week1y summary data (Figure 1) also reflect the differences in behavioral safecy period performance for each intervention period.

\section{Accident Data}

The overall injury incidence rate and the lost-time injury incidence rate were computed for the shop area of the plant. The rates reflect the number of injuries per 100 omployees (National Safety Council, 1980). The average total incidence rate for the three years prior to the study $(1978$ - 1980) was 84.77 injuries. The yearly rate for 1981 was 55.14 injuries. The lost-tino rates decreased from an average of 21.40 injuries to 9.88 injuries for 1981 . 


\section{DISCUSSION}

Theoretical Implications

The major finding of this study is that knowledge of results (KR) appears to be a beneficial condition for the achievement of maximum performance when specific and difficult but acceptable goals are set. While behavioral safety performance did improve significantly after a goal was assigned and apparently accepted, in general, the goal was not achieved until KR was provided. In fact, ten of the eleven departments averaged above the goal during the KR phase whereas only two of eleven departments achieved the goal without KR (see Appendix L). Thus, the evidence presented in this study provides external validity of the laboratory findings of other recent investigations (e.8., Arnett, 1974; Erez, 1977; Strang et a1., 1978). Further, the multiple-baseline design and time-series analysis of the present study corrected some of the potential methodological problems associated with other related field studies (e.g., Becker, 1978; Kim \& Hamer, 1976) while substantiating the findings of these studies. One question that can now be raised is what is the function or role of goal setting? A possible answer steming from the results of the present study is that goals "motivate" the individuals to perform. Though safety performance did increase significantly after training, further improvement was almost immediately seen efter a goal was assigned and accepted. In support of Locke's (1968, 1980) theory, the sharp increase at the beginning of the goal setting phase (see Figure 1; also Appendix L, Figure 2a-k) suggests that the employees 
cornitively chose to increase their efforts to work in accordance with the behavioral safety rules.

The results of the questionnaire completed prior to the introduction of explicit $K R$ may indicate an alternative hypothesis concerning the behavioral performance during the goal setting phase. The self-report measure revealed that the employees had probably not received much positive feedback (1.e., pratse) from their supervisors concerning their safety efforts. However, they did believe they were likely to be reprimanded and/or corrected if they performed their job unsafely. Whether the supervisors increased their efforts to correct and/or to reprimand an unsafe subordinate after the goal was assigned could not be directly assessed in this setting. It is suspected that this was not the case since the supervisors had known what the rules were prior to the baseline period and were expected to enforce them as part of their regular duties. Further, as Locke (1980) suggested, one would expect more of a gradual improvenent if these extrinsic conditions (i,e., reprimand and/or corrective feedback) were the primary causal factors. Since the increase in performance was sharp after goals were assigned and accepted, then the more plausible hypothesis is that the employees were "motivated" or were attempting to achieve their goal because they cognitively chose to do so.

A second query posed by the results of the current investigation concerns the role of $\mathrm{KR}$ in relation to goal setting. One possible explanation that has been suggested is that KR nay lead to an increase in effort (Becker, 1978; Latham Yuk1, 1975a). Evidence for this hypothesis is provided by the fact that wost of the 
departments did not achieve the goal until KR was introduced. Even though the majority of employees reported perceiving their department's performance to be less than the goal prior to receiving KR, actual goal achievement was infrequent. The KR may have served to substantiate their perceptions and thus they realized more attention to safety was required if they were to achieve the goal.

A second possible function of KR is that it may be used by individuals to set new standards or goals (Latham 6 Yuk1, 1975a; Locke, 1968, 1980), Evidence for this postulate was found when most of the employees perceived their department's goal to be closer to 95\% after the KR phase, as opposed to the assigned $90 \%$ safety goal. It is possible that once the employees knew they could achieve the goal, then they set new goals. Since goals were limited to a maximum of $100 \%$, attempts to achieve new, higher goals (i.e., within the 90 - 1009 range) served to maintain the high level of performance exhibited by most of the departments during the KR period.

Still a third possible function of $K R$ is that it permits intrinsic reinforcenent when it indicates goal achievement (Hall \& Foster, 1977; Hall \& Hal1, 1976). The continuance of goal level performance after KR was provided may suggest that the eaployees were being reinforced for their accomplishment. Since there was little evidence of extrinsic incentives (i.e., supervisory praise or safety awards), any operating reinforcers would probably have to be intrinsically derived. As Komaki ot al. (1980) found, some informal competition seemed to be present among the various departments. Further, the employees appeared to be quite interested when the daily 
and/or weekly $\mathrm{KR}$ was marked. Thus, there is at least indirect evidence suggesting that KR signifying goal achievement was valued and probably rewarding.

In sum, the results of this investigation indicate that $\mathrm{KR}$ plus goal setting improves performance more than the effects of goal setting alone. As Locke (1968, 1980) reported, however, assigning an acceptable, difficult, and specific goal can lead to an increase in performance. This study revealed that adding KR Improves performance even more. The function of $K R$ in relation to goal setting can only be speculated from the evidence of this investigation. It can be hypothesized that KR: 1) leads to an increase in effort, 2) encourages new goals to be attempted, and/or 3) reinforces performance. It may also be that KR serves all three functions simultaneously. Whatever the reason, KR appears to be a beneficial supplement for the maximum effects of goal setting to be realized.

Practical Implications

The results of this study also have practical implications in the area of occupational safety. Behavioral safety rules were obeyed more when employees received frequent feedback (KR) concerning their performance in relation to an accepted standard. Though the implementation of a training session to teach employees exactly what was expected of then did result in a significant increase in performance it was not sufficient for optimm improvement. Instead, assigning employees specific, difficult yet acceptable safety goals, and providing information concerning their performance in relation to the goals resulted in considerably more improvement. 
These results essentially generalize the findings of Komaki et al. (1980) to a different organization. Both investigations provide alternatives to the utilization of disciplinary sanctions or extrinsic incentives (i.e., safety awards) to encourage compliance with the rules. The present investigation differed from Komaki et a1.'s (1980) since it did not confound the effects of $\mathrm{KR}$ in relation to a goal with the effects of supervisory praise. The results suggest that the former may be sufficient to obtain substantial increases in behavioral performance. The durability of the effects of such a safety campaign remains to be seen. In this study, overall performance stayed above the expected goal level for a minimum of 12 weeks after KR was int roduced.

Another finding of practical importance is that there is at least indirect evidence supporting a behavioral approach to safoty. First, rank-order correlations revealed significant inverse relationships between departmental baseline performance and injury rates (both overall and lost-time injuries). Second, when a program was implemented to improve behavioral safety performance, the yearly accident rates per 100 employees decreased in comparison with the company's previous yearly average. In fact, the company estimated that the reduction in lost-time injuries alone resulted in monetary savings of at least six figures. Extended monitoring of behavioral performance and accident rates may provide further evidence of the benefits and limitations of this approach.

Conclusions

The benefits steming from the provision of knowledge of 
results in relation to acceptable assigned goals has both theoretical and practical significance. Goal Setting plus Training, and Training Only each had positive effects on behavioral safety performance; but the addition of KR resulted in even greater increases in performance. Future research is required to determine the role(s) fulfilled by KR with regard to goal setting. In addition, the generalizability of the findings to other organizations and/or other behaviors remains an issue of concern. 
REFERENCE NOTES 
REFERENCE NOTES

1. Wallin, J. A., Johnson, R. D. Improving omployee attendance behavior: An operant conditioning intervention in a field setting. Paper presented at the meeting of the American Psychological Assoctation, Washington, D. C., August, 1976.

2. Pritchard, R. D., Montagno, R. V. Effects of specific vs. nonspecific and absolute vs. comparative feedback on performance and satisfaction (AFHRL-TR-78-12). Brooks Air Force Base, TX: Air Force Human Resources Laboratory, Occupation and Manpower Research Division, May, 1978.

3. Pritchard, R. D., Montagno, R. V., \$ Moore, J. R. Enhancing productivity through feedback and job design (AFHRL-TR-78-44). Brooks AIr Force Base, TX: A1r Force Human Resources Laboratory, Occupational and Manpower Research Division, August, 1978.

4. Reitz, H. J. Managerial attitudes and perceived contingencies between performance and organizational response. Paper presented at the meeting of the Academy of Management, At lanta, August, 1971. 
REFERENCES 


\section{REFERENCES}

Adam, E. E., Jr. An analysis of changes in performance quality with operant conditioning procedures. Journel of Applied Psychology, 1972, 56, 480-486.

Ammon, R. B. Effects of knowledge of perfornance: A survey and tentative theoretical formulation. Journal of General Psychology, 1956, 54, 279-299.

Annett, J. Feedback and human behaviour. Baltimore: Penguin Books, 1969 .

Arnett, M. D. An experimental study of the effects of competition, knowledge of results, and goal setting upon task perfornance: A test of Locke's hypothesis (Doctoral dissertation, University of Cincinnati, 1974). Dissertation Abstracts International, 1975, 35A, 4779-A. (University Microfilms No. 7502686)

At Emery Air Freight: Positive reinforcement boosts performance. Organizational Dynamics, 1973, 41-50.

Baer, D. M., Wolf, M. M., Risely, T. R. Some current dimensions of applied behavior analysis. Journal of Applied Behavior Analysis, 1968, 1, 91-97.

Becker, L. J. Joint effect of feedback and goal setting on performance: A field study of residential energy conservation. Journal of Applied Psychology, 1978, 63, 428-433.

Bilodeau, E. A., \& Bilodeau, I. McD. Motor-skills learning. In P. R. Farnsworth, 0 . McNemar, and Q. MeNemar (Eds.), Annual reviow of psychology. Palo Alto, CA: Annual Roviews, Inc., 1961.

Bouchard, T. J., Jr. Field research methods: Interviewing, questionnaires, participant observation, systenatic observation, unobtrusive measures. In M. D. Dunnette (Ed.), Handbook of industrial and organizational psychology. Chicago: Rand McNal1y, 1976.

Box, G. E. P., Jenkins, G. M. Time series analysis: Forecasting and contro1 (Rev, ed.). San Francisco: Holden-Day, Inc., 1976.

Braunstein, D. N., Klein, G. A., \& Pachla, M. Feedback expectancy and shifts in student ratings of college faculty. Joumal of App1ied Psycholory, 1973, 58, 254-258.

Bryan, J. F., Locke, E. A. Parkinson's law as a goal-setting phenomenon. Organizationel Behavior and Human Performance, 1967. 2. $258-\overline{275}$. 
Campbe11, J. P., Dunnette, M. D., Lawler, E. E., III, \& Weick, K. E., Jr. Managerial behavior, performance, and effectiveness. New York: McGraw-Hill Book Company, 1970.

Campbel1, D. J., \& Ilgen, D. R. Additive effects of task difficulty and goal setting on subsequent tack performance. Journal of Applied Psychology, 1976, 61, 319-324.

Campbel1, J. P., \& Pritchard, R. D. Motivation theory in industrial and organizational psychology. In M. D. Dunnette (Ed.), Handbook of industrial and organizational psycholory. Chicago: Rand McNa11y, 1976.

Campbel1, D. T., Stanley, J. C. Experimental and quasi-experimental designs for research. Chicago: Rand McNaliy, 1963.

Catano, V. M. Improvement in workers' performance through feedback of information on system performance. Perceptual and Motor Skil1s, $1976, \underline{42}, 478-490$.

Chapanis, A. Knowledge of performance as an incentive in repetitive, monotonous tasks. Journal of Applied Psychology, 1964, 48, 263-267.

Church, R. M., Canp, D. S. Change in reaction time as a function of knowledge of results. American Journal of Psychology, 1965, 78, 102-106.

Cohen, A., Smith, M., Cohen, H. H. Safety program practices in high versus low accident rate companies (HEW Publication No. NIOSH75-185). Washington, D. C : U. S. Government Printing Office, June, 1975.

Crawford, P. Hazard exposure differentiation necessary for the identification of the accident prone employees. Journal of Applied Psychology, 1960, 44, 192-194.

Curnings, L. L., Schwab, D. P., \& Rosen, M. Performance and knowledge of results as determinants of goal setting. Journal of Applied Psychology, 1971, 55, 256-530.

Dachler, H. P., Mobley, W. H. Construct validation of an instrumentality-expectancey-task-goal model of work motivation. Journal of Applied Psychology, 1973, 58, 397-418.

Davids, A., Mahoney, J. Personality dynamics and accident proneness in an industrial setting. Journal of App1ied Psychology, 1957, 41, 303-306. 
Dossett, D. L., Latham, G. P., M Mitche11, T. R. Effects of assigned versus participatively set goals, knowledge or results, and individual differences on employee bohavior when goal difficulty is held constant. Journal of Applied Psycholory, 1979, 64, 291-298.

Dossett, D. L., Latham, G, P., Saari, L. M. The impect of goal setting on survey returns. Academy of Managenent Journal, $1980,23,561-567$.

Dubin, R. Theory building in applied areas, In $M$. D. Dunnette (Ed.), Handbook of industrial and organizational psychology. Chicago: Rand McNal1y, 1976.

Dulany, D. E., Jr. The place of hypotheses and intentions: An analysis of verbal control in verbal conditioning. In $C$. $W$. Eriksen (Ed.), Behavior and awareness. Durham, N. C.: Duke Univorsity Press, 1962.

Dulany, D. E., Jr. Awareness, rules and propositional control: A confrontation with S-R behavior theory. In D. Horton and $T$. Dixon (Eds.), Verbal behavior and reneral behavior theory. Englewood Cliffs, N. J.: Prentice-Ha11, 1968.

Ellis, L. A review of research on efforts to promote occupational safety. Journal of Safety Research, 1975, $7,180-189$.

Erez, M, Feedback: A necessary condition for the goal settingperformance relationship. Journal of Applied Psycholoty, $1977,62,624-627$.

Fitch, H. G., Hermann, J., \& Hopkins, B. L. Safe and unsafe behavior and its modification. Journal of Occupational Medicine, $1976,18,618-622$.

Fryer, F. W. An evaluation of aspiration as a training procedure. Englewood C1iffs, N.J.: Prentice-Ha11, 1964.

Goldstein, I. L. Training. In B. L. Margolis \& W. H. Kroes (Eds.), The human side of accident prevention. Springfield, I11.: Charles C. Thomas, 1975, 92-113.

Grimaldi, J. V. The measurement of safety performance. Journal of Safety Research, 1970, 2, 137-159.

Grimaldi, J. V., Simonds, R. H. Safety management (3rd. ed.). Honewood, I11.: Irwin, $197 \overline{5}$

Hale, A. R., Hale, M. Accidents in perspective. Occupational Psychology, 1970, 44, 115-121. 
Ha11, D. T., Foster, L. W. A psychological success cycle and goal setting: Goals, performance, and attitudes. Academy of Manapement Journal, 1977, 20, 282-290.

Ha11, D. T., Hall, F. S. The relationships between goals, performance, success, self-image, and involvement under different organization climates. Journal of Voct lonal Behavior, 1976, 9, 267-278.

Harris, F. J. Can personality tests identify accident prone employees? Personnel Psycholory, 1950, 3, 455-459.

Haskins, J. B. Effect of safety connunication campaigns: A review of the research evidence. Journal of Safety Research, 1969, $\underline{1}, 58-66$.

Haskins, J. B. Evaluative research on the effects of mass communications safety campaigns: A methodological critique. Journa1 of Safety Research, 1970, 2, 86-95.

Hayes, S. C., \& Cone, J. D. Reducing residential electrical energy use: Payments, information, and feedback. Journal of Applied Behavior Analysis, 1977, 10, 425-435.

Heinrich, H. W. Industrial accident provention: A scientific approach. (4th ed.). New York: McGraw-Hi11, 1959.

Hermann, J. A., deMontes, A. I., Dominguez, B., Montes, F., \& Hopkins, B. L. Effects of bonuses for punctuality on the tardiness of industrial workers. Journal of Applied Behavior Analysis, $1973,6,563-570$.

Hersen, M., Barlow, D. H. Single-case experimental designs: Strategies for studying behavior change. New York: Pergamon, 1976.

Hunda1, P. S. Knowledge of performance as an incentive in repetitive industrial work. Journal of Applied Psychology, 1969, $\underline{53}$ 224-226.

Ivancevich, J. M. Effects of goal sotting on performance and job satisfaction. Journal of Applied Psychology, 1976, 61, 605-612.

Jablonsky, S. F., \& DeVries, D. L. Operant conditioning principles extrapolated to the theory of managenent. Organizational Behavior and Human Performance, 1972, $7,34 \overline{0-358 .}$

Jacobs, H. H. Towards more effective safoty measureant systens. Journal of Safety Research, 1970, 2, 160-175. 
Jones, R. R., Vaught, R. S., \& Weinrot, M. Time-series analysis in operant research. Journal of Applied Behavior Analysis, 1977. 10, 151-166.

Kerr, W. Complementary theories of safety psychology. The Journal of Social Psycholory, 1957, 45, 3-9.

Kazdin, E. E. Methodological and assessment considerations in evaluating reinforcenent programs in applied settings. Journal of Applied Behavior Analys is, 1973, 6, 517-531.

Kin, J. S., \& Hamner, W. C. Effect of performance feedback and goal setting on productivity and satisfaction in an organizational setting. Journal of Applied Psycholory, 1976, 61, 48-57.

Komaki, J. Alternative evaluation strategies in work settings: Reversal and multiple-baseline designs. Journal of Organizationa 1 Behavior Management, $1977, \frac{1}{1,53-77}$.

Komaki, J. Barwick, K. D., G Scott, L. R. A behavioral approach to occupational safety: Pinpointing and reinforcing safe performance in a food manufacturing plant. Journal of Applied Psychology, 1978, 63, 434-445.

Komaki, J., Heinzmann, A. T., \& Lawson, L, Effect of training and feedback: Component analysis of a behavioral safety program. Journal of Applied Psychology, 1980, 65, 261-270.

Komaki, J., Waddell, W. M., \& Pearce, M. G. The applied behavior analysis epproach and individual employees: Improving performance in two small businesses. Organizational Behavior and Human Performance, 1977, 19, 337-352.

Laner, E., G Sel1, R. G. An experiment on the effect of specially designed safety posters. Occupational Psychology, 1960, 34 . 153-169.

Larson, L. D., Schnelle, J. F., Kirchner, R., Jr., Carr, A. F., Domash, M., G Risley, T. R. Reduction of police vehicle accidents through mechanically alded supervision. Journal of Applied Behavior Ana1ysis, 1980, 13, 571-581.

Latham, G. P., G Baldes, J. J. The "practical significance" of Locke's theory of goal setting. Journal of Applied Psycholory, 1975, 60, $122-124$.

Latham, G. P., 8 Kinne, S. B., III. Improving job performance through training in goal setting. Joumal of Applied Psycholory, 1974, 59, 187-191. 
Latham, G. P., G Locke, E. A. Increasing productivity with decreasing time 1inits: A field replication of Parkinson's law. Joumal of Applied Psycholory, 1975, 60, 524-526.

Latham, G. P., Mitche11, T. R., \& Dossett, D. L. Importance of participative goal setting and anticipated rewards on goal difficulty and job performance. Journal of Applied Psychology. $1978,63,163-171$.

Latham, G. P., \& Sari, L. M. The effects of holding goal difficulty constant on assigned and participatively set goals. Acedemy of Management Journal, 1979, 22, 163-168.

Latham, G. P., \& Yuk1, G. A. A review of research on the application of goal setting in organizations. Academy of Management Journal, 1975, 18, 824-845. (a)

Latham, G. P., \& Yuk1, G. A. Assigned versus participative goal setting with educated and uneducated woods workers. Journs 1 of Applied Psychology, 1975, 60, 299-302. (b)

Latham, G. P., Guk1, G. A. Effects of assigned and participative goal setting on performance and job satisfaction. Journal of Applied Psycholopy, 1976, 61, 166-171.

Leamon, T. B. An investigation into the effects of knowledge of results on operator performance. Erronomics, 1974, 17, 639-650.

Locke, E. A. A closer look at level of aspiration as a training procedure: A re-analysis of Fryer's data. Journal of Applied Psychology, 1966, S0, 417-420.

Locke, E. A. The motivational effects of knowledge of results: Know ledge of goal-setting? Journal of Applied Psychology. $1967,51,324-329$.

Locke, E. A. Toward a theory of task motivation and incentives. Organizational Behavior and Human Performance, 1968, $3,157-189$.

Locke, E. A. Personnel attitudes and motivation. In M. R. Rosenzweig and L. W. Porter (Eds.), Annual review of psychology. Palo Alto, CA: Annual Reviews, Inc., 1975.

Locke, E. A. The myth of behavior mod in organizations. Academy of Management Review, 1977, 2, 543-553.

Locke, E. A. Latham vs. Komaki: A tale of two paradigms. Journal of Applied Psycholory, 1980, 65, 16-23.

Locke, E. A., Bryan, J. F. The effects of goal-setting, rulelearning, and knowledge of score on performance. Anerican Journal of Psychology, 1966, 79, 451-457. 
Locke, E. A., Bryan, J. F. Goal-setting as a determinant of the effect of knowledge of score on performance. Anerican Journal of Psychology, 1968, 81, 398-406.

Locke, E. A., 8 Bryan, J. F. The directing function of goals in task performance. Organizational Behavior and Human Performance, $1969,4,35-42$, (a)

Locke, E. A., E Bryan, J. F. Knowledge of score and goal level as determinants of work rate. Journal of Applied Psycholory, 1969, 53, 59-65. (b)

Locke, E. A., Bryan, J. F., Kenda11, L. M. Goals and intentions as mediators of the effects of monetary incentives on behavior. Journa 1 of Applied Psychology, 1968, 52, 104-121.

Locke, E. A., Cartledge, N., \& Koeppel, J, Motivational effects of knowledge of results: A goal-setting phenomenon? Psycholorical Bulletin, 1968, 70, 474-485.

London, M., 5 oldham, G. R. Effects of varying goal types and incentive systems on performance and satisfaction. Academy of Management Journal, 1976, 19, 537-546.

Luthans, F., Kreitner, R. Organizational behavior modification. Glenview, I11.: Scott, Foresman and Co., 1975.

Mace, C. A. Incentives: Some experimental studies. Report No. 72, Industrial Health Research Board, London, England, 1935.

McCain, L. J., McCleary, R. The statistical analysis of the simple interrupted time-series quasi-experiment. In T. D. Cook and D. T. Campbe11, Quasi-experimentation desim and analysis issues for field setting. Chicaco: Rand McNally, 1979 .

McIntire, R. W., White, J. Behavior modification. In B. L. Margolis 8W. H. Kroes (Eds.), The human side of accident prevention. Sprinfield, I11.: Charies C. Thomas, 1975 .

Mckelvey, R. K., Engen, T., \& Peck, M. B. Performance and injury avoidance as a function of positive and negative incentives. Journal of Safety Research, $1973, \underline{5}, 90-96$.

Miner, J. B., Dachler, H. P. Personnel attitudes and motivation. In P. H. Mussen and M. R. Rosenzweig (Eds.), Annual rovi ow of psychology. Palo Alto, CA: Annual Roview, Inc.. 1973 .

Mint 2, A., 8 Blum, M. L. A re-examination of the accident proneness concept. Journal of Applied Psychology, 1949, 33, 195-211. 
Mitche11, T. R. Organizational behavior. In $M$. R. Rosenzweig and L. W. Porter (Eds.), Annual review of psycholory. Palo Alto, CA: Annual Reviews, Inc,, 1979.

National Safety Council. Accident facts (1980 ed.). Chicago: Author, 1980.

Nevin, J. R., Ford, N. M. Effects of a deadline and a velled threat on mail survey responses. Journal of Applied Psycholory, $1976,61,116-118$.

Nord, W. R. Beyond the teaching machine: The neglected area of operant conditioning in the theory and practice of managenent Organizationa1 Bohavior and Human Performance, 1969, 4, 375-401.

Panyan, M., Boozer, H., \& Morris, N. Feedback to attendants as a reinforcer for applying operant techniques. Journal of Applied Bohavior Analysis, $1970,3,1-4$.

Payne, R. B., Hauty, G. T. Effect of psychological feedback upon work decrement, Journal of Experimental Psychology, 1955 , 50, 343-351.

Pendalino, E., Gamboa, V. U. Behavior modification and absenteeism: Intervention in one industrial setting. Journal of Applied Psychology, 1974, 59, 694-698.

Pritchard, R. D., \& Curtis, M. I. The influence of goal setting and financial incentives on task performance. Orranizational Behavior and Human Performance, 1973, 10, 175-183.

Quilitch, H. R. A comparison of threo staff-management procedures. Journal of Applied Behavior Analys 1s, 1975, $8,59-66$.

Rhoton, W. W. A procedure to improve compliance with coal mine safety regulations. Journal of Organizational Behavior Management, $1980,2,243-2 \overline{49}$.

Ronan, W. W., Latham, G. P., Kinne, S. B., III. Effects of goal setting and supervision on worker behavior in an industrial situation. Journal of Applied Psychology, 1973, 58, 302-307.

Rubinsky, S., Smith, N. Safety training by accident simulation. Journal of Applied Psycholory, 1973, 57, 68-73.

Ryan, T. A. Drives, tasks, and the initiation of behavior. American Journal of Psychology, 1958, 71, 74-93.

Ryan, T. A. Intentional behavior. New York: Ronald Press, 1970. 
Schenkelback, L. The safety management primer. Honewood, I11.: Dow Jones-I rwin, Inc., 1975.

Schneier, C. E. Behavior modification in management: A review and critique. Acadeny of Management Journal, 1974, 17, 528-548.

Scott, W. E., Jr. The development of semantic differential scales as measures of "morale". Personnel Psychology, 1967, 20, 179-188.

Scott, W. E., Jr., 8 Rowland, K. N. The generality and significance of semantic differential scales as measures of "morale". Organizational Behavior and Human Performance, 1970, 5 , 576-591.

Seligman, C., \& Darley, J. M. Feedback as a means of decreasing residential energy consumption. Journal of Applied Psychology, $1977,62,363-368$.

Shafai-Sahrai, V. Determinants of occupational injury experiments. East Lansing, Mich.: Michigan State University Business Studies, 1973.

Sherman, P. A., Kert, W., Kosinar, W. A study of accidents in 147 factories. Personnel Psychology, 1957, 10, 43-51.

Smith, M. J., Anger, W. K., Uslan, S. S. Behavioral modification applied to occupational safety. Joumal of Safety Research, $1978, \underline{10}, 87-88$.

Smith, P. C. Behaviors, results, and organizational effectiveness: The problew of criteria. In $M$. D. Dunnette (Ed.), Handbook of industrial and organizational psycholosy. Chicago: Rand McNaIIY, 1976 .

Steers, R. M., \& Porter, L. W. The role of task-goal attributes in employee performance. Psycholopical Bulletin, 1974, 81, 434- 452 .

Strang, H. R., Lawrence, E. C., Fowler, P. C. Effects of assigned goal level and knowledge of results on arithmetic colputation: A laboratory study. Journal of Applied Psychology, 1978, 63, 446- 450 .

Sulzer-Azaroff, B. Behavioral ecology and accident prevention. Journal of Organizational Bohavior Management, 1978, 2, 11-44.

Sulzer-Azaroff, B., deSantamaria, M. C. Industrial safety hazard reduction through performance feedback. Journal of Applied Behavior Analysis, 1980, 13, 287-295.

Tarrants, w. E. A definition of the safety measurement problem. Journal of Safety Research, 1970, 2, 106-108. 
Terborg, J. R. The motivational components of goal setting. Journal of Applied Psycholopy, 1976, 61, 613-621.

Terborg, J. R., Miller, H. E. Motivation, behavior, and performance: A closer examination of goal setting and monetary incentives. Journal of Applied Psycholory, 1978, 63, 29-39.

Tuttle, T. C., Dachler, H. P., Schneider, B. Organizational psychology. In B. L. Margolis \& W. H. Kroes (Eds.), The human side of accident prevention. Springfield, I1l: Charles C. Thomas, 1975 .

Umstot, D. D., Bell, C. H., Jr., E Mitchell, T. R. Effects of job enrichment and task goals on satisfaction and productivity: Implications for job design. Journal of Applied Psychology, $1976,61,379-394$.

Umstot, D. D., Mitchell, T. R., Bell, C. H., Jr. Goal setting and job enrichment: An integrated approach to job design. Academy of Management Review, 1978, 3, 867-879.

U. S. Department of Labor. A11 about OSHA (Rev. ed.). Washington, D. C.: U. S . Govemment Printing Office, 1976.

Van Zelst, R. H. The effect of age and experience upon accident rate. Journal of Applied Psychology, 1954, 38, 313-317.

Wexley, K. N., \& Nemeroff, W. F. Effectiveness of positive reinforcement and goal setting as methods of management development. Journal of Appli ed Psychology, 1975, 60, 446-450.

White, S. E., Mitchell, T. R., \& Bell, C. H., Jr. Goal setting, evaluation apprehension, and social cues as determinants of job performance and job satisfaction in a simulated

organization. Journal of Applied Psychology, 1977, 62, 665-673.

Yuk1, G. A., Latham, G. P. Consequences of reinforcement schedules and incentive magnitudes for employee performance: Problems encountered in an industrial setting. Journal of Applied Psychology, 1975, 60, 294-298.

Yuk1, G. A., Latham, G. P. Interrelationships anong enployee participation, individual differences, goal difficulty, goal acceptance, goal instrumentality, and performance. Personnel Journal, $1978,31,302-323$.

Yuk1, G. A., Wexley, K. N., S Seymore, V. D. Effectiveness of pay incentives under variable ratio and continuous reinforcenent schedules. Journal of Applied Psychology, 1972, 56, 19-23. 
Zohar, D. Promoting the use of personal protective equipment by behavior nodification techniques. Journal of Safety Research, $1980,12,78-85$.

Zohar, D., Cohen, A., Azar, N. Pronoting increased use of ear protectors in noise through information feedback. Human Factors, $1980,22,69-79$. 
Table 1

Mean Group Response for Each Questionnaire Factor

\begin{tabular}{|c|c|c|c|c|c|c|c|c|c|}
\hline \multirow[b]{2}{*}{ Group } & \multirow[b]{2}{*}{$\underline{\mathbf{n}}$} & \multicolumn{7}{|c|}{ Factor ${ }^{a}$} & \multirow[b]{2}{*}{$\begin{array}{l}\text { Estinated } \\
\text { Perforance } \\
\text { (\$) }\end{array}$} \\
\hline & & $\begin{array}{c}\text { Coal } \\
\text { Acceptance }\end{array}$ & $\begin{array}{c}\text { Goal } \\
\text { Clarity }\end{array}$ & $\begin{array}{c}\text { Goal } \\
\text { Difficulty }\end{array}$ & $\begin{array}{l}\text { Positive } \\
\text { Feedback }\end{array}$ & $\begin{array}{l}\text { Negative } \\
\text { Feedback }\end{array}$ & $\begin{array}{l}\text { Corrective } \\
\text { Feedback }\end{array}$ & $\begin{array}{l}\text { Current } \\
\text { Safety }\end{array}$ & \\
\hline One & 35 & 5.72 & 5.94 & 4.77 & 3.00 & 5.46 & 4.57 & 4.97 & 77.23 \\
\hline Two & 32 & 5.94 & 5.75 & 4.55 & 3.50 & 5.97 & 5.03 & 5.44 & 82.50 \\
\hline Three & 19 & 5.76 & 5.84 & 4.08 & 3.15 & 4.73 & 4.47 & 4.94 & 77.47 \\
\hline All & 86 & 5.78 & 5.82 & 4.54 & 3.28 & 5.49 & 4.76 & 5.12 & 79.43 \\
\hline
\end{tabular}

amean responses are based on a 7-point scale with a score of seven being desired. 
Table 2

Mean Group Safety Perfornance for Each Period

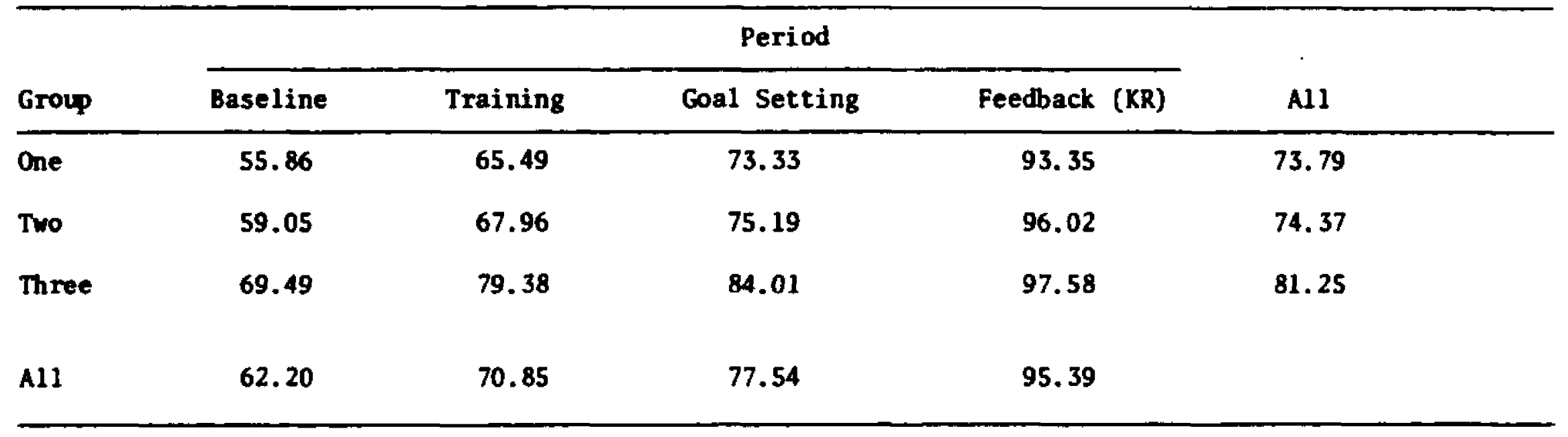

Note. Safety performance refers to the percentage of eployees working in a completely safe manner. 


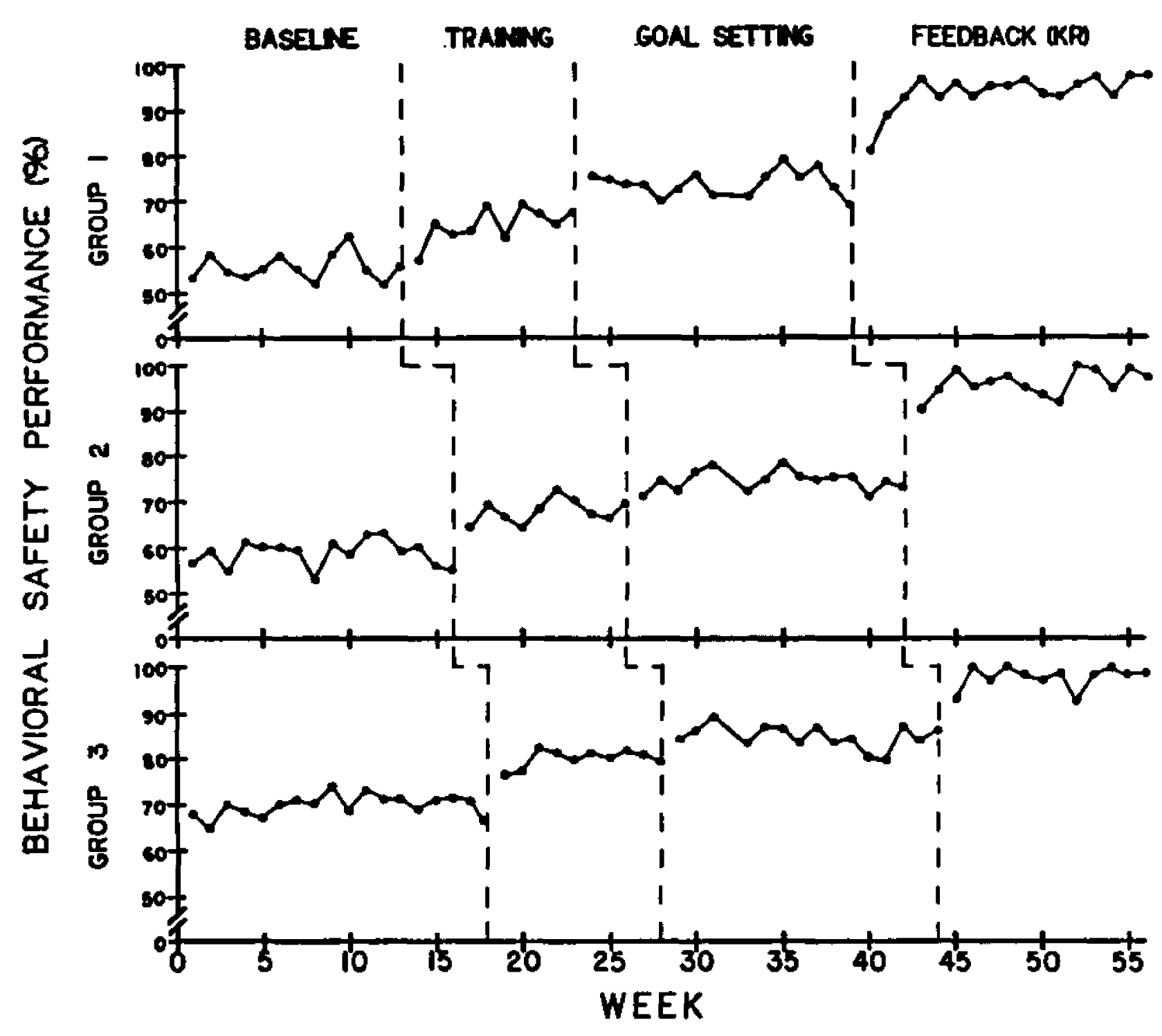

Figure 1. Average weekly behavioral safety performance for each group. 
APPENDICES 
APPENDIX A :

Description of Departments 


\begin{tabular}{|c|c|c|c|c|c|c|c|c|}
\hline $\begin{array}{c}\text { GRotP } \\
\text { No. }\end{array}$ & DEPARTIENT & $\mathbf{N}$ & DESCRIPTION & $\begin{array}{c}\bar{X} \\
\text { AGE } \\
\text { (years) }\end{array}$ & $\begin{array}{l}\text { EMPLOY } \\
\overline{\bar{X}} \\
\text { EDUC. } \\
\text { (years) }\end{array}$ & $\begin{array}{l}\text { DATA } \\
\bar{X} \\
\text { HOURLY } \\
\text { PAY } \\
\end{array}$ & $\begin{array}{c}\bar{X} \\
\text { TENURE } \\
\text { (years) }\end{array}$ & $\begin{array}{r}\text { FREQUENCY } \\
\text { OF INJURIES } \\
1979-1980 \\
\end{array}$ \\
\hline 1 & Final Asseibly & 25 & $\begin{array}{l}\text { Assembles and tests the } \\
\text { final product. Operations } \\
\text { include buffing, grinding, } \\
\text { oxygen/acetylene cutting, } \\
\text { arc welding, hand tool use, } \\
\text { fitting, crane/hoist use, } \\
\text { lubrication, and driving } \\
\text { the tractors, combines, etc. }\end{array}$ & 33.10 & 11.04 & $\$ 7.02$ & 3.73 & 92 \\
\hline 1 & Hydraulics & 7 & $\begin{array}{l}\text { Installs hydraulic systems } \\
\text { on the product in Final } \\
\text { Assewbly. Operations } \\
\text { involve cutting hoses, } \\
\text { attaching fittings, pipe } \\
\text { threading, installing fluid, } \\
\text { and preparing parts for } \\
\text { installation. Also does } \\
\text { some colpany vehicle } \\
\text { eaintenance. }\end{array}$ & 29.75 & 11.75 & $\$ 7.56$ & 4.25 & 14 \\
\hline 1 & Mechanics & 6 & $\begin{array}{l}\text { Receives, prepares, and } \\
\text { installs the engines in the } \\
\text { tractors in Final Asseibly. } \\
\text { Also prepares and installs } \\
\text { the tractors' instruent } \\
\text { panel and lights. Mainten- } \\
\text { ance and repair of company } \\
\text { vehicles and tractor engines } \\
\text { are also done. }\end{array}$ & 27.71 & 11.43 & $\$ 6.99$ & 3.79 & 14 \\
\hline
\end{tabular}




\begin{tabular}{|c|c|c|c|c|c|c|c|c|}
\hline $\begin{array}{c}\text { GROUP } \\
\text { No. }\end{array}$ & DEPARIMENT & $\mathbf{N}$ & DESCRIPTION & $\begin{array}{c}\overline{\bar{X}} \\
\text { AGE } \\
\text { (years) }\end{array}$ & $\begin{array}{l}\text { ENPLOYEE } \\
\overline{\mathrm{X}} \\
\text { EDUC. } \\
\text { (years) }\end{array}$ & $\begin{array}{c}\text { DATA } \\
\bar{X} \\
\text { HOURLY } \\
\text { PAY } \\
\end{array}$ & $\begin{array}{c}\overline{\mathbf{X}} \\
\text { TENURE } \\
\text { (years) }\end{array}$ & $\begin{array}{c}\text { FREQUENCY } \\
\text { OF INWURIES } \\
1978-1980\end{array}$ \\
\hline 1 & $\begin{array}{l}\text { Painting/ } \\
\text { Sandblasting }\end{array}$ & 5 & $\begin{array}{l}\text { Cleans, sands, primes, and } \\
\text { paints the final product for } \\
\text { shipping. Equipinent used } \\
\text { includes pnewatic paint } \\
\text { guns, stean cleaner, shot } \\
\text { blasting equipment, sanders, } \\
\text { and grinders. }\end{array}$ & 43.00 & 8.50 & $\$ 4.04$ & 4.00 & 26 \\
\hline 2 & Heavy Equipient & 10 & $\begin{array}{l}\text { Mainly constructs prefabri- } \\
\text { cated parts for asse-bly } \\
\text { elsewhere. Major } \\
\text { operations are arc welding, } \\
\text { oxygen/acetylene cutting, } \\
\text { fitting, grinding, shipping, } \\
\text { scaling, crane use, and } \\
\text { punching. }\end{array}$ & 30.73 & 9.50 & $\$ 7.73$ & 4.04 & 42 \\
\hline 2 & $\begin{array}{l}\text { Raw Material } \\
\text { Prep }\end{array}$ & 14 & $\begin{array}{l}\text { Receives, cuts, bends, and } \\
\text { shapes raw netal for } \\
\text { fabrication in other } \\
\text { departments. Equipwent used } \\
\text { includes power punch } \\
\text { (piranha), shear press brake, } \\
\text { autowatic saw, electric eye } \\
\text { torch, cutting torches, } \\
\text { grinders, N-C punch and } \\
\text { torch (panelmaster), and } \\
\text { cranes. }\end{array}$ & 37.44 & 11.93 & $\$ 7.23$ & 5.51 & 28 \\
\hline
\end{tabular}




\begin{tabular}{|c|c|c|c|c|c|c|c|c|}
\hline $\begin{array}{c}\text { GROUP } \\
\text { NO. }\end{array}$ & DEPARTMENT & $\mathbf{N}$ & DESCRIPTION & $\begin{array}{c}\overline{\mathbf{X}} \\
\text { AGE } \\
\text { (years) }\end{array}$ & $\begin{array}{l}\text { EMPLOYEE } \\
\overline{\mathbf{X}} \\
\text { EDUC. } \\
\text { (years) }\end{array}$ & $\begin{array}{c}\text { DATA } \\
\overline{\bar{x}} \\
\text { HOURLY } \\
\text { PAY } \\
\end{array}$ & $\begin{array}{c}\overline{\bar{x}} \\
\text { TENURE } \\
\text { (years) }\end{array}$ & $\begin{array}{c}\text { FREQUENCY } \\
\text { OF INJURIES } \\
1978-1980\end{array}$ \\
\hline 2 & Sub-Assembly & 8 & $\begin{array}{l}\text { Fits, tacks, and otherwise } \\
\text { partially assembles parts } \\
\text { for Final Assembly. } \\
\text { Primary functions include } \\
\text { arc welding, oxygen/ } \\
\text { acetylene cutting, grinding, } \\
\text { fitting, and crane/hoist } \\
\text { operation. }\end{array}$ & 38.30 & 10.44 & $\$ 7.20$ & 5.06 & 25 \\
\hline 2 & Welding & 5 & $\begin{array}{l}\text { Does the major portion of } \\
\text { the arc welding on the } \\
\text { fitted parts fron Sub- } \\
\text { Assenbly. Other equipment } \\
\text { use includes pnematic } \\
\text { chipping tools, scaling } \\
\text { tools, and grinders. }\end{array}$ & 28.50 & 10.25 & $\$ 8.30$ & 4.88 & 10 \\
\hline 3 & Crating & 6 & $\begin{array}{l}\text { Prepares the final product } \\
\text { and accessories for } \\
\text { shipment. Primary } \\
\text { operations include use of } \\
\text { power saws, pneumatic nail } \\
\text { guns, hamers, banding } \\
\text { equipent, fork lifts, and } \\
\text { some rustproofing and } \\
\text { painting. }\end{array}$ & 32.43 & 11.33 & $\$ 6.69$ & 4.16 & 15 \\
\hline
\end{tabular}




\begin{tabular}{|c|c|c|c|c|c|c|c|c|}
\hline $\begin{array}{l}\text { GROUP } \\
\text { NO. } \\
\end{array}$ & DEPARTEENT & $\mathbf{N}$ & DESCRIPTION & $\begin{array}{c}\bar{X} \\
\text { AGE } \\
\text { (years) }\end{array}$ & $\begin{array}{c}\text { EMPLOYI } \\
\overline{\bar{x}} \\
\text { EDUC. } \\
\text { (years) }\end{array}$ & $\begin{array}{c}\text { DATA } \\
\overline{\bar{x}} \\
\text { HOURLY } \\
\text { PAY }\end{array}$ & $\begin{array}{c}\bar{x} \\
\text { TENURE } \\
\text { (years) }\end{array}$ & $\begin{array}{c}\text { FREQUENCY } \\
\text { OF INJURIES } \\
1978-1980\end{array}$ \\
\hline 3 & Machine Shop & 6 & $\begin{array}{l}\text { Machine parts for use in } \\
\text { final and sub-asse-bly of } \\
\text { the products. Equipment } \\
\text { used includes lathes, } \\
\text { drill presses, nilling } \\
\text { nachines, N-C lathes, } \\
\text { grinders, crane/hoists, } \\
\text { and life nagnets. }\end{array}$ & 27.63 & 10.67 & $\$ 7.85$ & 4.50 & 19 \\
\hline 3 & Parts & 13 & $\begin{array}{l}\text { Taintains parts inventory } \\
\text { for product assembly and } \\
\text { sales. jor operations } \\
\text { include lifting and } \\
\text { stacking parts, rust- } \\
\text { proofing parts and tagging } \\
\text { parts received. Equipwent } \\
\text { used includes fork truck, } \\
\text { hydraulic pallet lift, and } \\
\text { hand carts. }\end{array}$ & 29.69 & 12.08 & $\$ 6.60$ & 4.00 & 23 \\
\hline
\end{tabular}


84

APPENDIX B

Location of Departments 


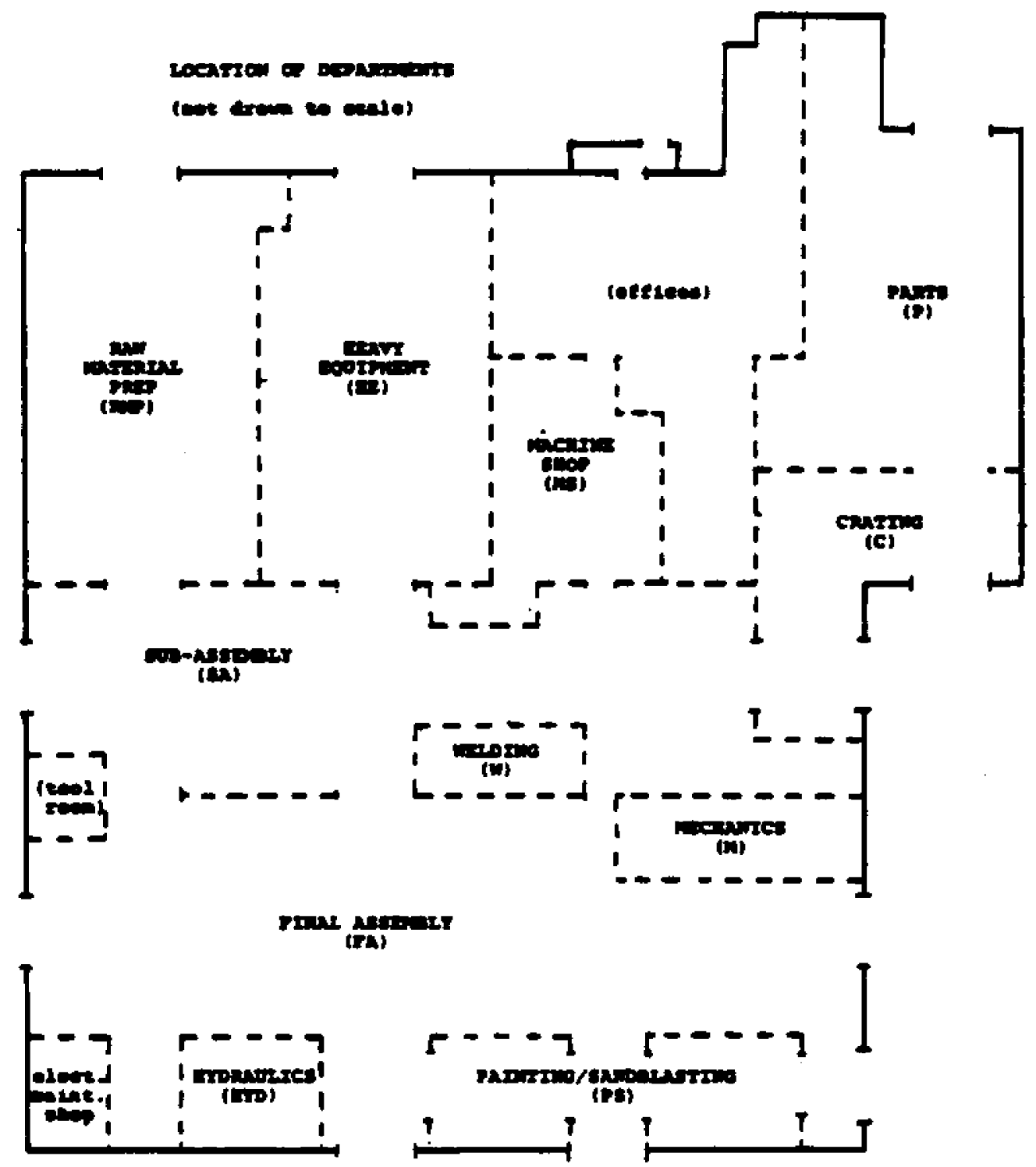


APPENDIX C

Company Safety Manual 


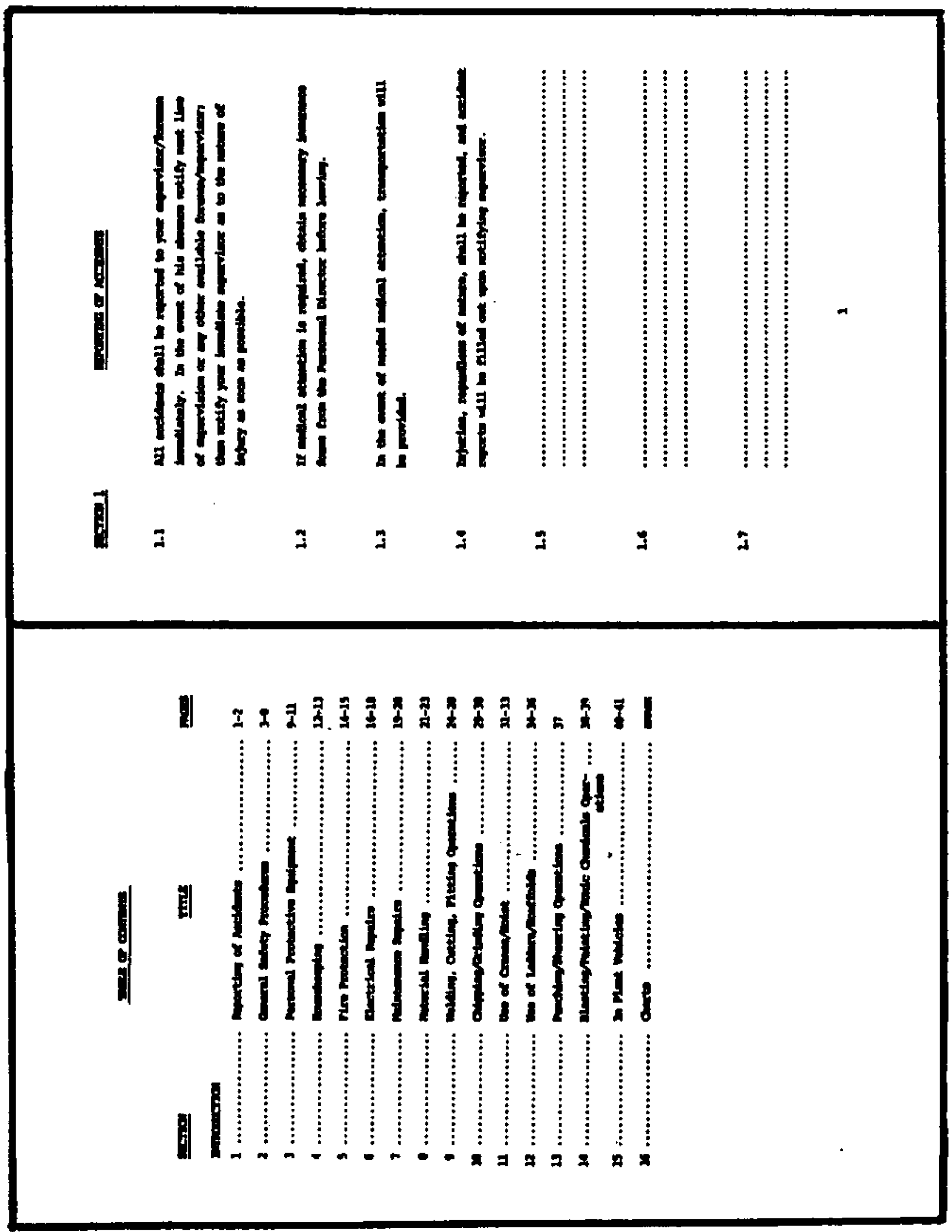




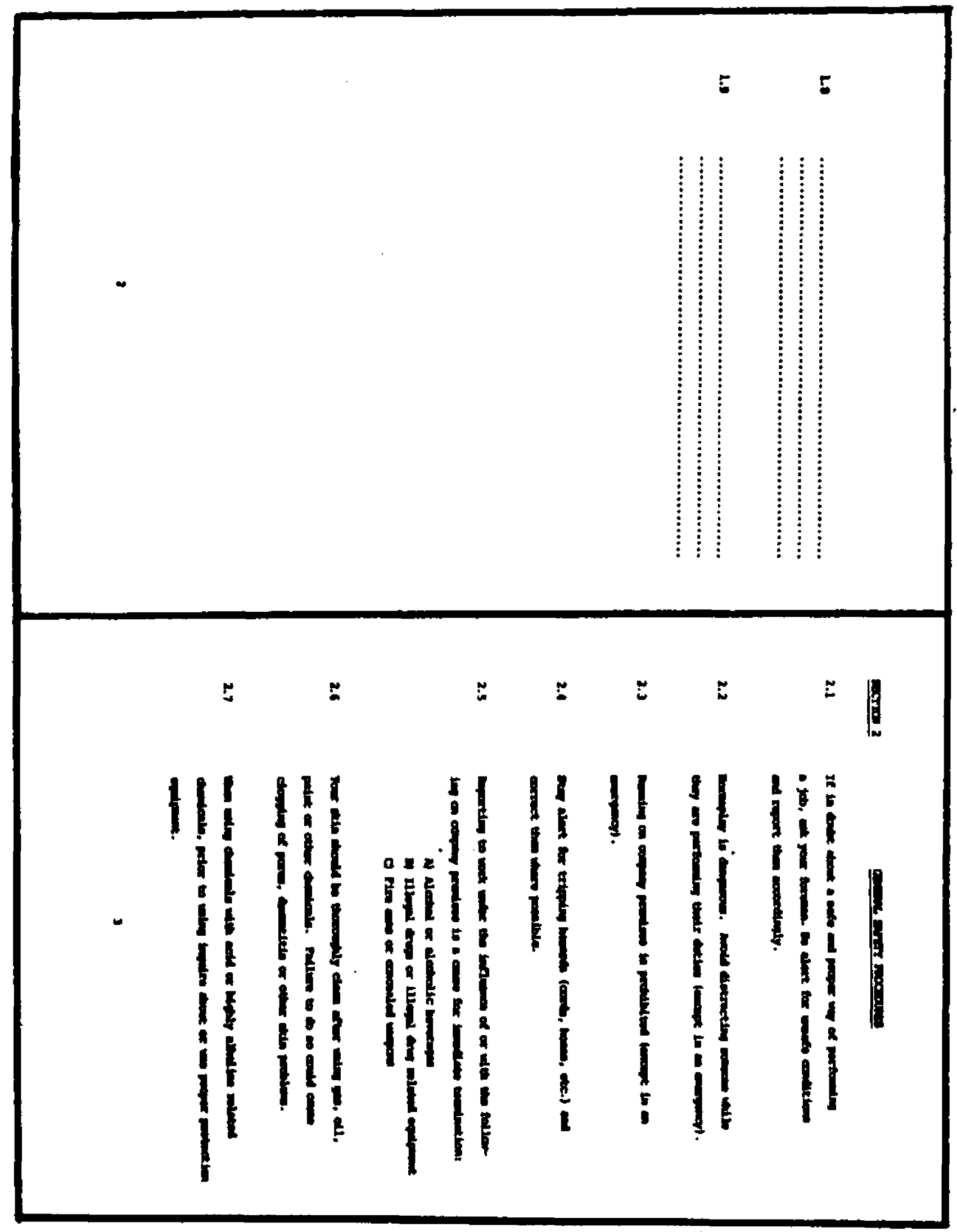




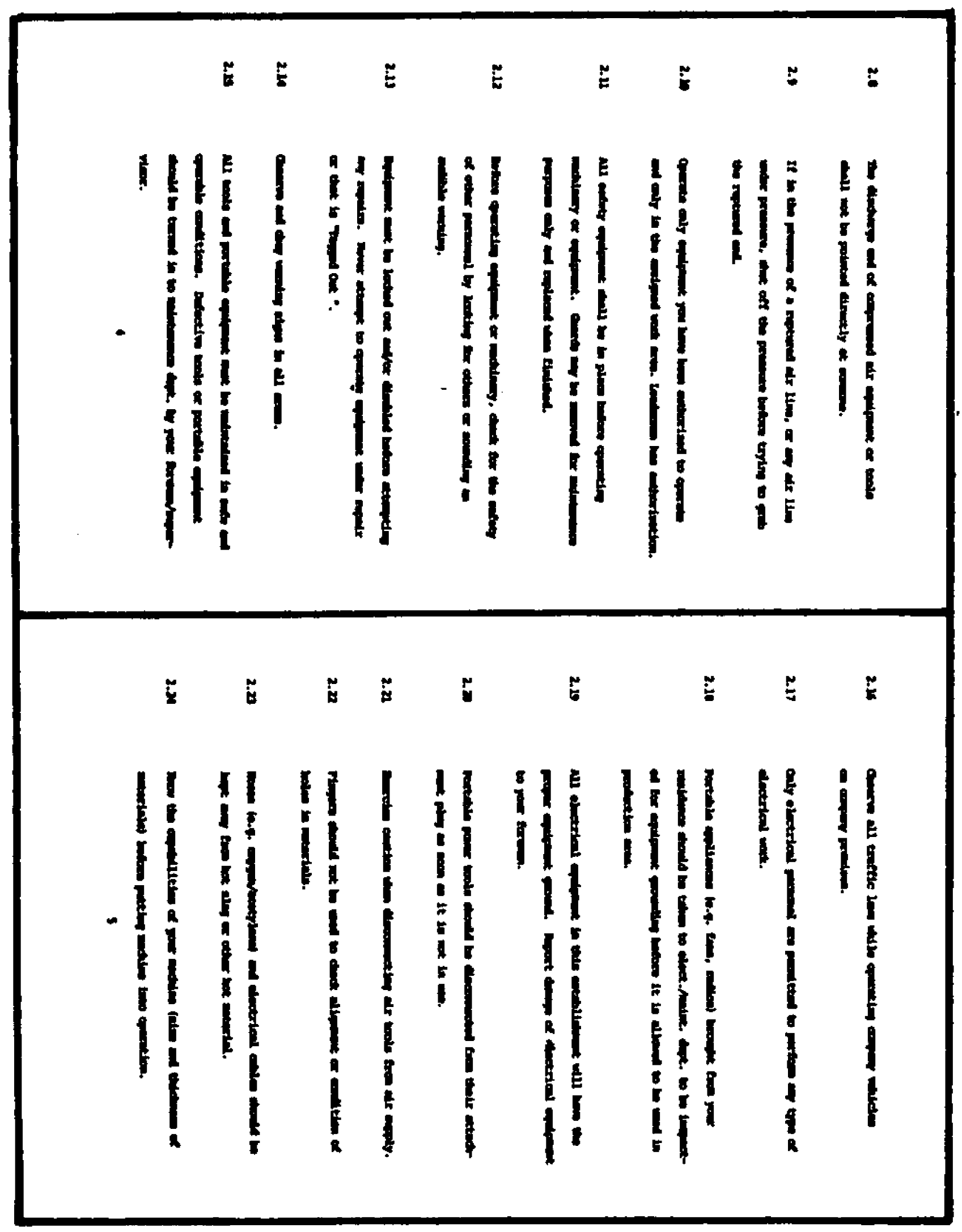




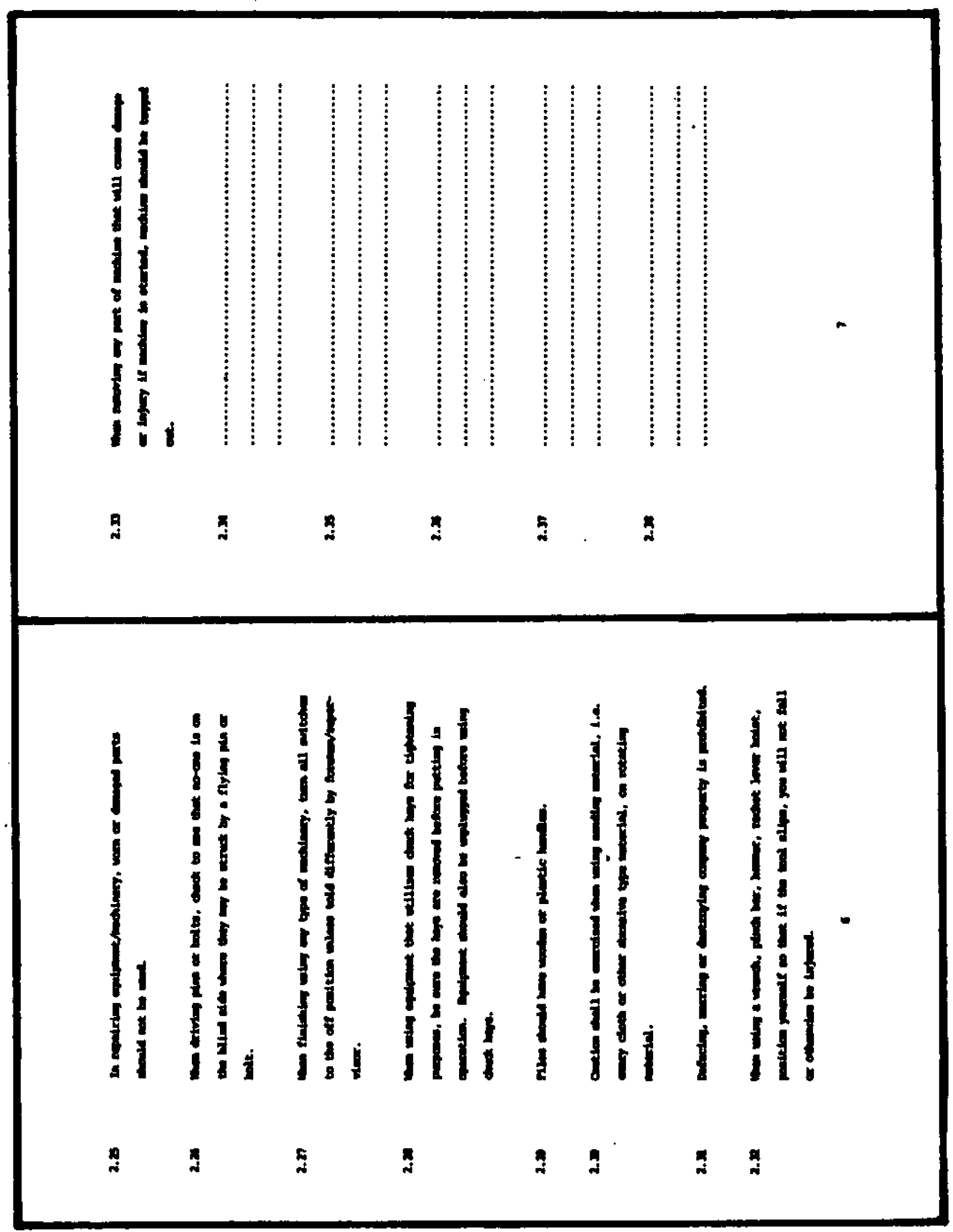




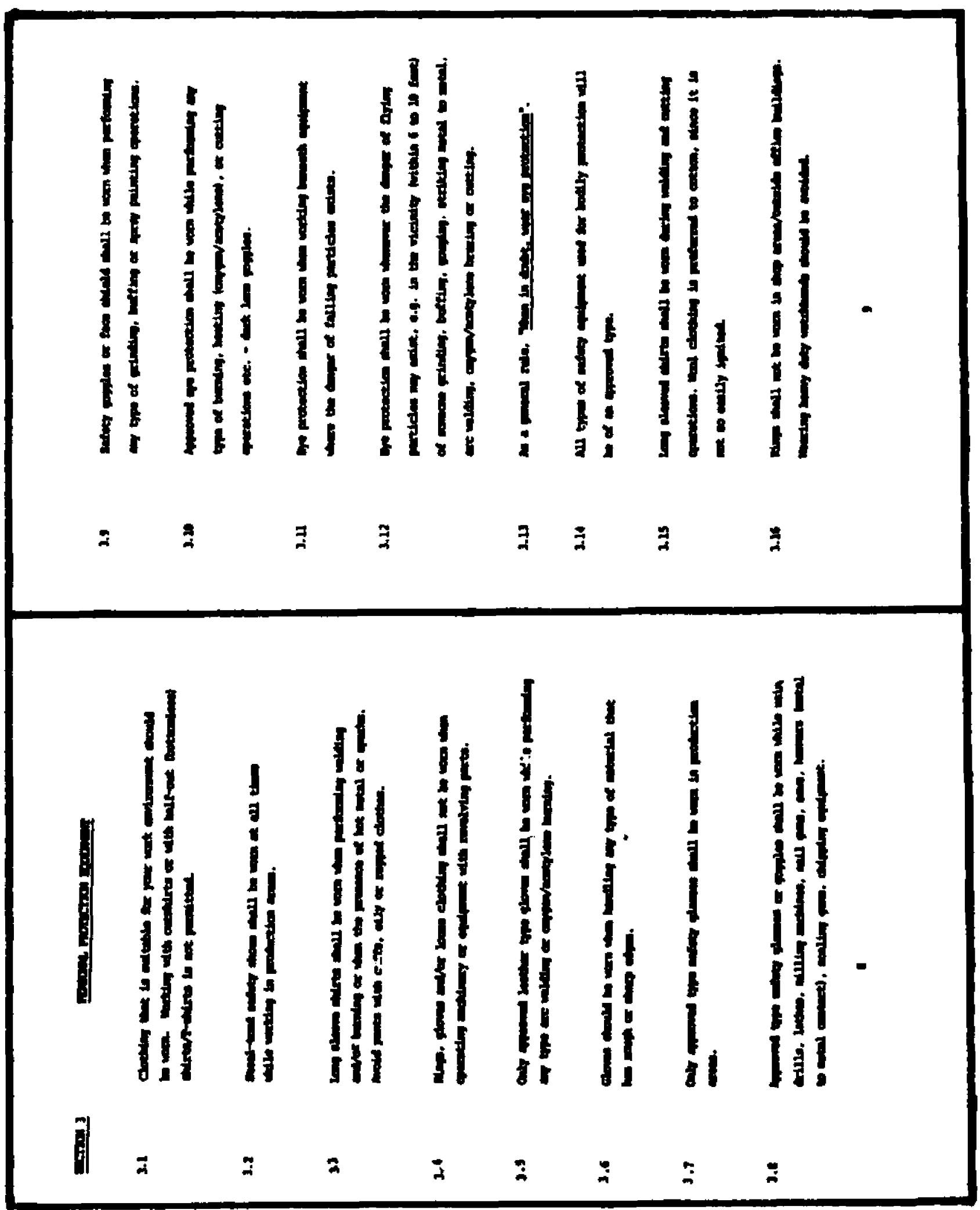




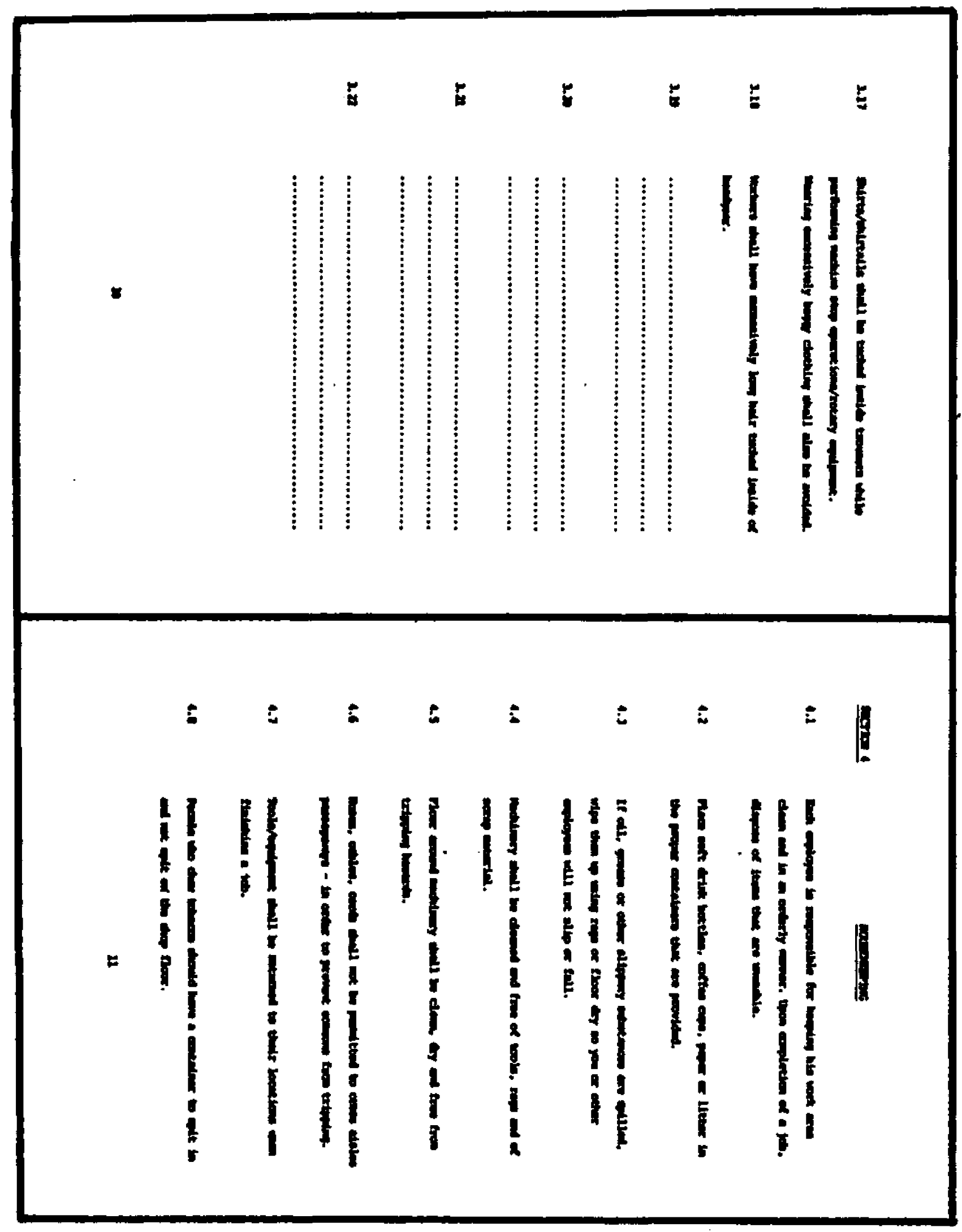




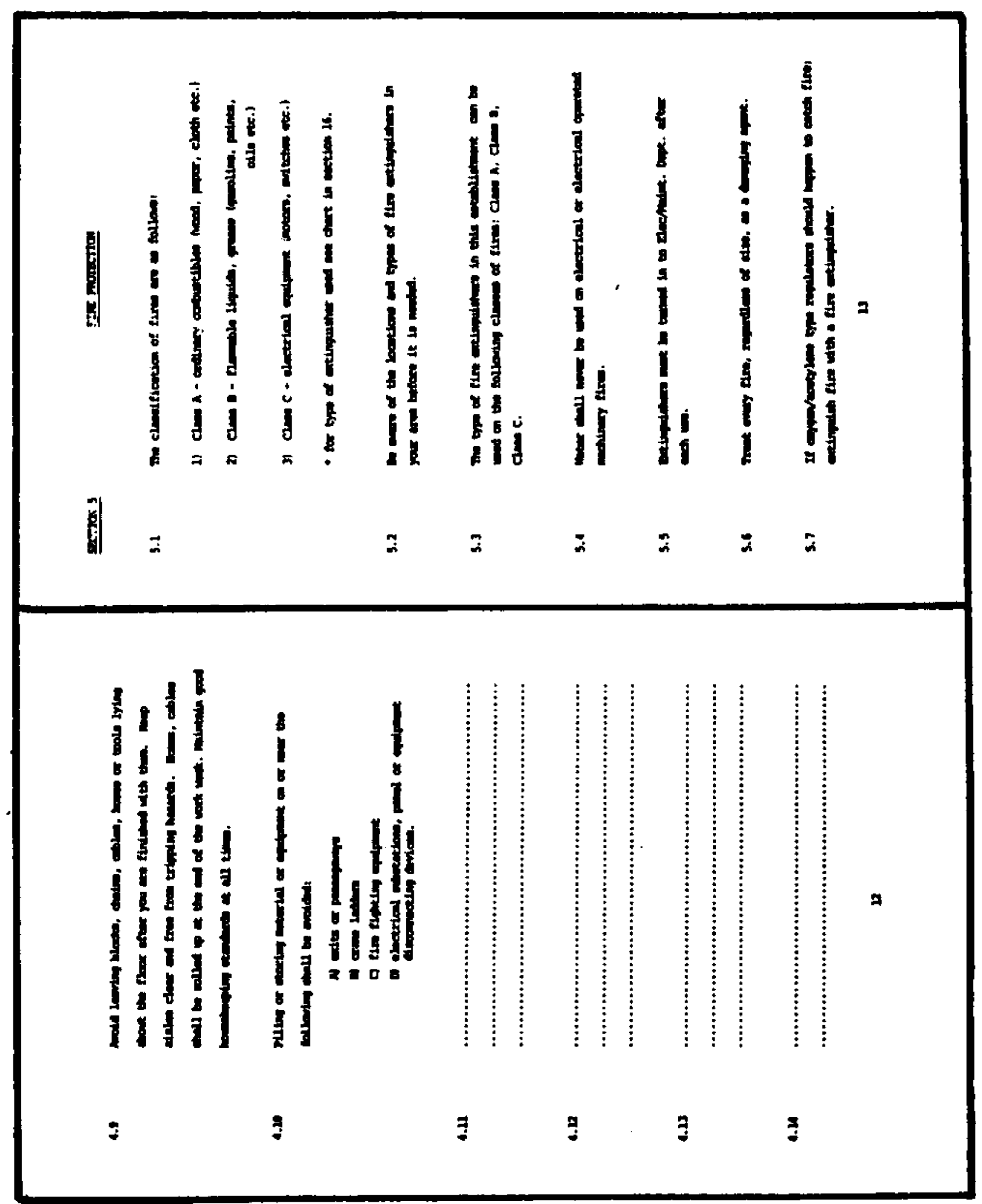




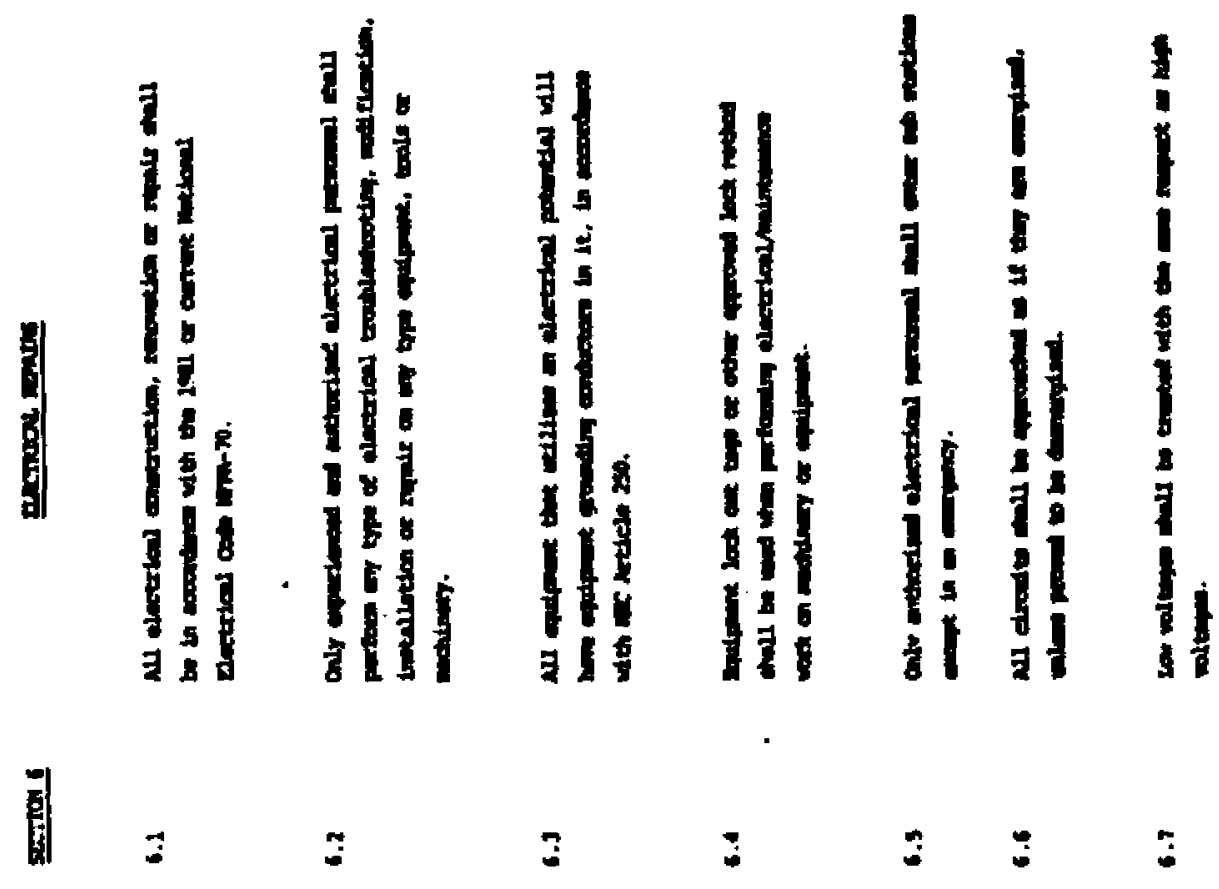

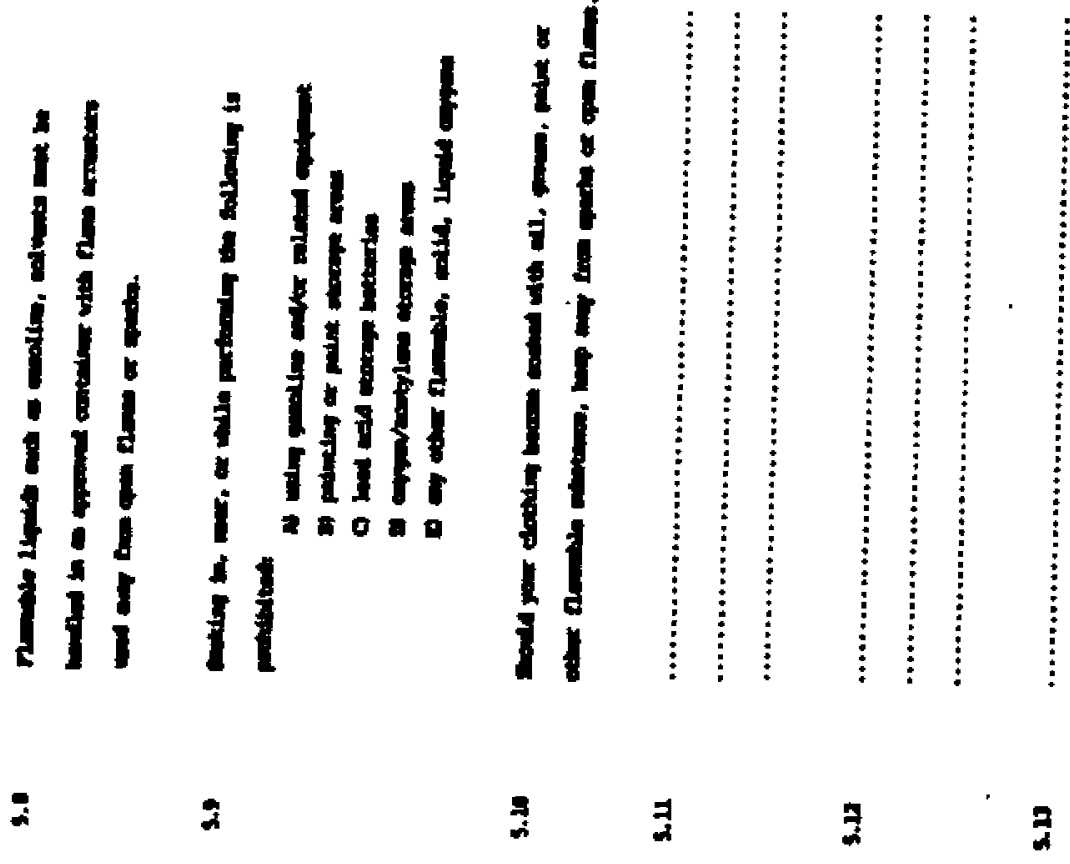




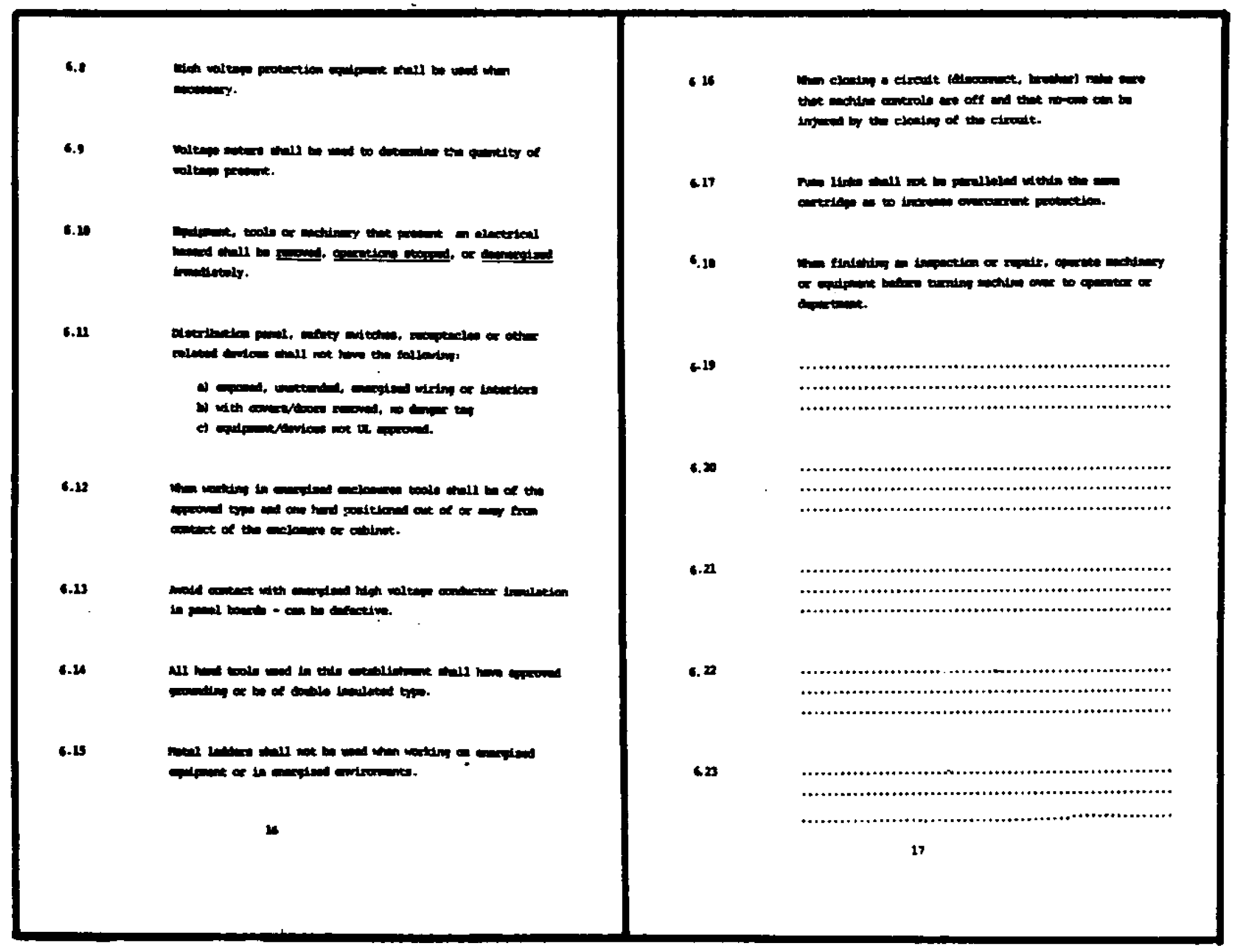




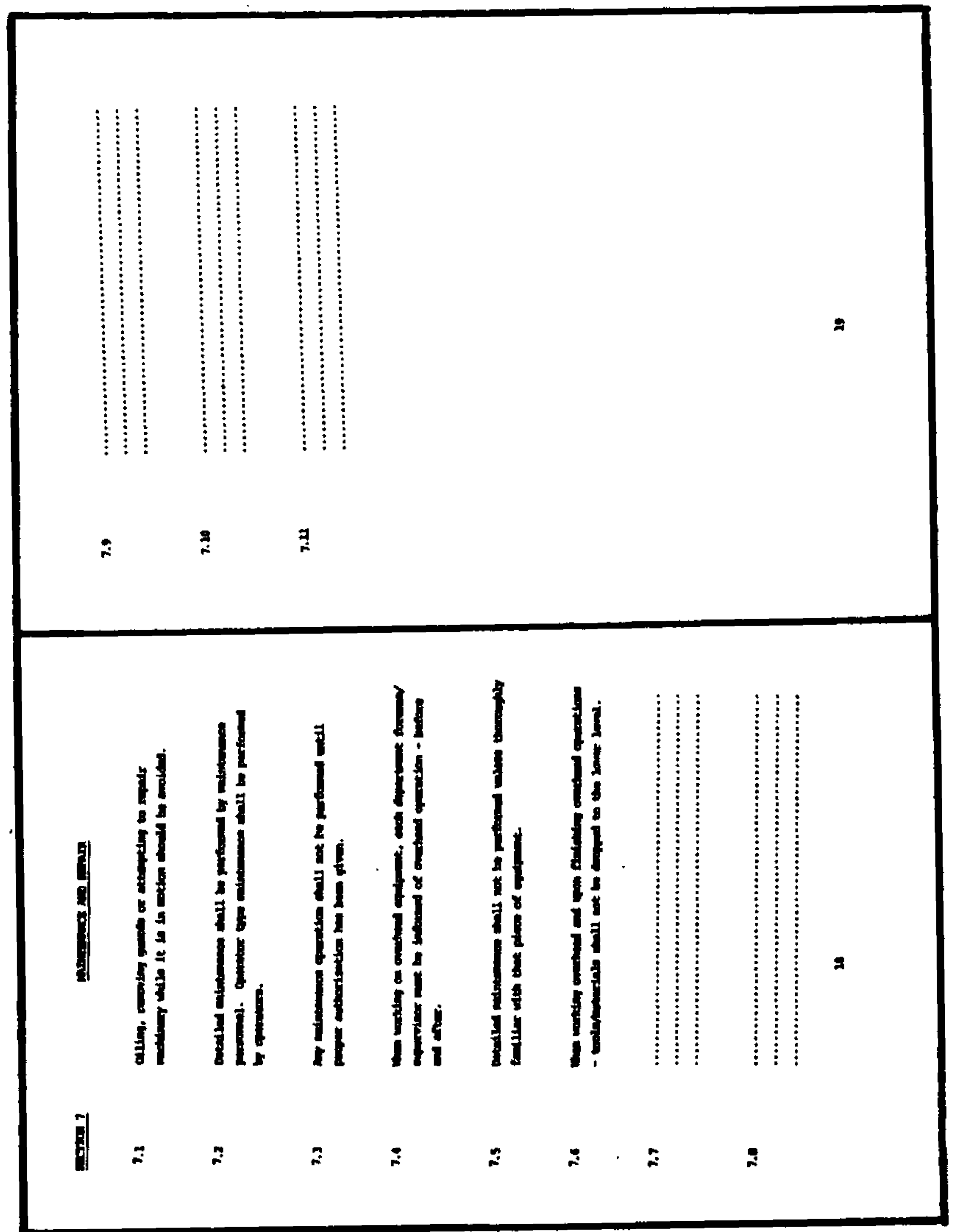




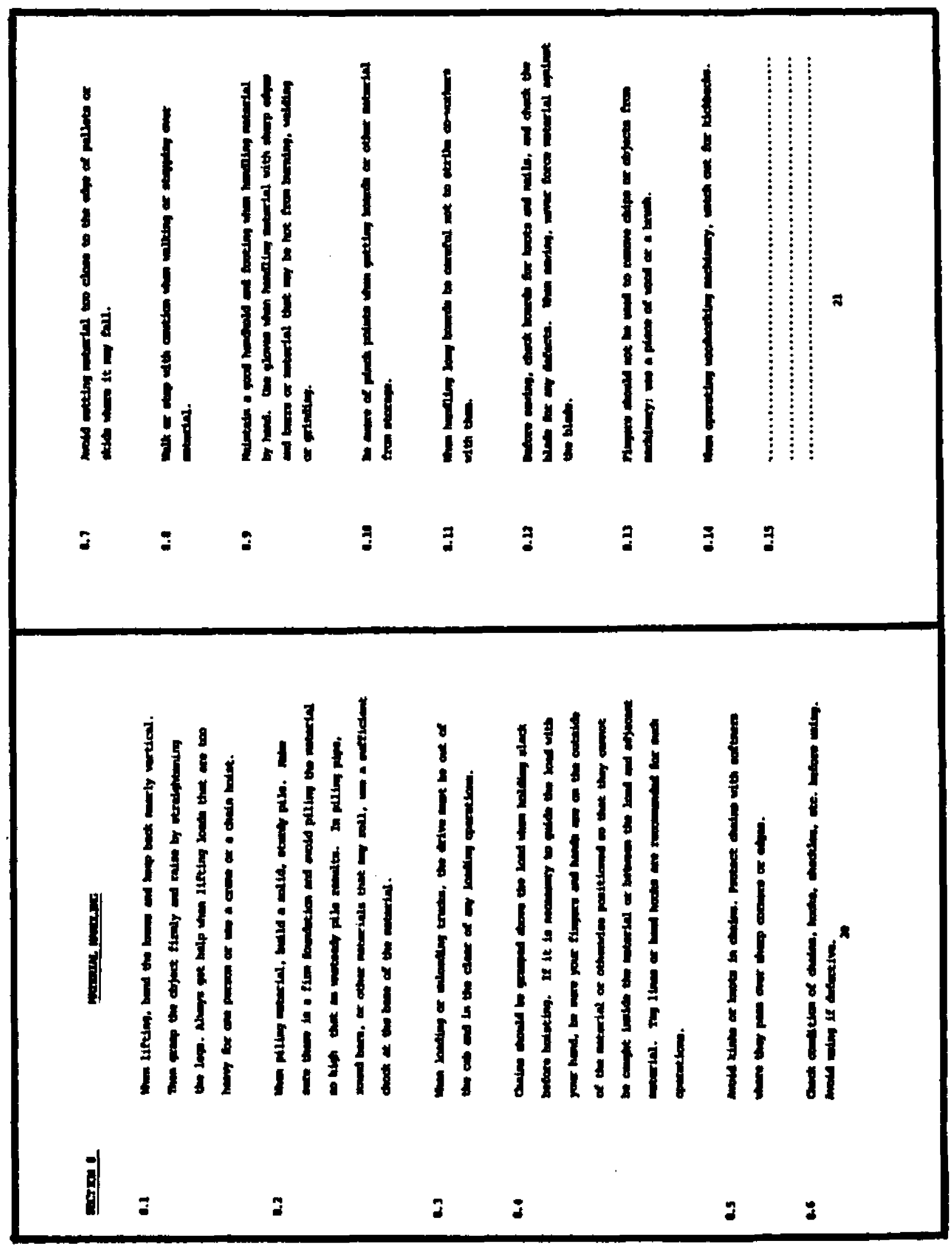




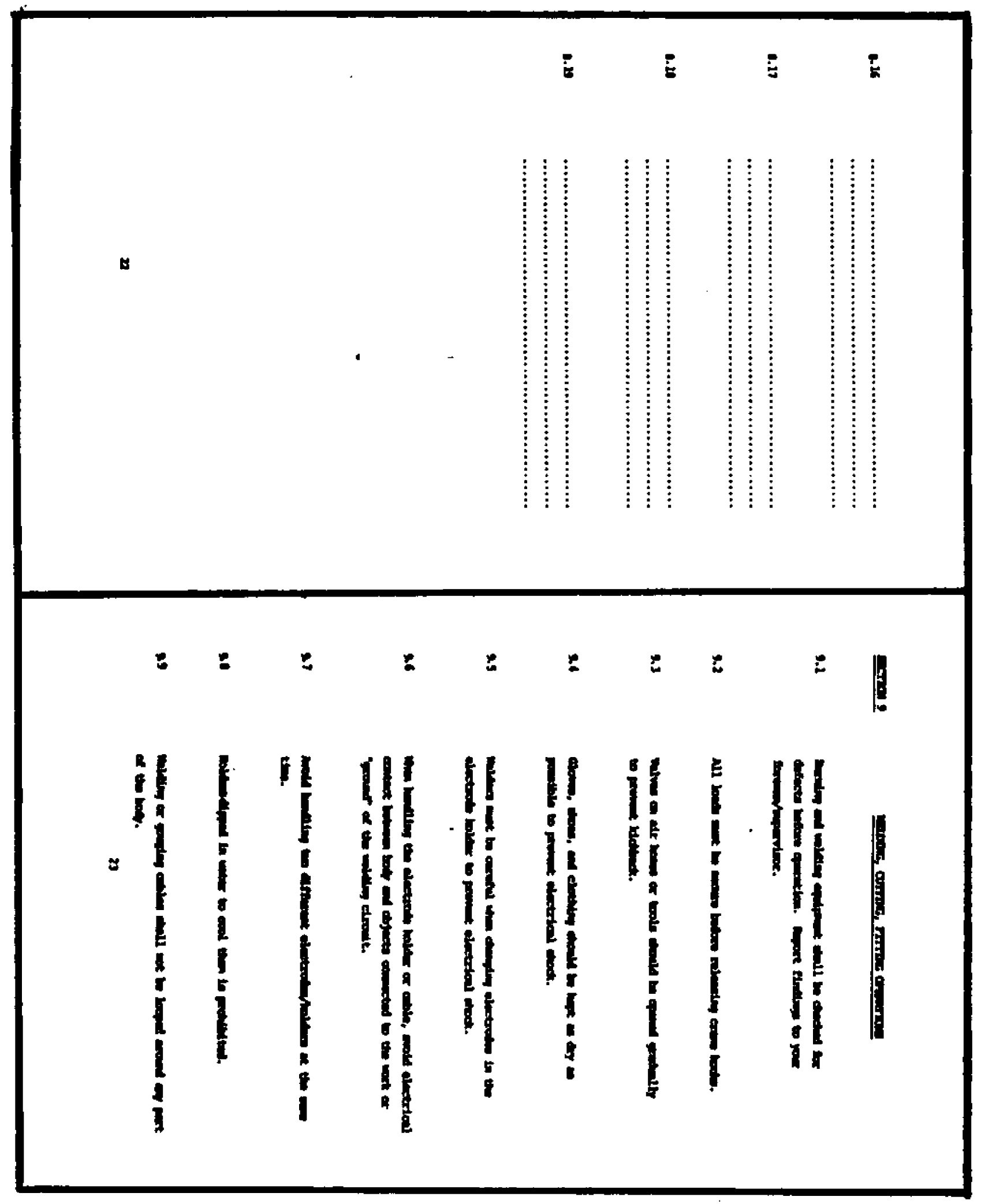




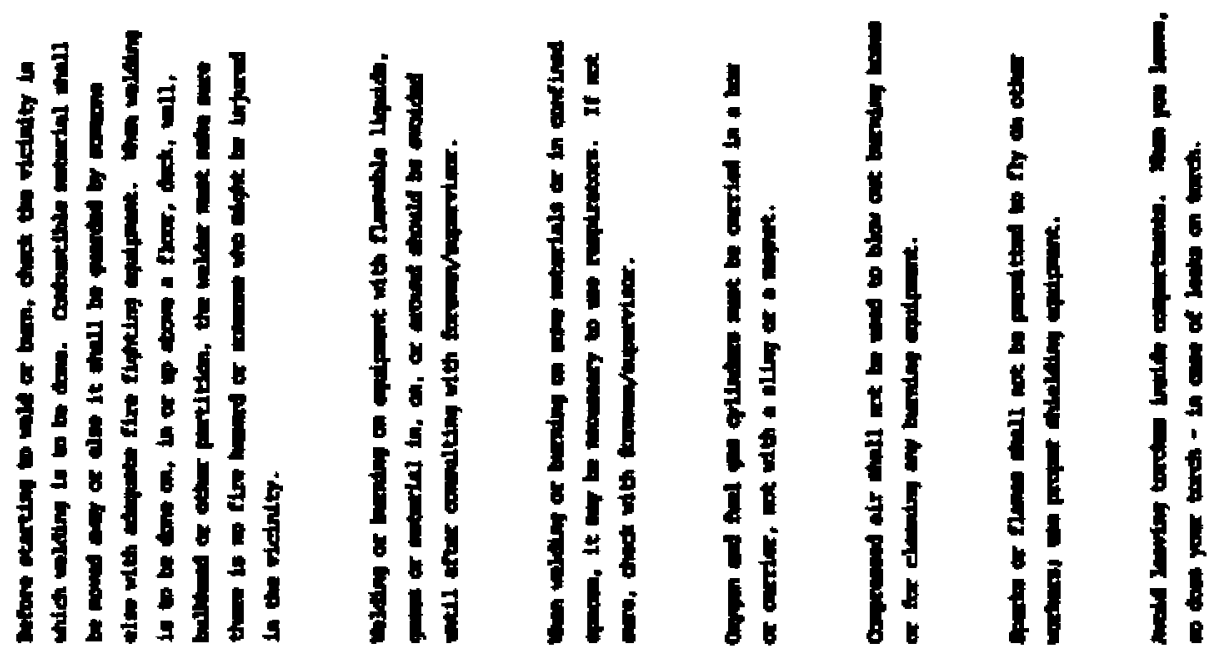

3 $\$ \$ \$$

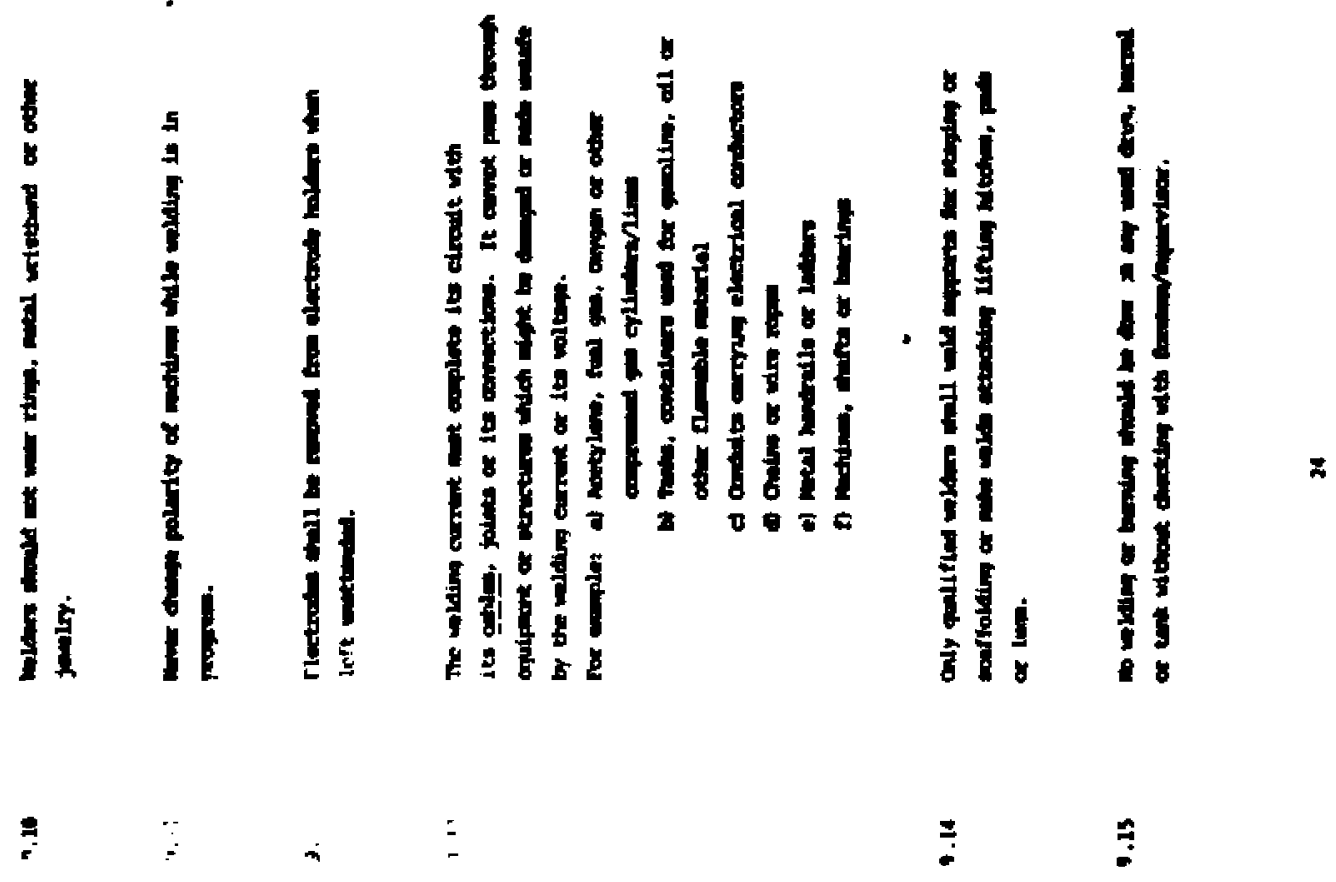




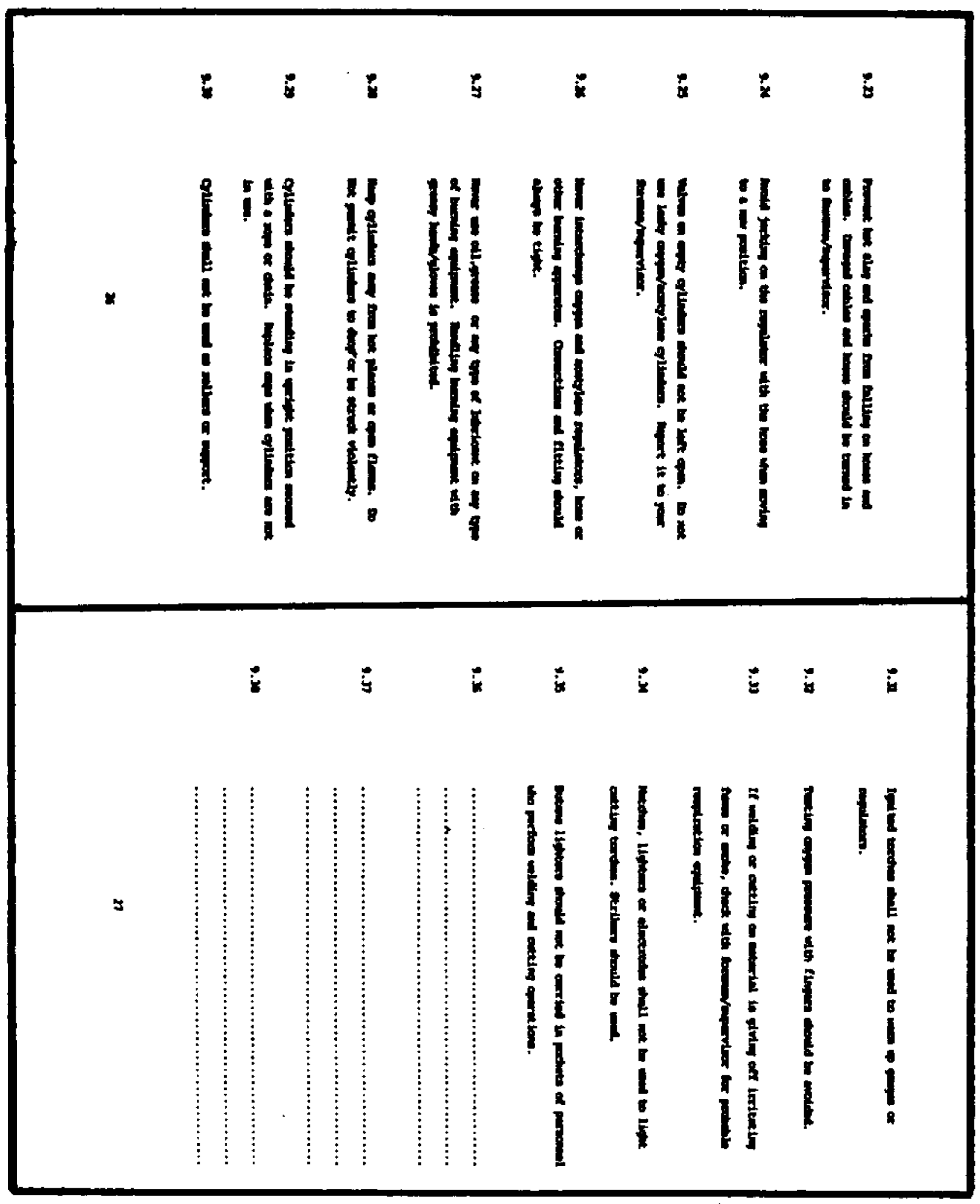




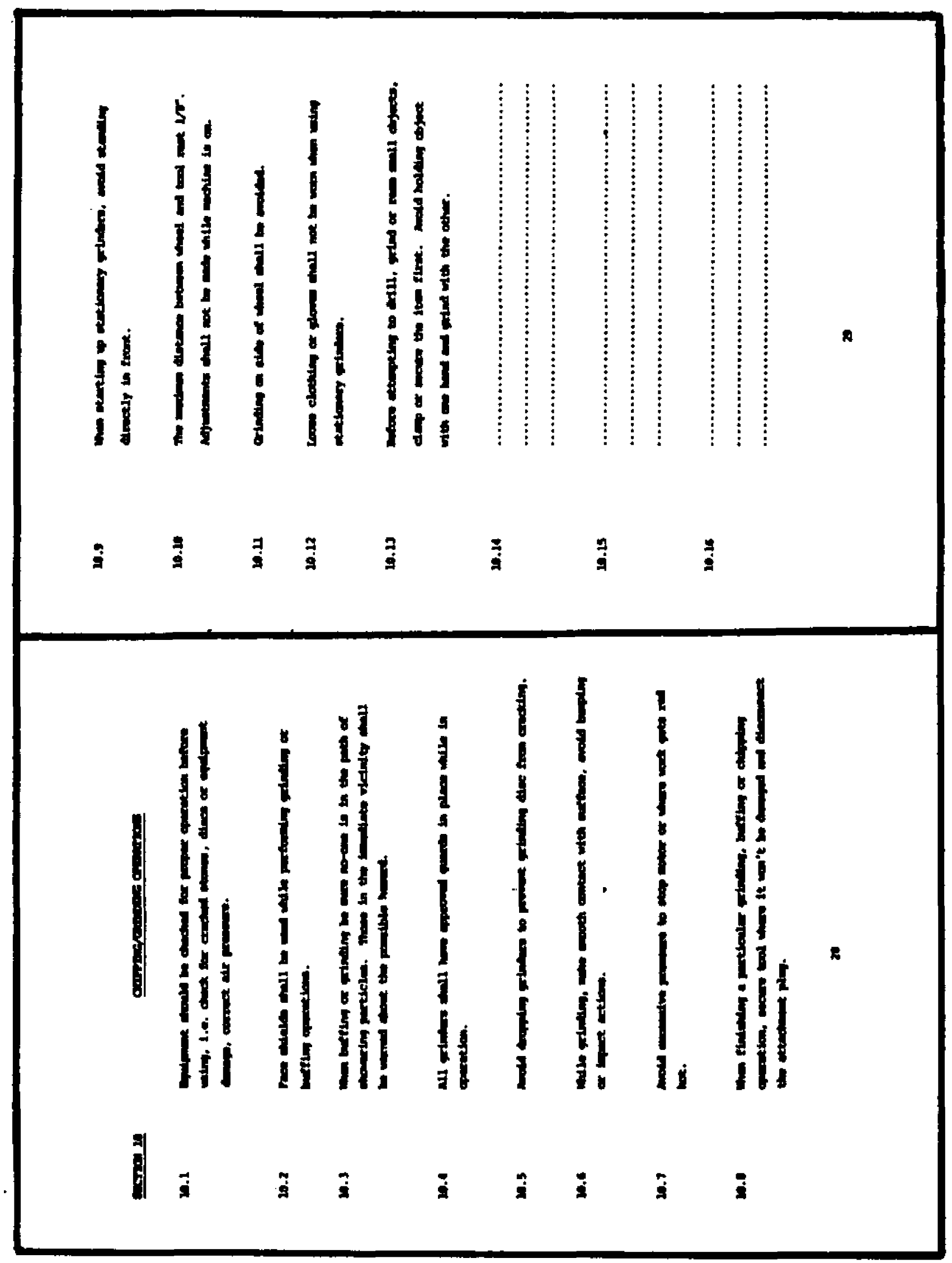




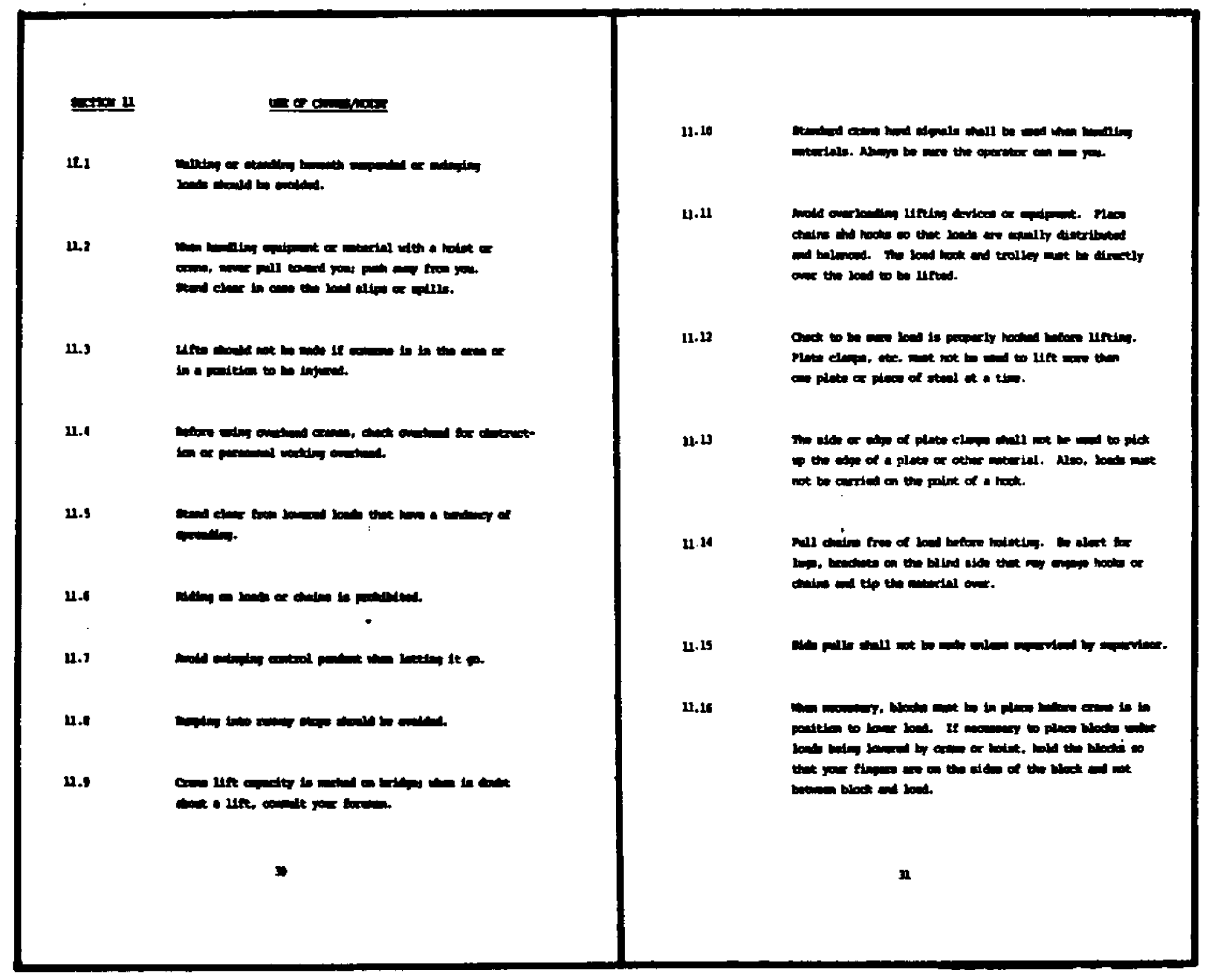




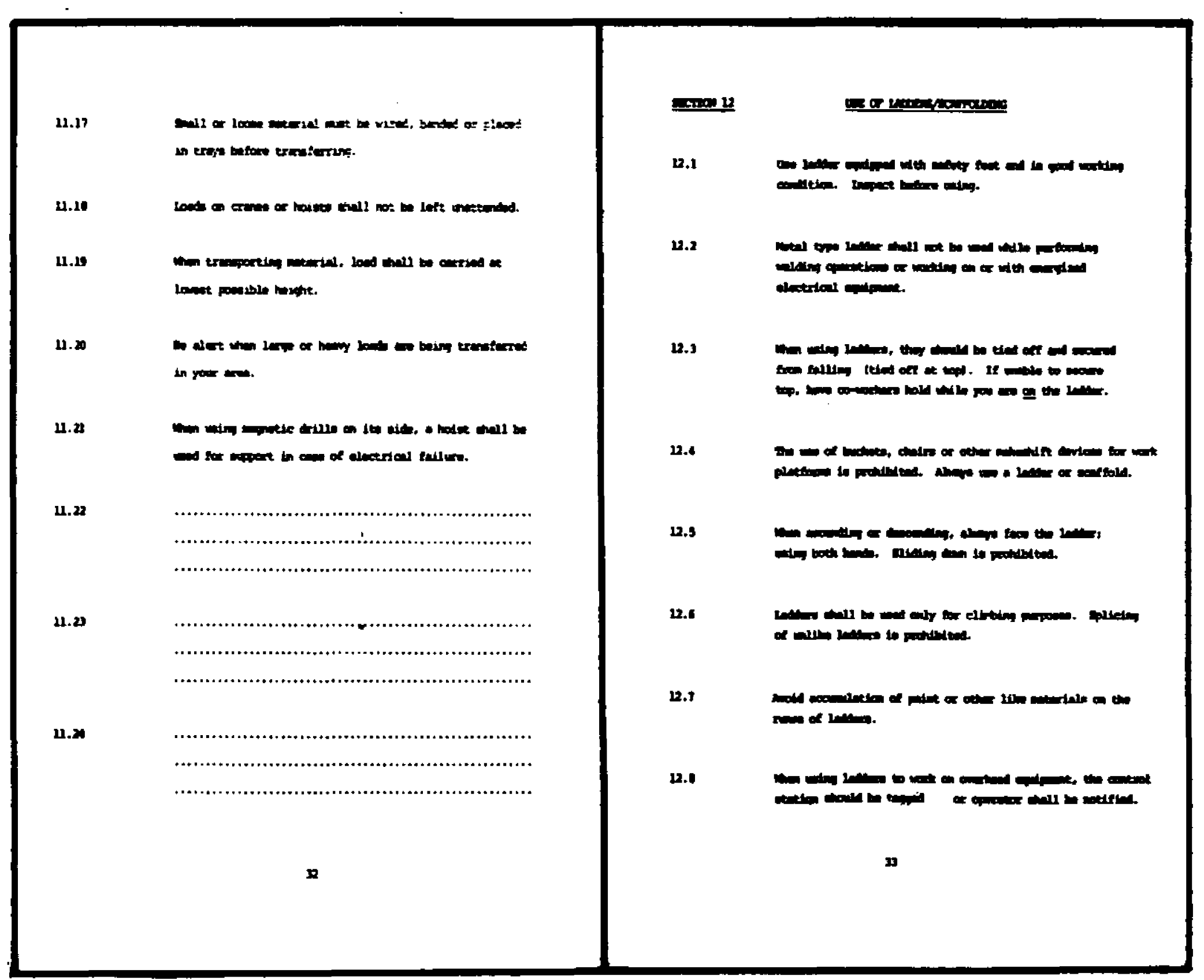




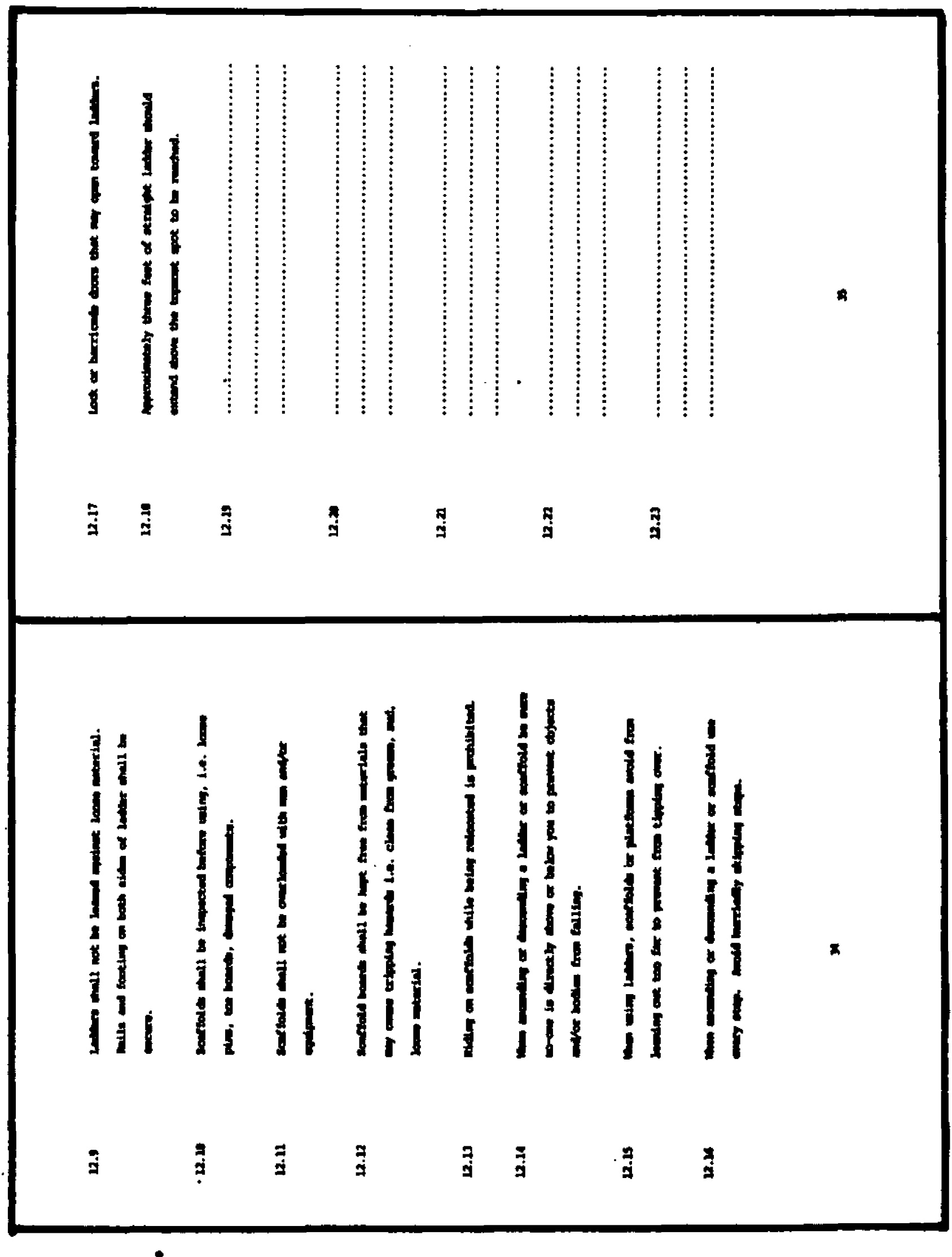




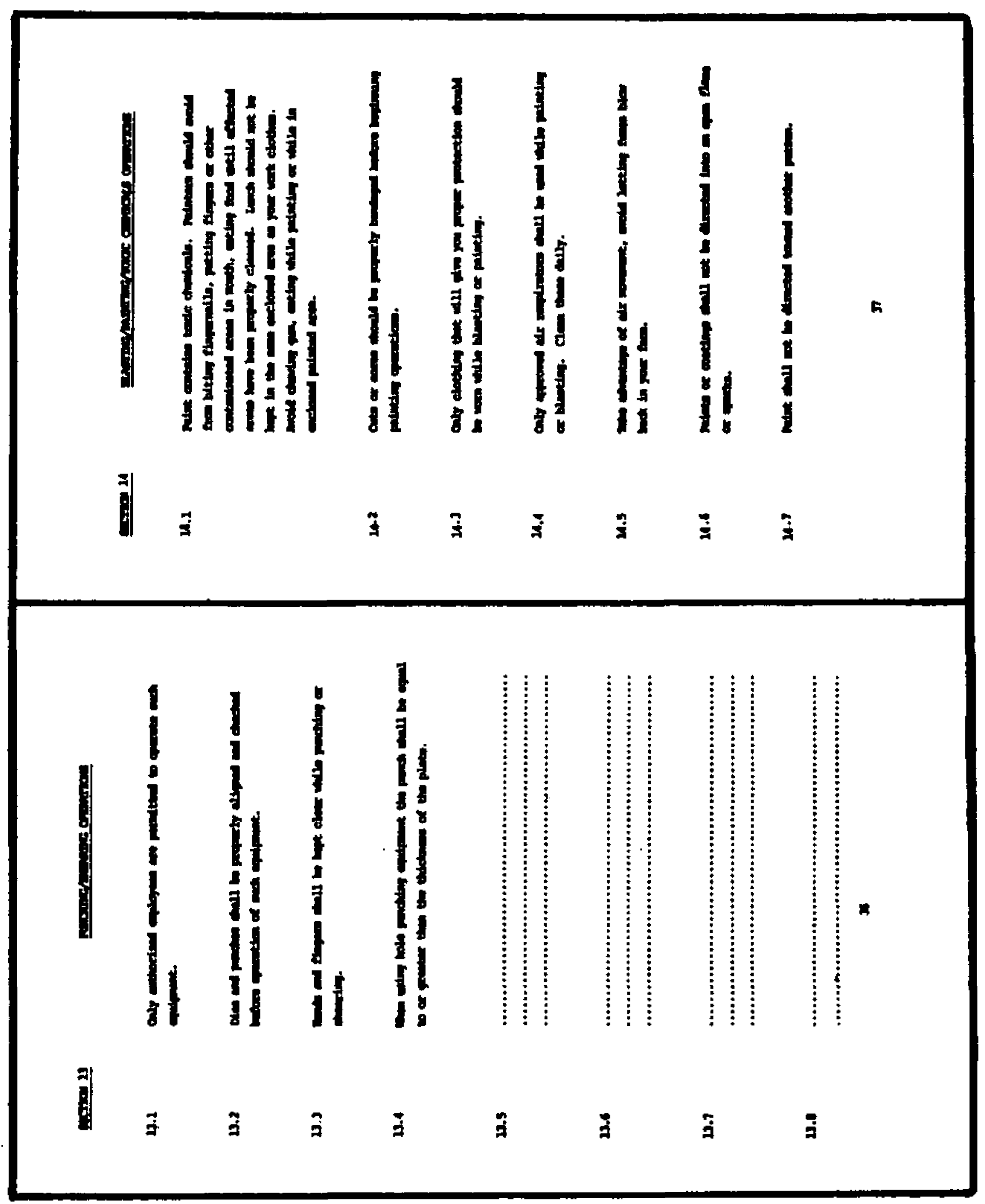




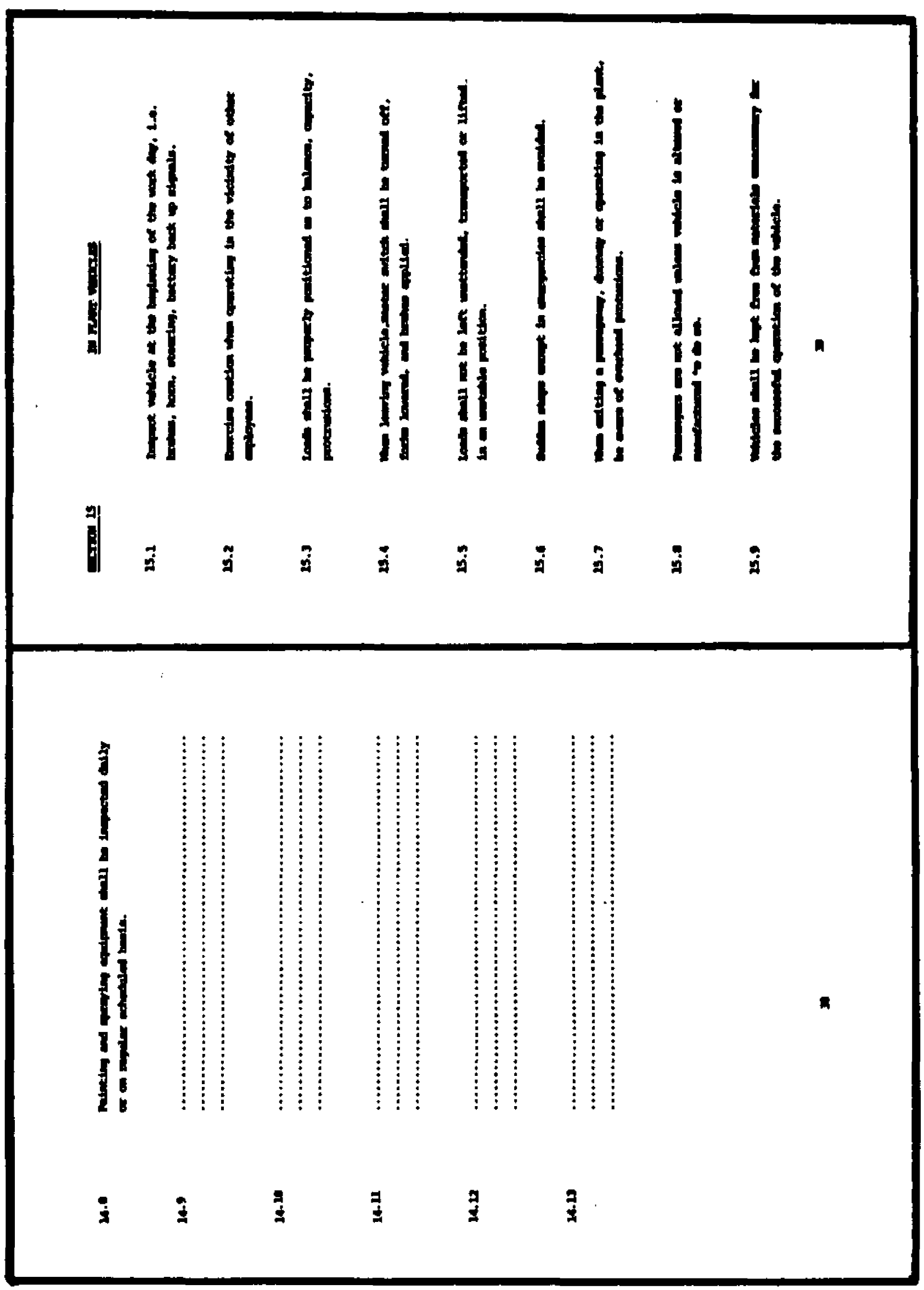




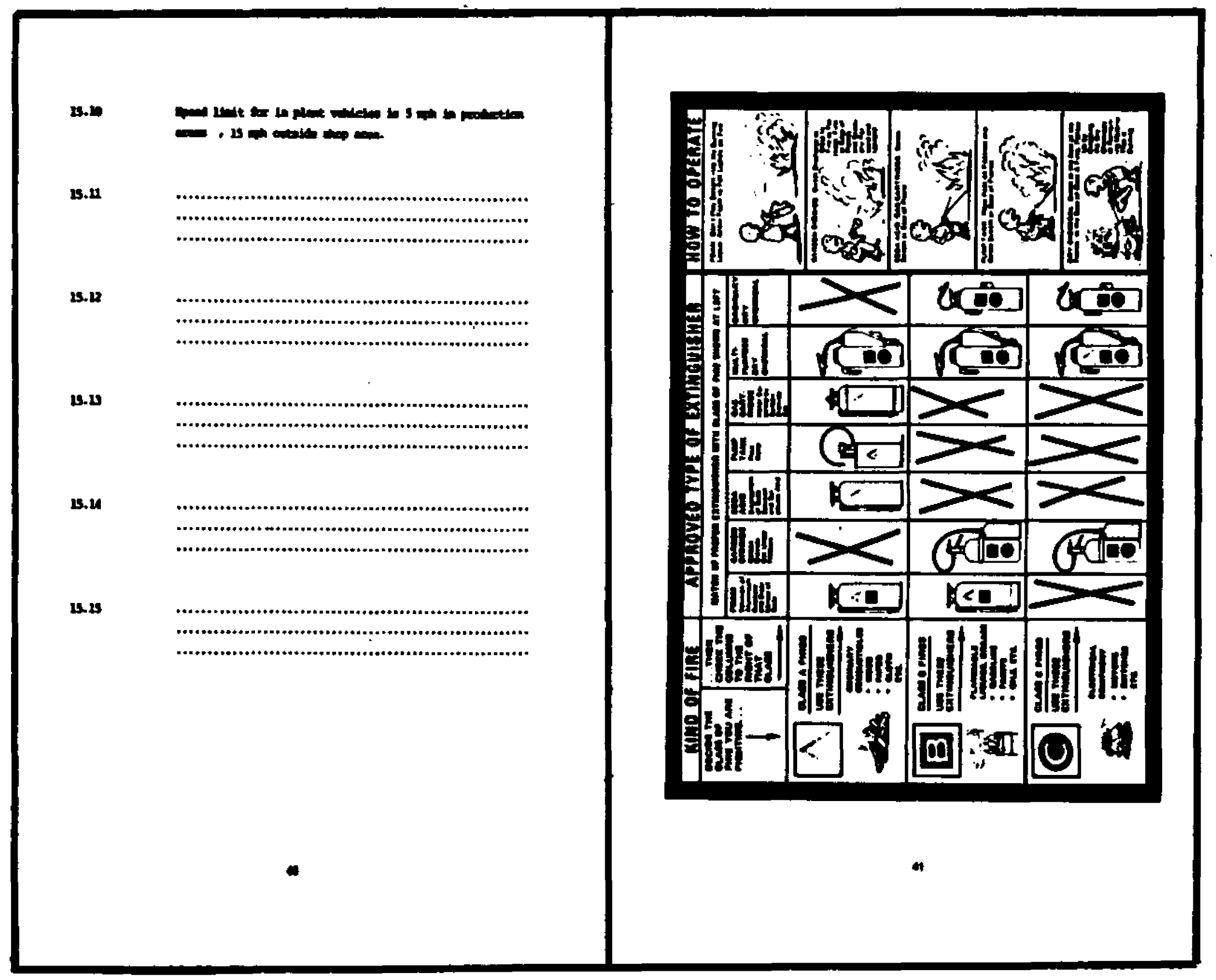




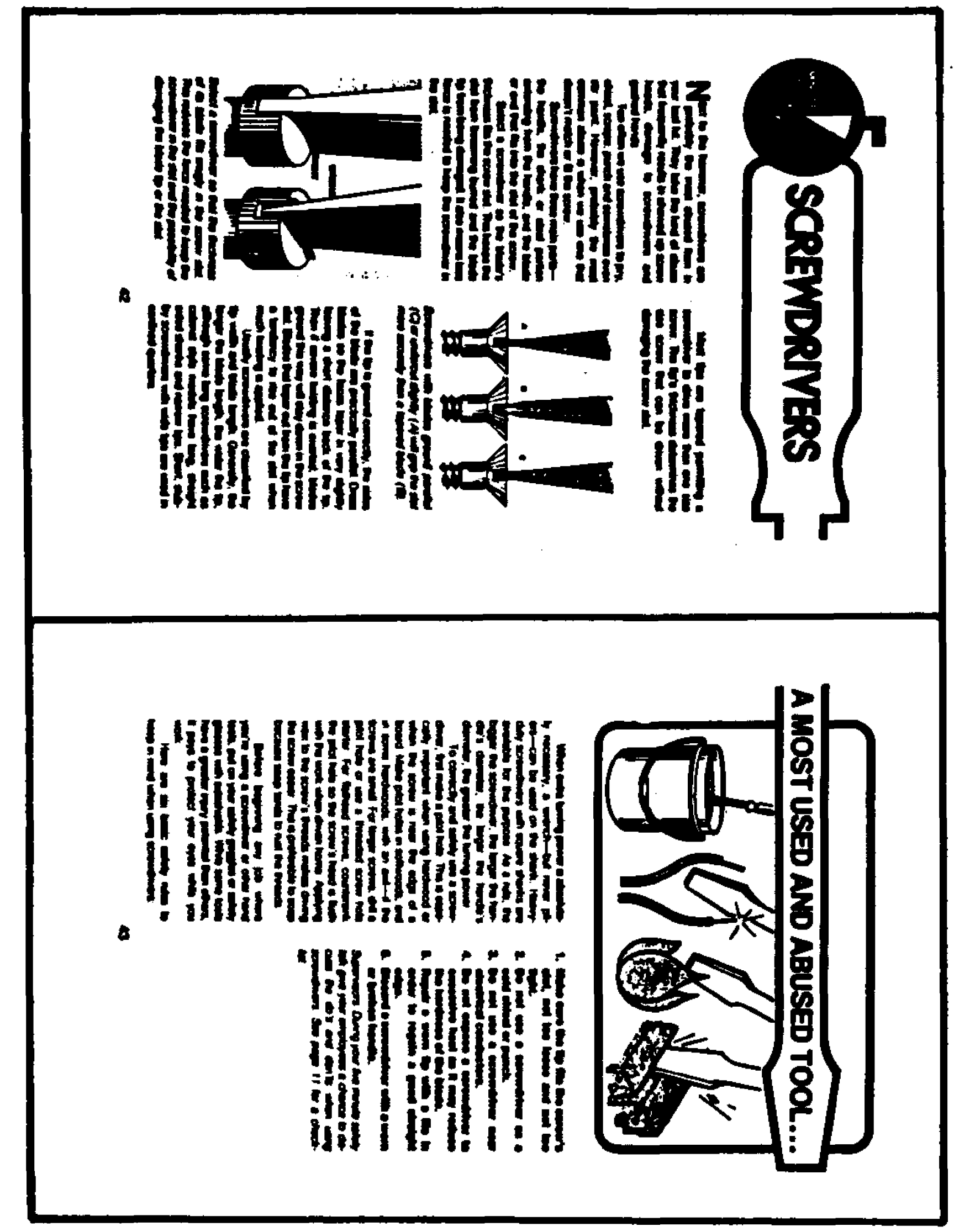




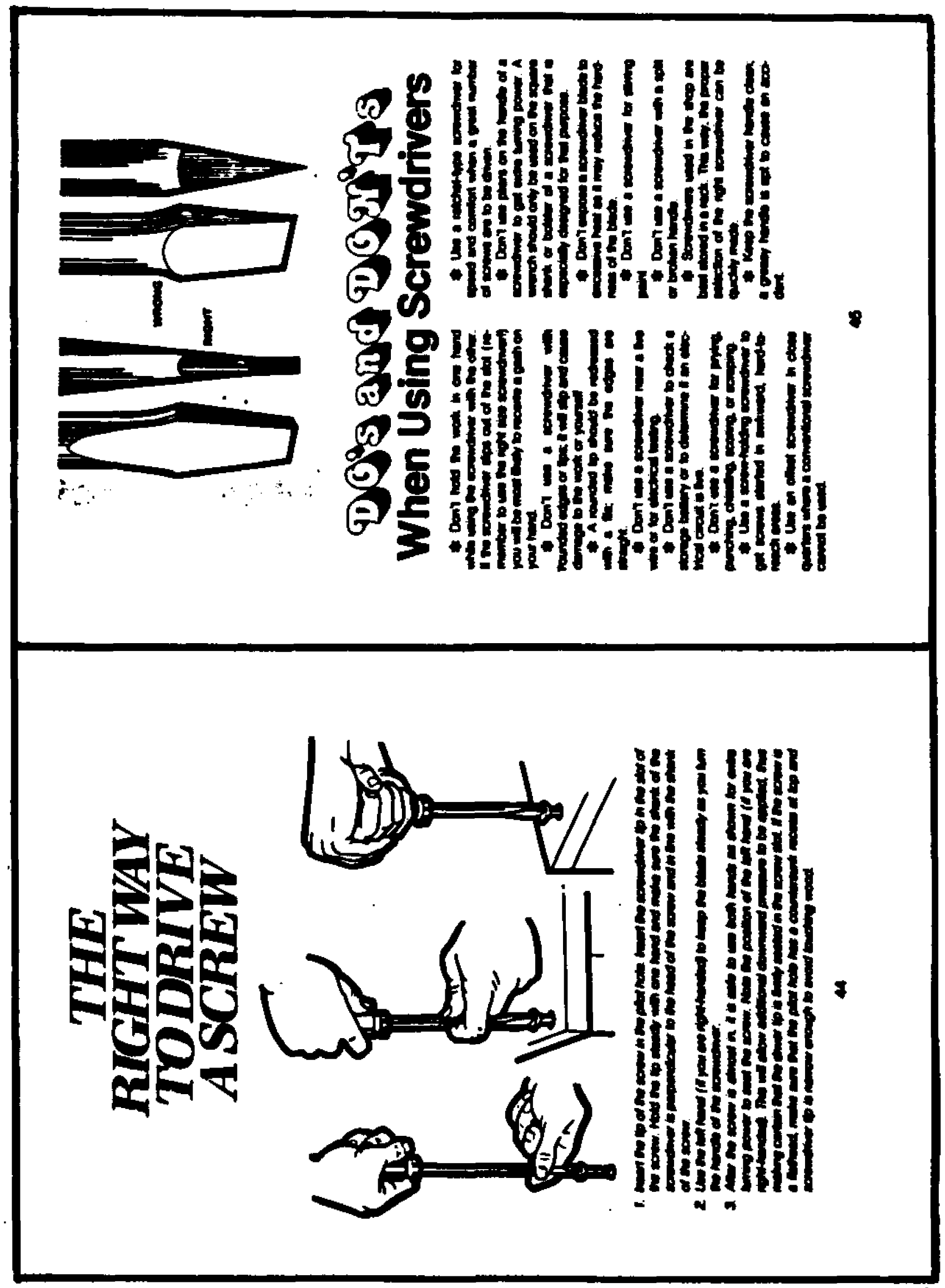



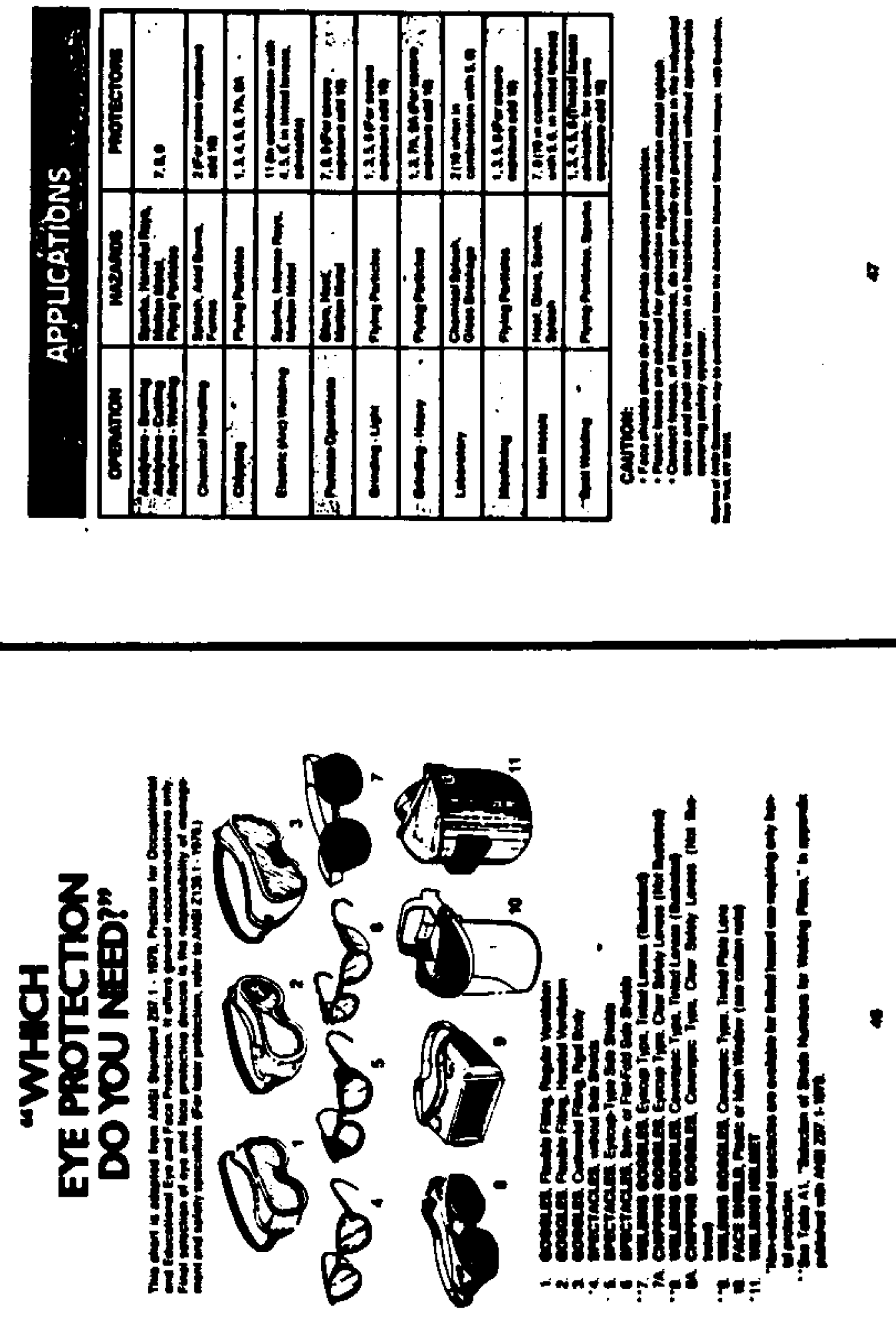
APPENDIX $D$

Observation Form 
ENtory arox

mere

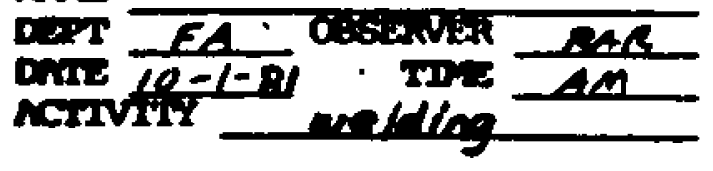

Crume givery

Ibomelay

$\checkmark$ Postition of colt

$\checkmark$ Posteton of otherm

Thas (hecify below)

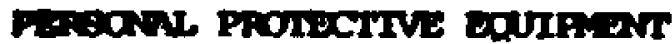

$\angle$ Bres/Taco

7 lind $/$ man

Clothing

$>$ other (frocts balow

tousucuping

1 epil1.

Lopipment a Toole

L Trippling hands

Z other (Bpolfy below)

mowert laxphose

Iffting (manualy)

T stocking/Crating

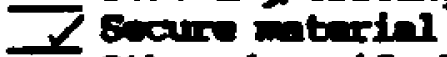

Other (epolfy below)

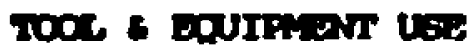

L inlatng/arting/ritelng

- Chipplong/orinaling

- Cremenbloto

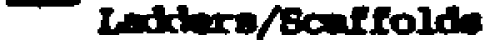

- Palnt/Ononicilo

- Inend toole

T othar (epelfy below)

comprs

1. Example of completed form for olployee working safely. gnran Orox

nars

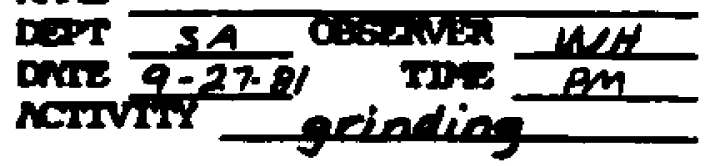

canthe entur

formploy

Z Poptition of ale

$\angle$ Postetion of othare

Othar (bectry balow)

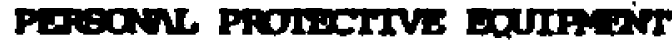

$x$ Dres $/$ reco

$\angle$ nonde/nmon

$>$ clothing

I Otha (nectify bilou)

totseconge

$<$ Epillo

$<$ pilpont o nools

$\angle$ Trippling haraxds other (cpolfy blow)

maral bovate Wfeting (nomally)

T Btacking/Crating

$\zeta$ Ecane Entaring

othrr (apolfy below)

zoon a Dourtwar use miding/arting/Fitting

Chipping/oringing Crenentible.

- Indiere/Schefolds

- Pativenoulon.

- Iland toole

Z Other (fpedfy below)

conenrs

2. Example of conpleted form for enployee working unsafely. 
APPENDIX E

Observational Code 
OBSERVATIONAL CODE

OBSERVATION

FORM

CODE

(Applicable Groups)

BEHAVIORAL DESCRIPTION

SAFETY MANUAL

REFERENCES

GENERAL SAFETY (GS)

GS- 1

(A11)

Position of self: When using a wrench, pinch bar, hammer, or ratchet lever hoist, position yourself so that if the tool slips, you will not fall or otherwise be injured. Never rely on the tool to support your weight or force.

Position of self: When handling equipment of material with a hoist or crane, never pull it toward yourself, push away from your person. Stand clear in case the load slips or spills. (Also score "crane/hoists" under Tool and Equipment Use)

GS-3 Position of others: When buffing, (A11) grinding, welding, or cutting, be sure no one is in the path of showering particules or sparks. Use proper shielding equipment or wam those in the vicinity (within $5 \mathrm{ft}$. radius) about the possible hazard. (Also score "chipping/ grinding", or "welding/cutting/fitting" under Tool and Equipment Use)

$9.16,9.21,10.3$

GS-4 Position of others: When driving pins or

(A11) bolts, check to see that no one is on the opposite side where they may be struck by a flying pin or bolt.

GS-5 Position of others: When ascending or (A11) descending a ladder or scaffold, be sure no one is directly above or below you. (Also score "ladders/scaffolding" under Tool and Equipment Use)

GS-6 Position of others: Crane/hoist lifts should

(A11) not be made if someone is in a position to be injured. Transport material at the lowest possible height, and never pass a load over someone. (Also score "crane/ hoists" use) 
OBSERVATIONAL CODE, cont'd.

CODE

BEHAVIORAL DESCRIPTION

REFERENCE

GS-7 Other: Running and/or jumping on company

(A11) premises is prohibited. Always walk (except in an emergency), especially at breaks, lunch time, and quitting time.

2.3

GS-8 Other: Equipment must be locked out and/ (A11) or disabled before attempting any repairs. Never at tempt to operate equipment under repair or that is "Tagged out".

$2.13,2.33$

PERSONAL PROTECTIVE EQUIPMENT (PPE)

PPE-1 Eyes/Face: Approved safety glasses or

(A11) goggles shall be worn while using nail guns, hammers (metal to metal contact), chipping guns, or punching equipment.

3.8

PPE-2 Eyes/Face: Approved safety glasses or

(1 only) goggles shall be worn when working beneath equipment where the danger of falling particules exists.

PPE-3 Eyes/Face: Approved safety glasses with side shields or goggles shall be worn when grinding, buffing, spray painting, drilling, machining, scaling, or sawing. For heavy buffing and grinding, e.g. , sparks flying toward yourself, a face shield is also recommended.

$3.8,3.9,10.2$

PPE-4 Eyes/Face: Dark lens cutting goggles shall

(A11) be worn when performing any type of oxygen/acetylene burning, cutting, or heating operations.

PPE-5 Eyes/Face: A welding helmet is required

(Al1) for performing any arc welding operations. (Item added to the manual.)

PPE-6 Eyes/Face: Eye protection should be worn (A11) whenever the danger of flying particles may exist. For example, when you are in the vicinity (within $6 \mathrm{ft}$.) of someone grinding, buffing, gouging, hamering, sawing, using a nail gun, spray painting, welding, or oxygen/acetylene brazing or cutting. 
OBSERVATIONAL CODE, cont'd.

CODE

BEHAVIORAL DESCRIPTION

REFERENCE

PPE-7 Hands/Arms: Long sleeve shirts shall be

(A11) worn when performing welding operations.

$3.3,3.15$

PPE-B Hands/Arms: Gloves shall be worn while performing any arc welding or oxygen/ acetylene cutting or burning.

3.5

PPE-9 Hands/Arms: Gloves should be worn when

(A11) handling any type of raw material or machined material that has rough or sharp edges.

$8.6,8.9$

PPE- 10

(A11)

Clothing: Shirts/shirtails shall be tucked inside trousers while performing machine shop operations or using rotary equipment such as grinders, drills, power saws, reamers, and impact wrenches. Wearing excessively baggy clothing shall also be avoided.

$3.4,3.17$

PPE-11 Other: Approved air respirators shall be

(1, 3) used while painting or blasting. Clean these daily. (Specific iten for painting/sandblasting and crating departments.)

14.4

PPE-12 Other: A welding cap or other approved (A11) head protection should be worn when arc welding or oxygen/acetylene cutting or burning. (Item added to the manual).

HOUSEKEEPING (HK) **

**For observational purposes, employees should be scored for the housekeeping of the area within a $5 \mathrm{ft}$. radius of their observed position. Therefore, the observable result of an act is scored rather than the actual behavior per se.

HK-1 Spills: If oil, grease, or other liquid

(A11) substances are spilled, wipe them up using rags or floor-dri so you or other employees will not slip or fall. 4.3

HK-2 Equipment \& Tools: Portable power tools

(Al1) should be disconnected from their attachment plug as soon as they are not in use. Secure the tool where it won't be damaged or return it to its proper location upon fintshing a job. 
OBSERVATIONAL CODE, cont'd.

CODE

HK-3

(Al1)

(A11)
BEHAVIORAL DESCRIPTION

Tripping hazards: Avoid leaving blocks, chatns, hooks, cables, hoses, or tools lying on the floor after you are finished with them. Keep alsies (designated by yellow lines) clear and free from these tripping hazards at all times. Stay alert for tripping hazards and correct them where possible.

Other: Piling or storing material or equipment near the following should be avoided: A) exits or passageways,

B) crane ladders, C) fire fighting equipment, D) electrical substations, panels or equipment disconnecting devices (emergency shut-offs).

4.10

REFERENCE

$2.4,4.5,4.9$

MATERIAL HANDLING (MH)

M-1 Lifting: When lifting an object, bend

(Al1) your knees and keep your back nearly vertica1. Then grasp the object firmly and raise by straightening your legs. (See chart in the back of the manual). Always get help when lifting loads that are too heavy for one person and/or use a crane or hoist.

MH-2 Secure material: Before attempting to

(A11) dril1, grind, or ream smal1 objects, clamp or secure the item first. Avoid holding the object with one hand while performing the operation with the other. 10.13

M-3 Secure material: Have a good foundation ( 3 only) for cutting boards. Never cut between two saw horses. Set the blade for the job and cut across the two saw horses. Also, never balance a board on just one saw horse while sawing. Always use two saw horses. (Item added to the manual. Applies to Crating only). 
OBSERVATIONAL CODE, cont'd.

CODE

BEHAVIORAL DESCRIPTION

REFERENCE

TOOL \& EQUIPMENT USE (TE)

TE-1 Welding/Cutting/Fitting: Matches, lighters,

(A11) or electrodes shall not be used to light

oxygen/acetylone cutting torches.

Strikers should be used. Butane lighters

should not even be carried in the pockets

of personnel who perform welding and

cutting operations.

$9.34,9.35$

TE-2 Chipping/Grinding: Always use both

(A11) hands to operate a pneumatic grinder or chipper.

10.13

TE-3 Cranes/Hoists: Riding on a load or chain

(A11) is prohibited. Balance the load and walk beside it while transporting it at the lowest possible height.

$11.2,11.6,11.19$

TE-4 Cranes/Hoists: Plate clamps should be

(Al1) used to $11 \mathrm{ft}$ only one plate or piece of stee 1 at a time. Attach the clamp near the center of the plate and thus avoid making an unbalanced load or side pul1s. 11.12, 11.13, 11.15

TE-5 Ladders/Scaffolds: The use of buckets, chairs, fork lifts, or other makeshift devices for work platforms is prohibited. Always stand on a ladder or scaffold when working more than $1 \mathrm{ft}$. off the ground.

12.4

TE-6 Ladders/Scaffolds: When ascending or

(A11) descending a ladder or scaffold, use every step. Avoid hurriedly skipping steps or jumping off.

12.16

TE-7 Paint/Chenicals: Paint booth doors should

(1 only) be kept closed when any spray painting

is taking place inside. (I tem added

to the manual. Applies to painting/

Sandblasting department only)

14.9

TE-8 Hand tools: Hand tools should only be used

(A11) within their maximun capability. Never use add-on devices to try to extend the tools limits. For example, avoid attaching a cheater pipe to a wrench, use a larger wrench instead. (Item added to the manua 1) 
OBSERVATIONAL CODE, cont'd.

CODE

BEHAVIORAL DESCRIPTION

REFERENCE

TE-9 Hand tools: Always use a tool for its

(A11) designed purpose only. For example, never use a wrench or crane hook as a haminer. (Item added to the manual)

TE-10 Other: Never use your fingers to check

(2 only) alignment or the condition of a hole when using a punch press. Always use the proper tool to place the material in position for the punch. 
APPENDIX F

Multiple-Baseline Design of the Study 


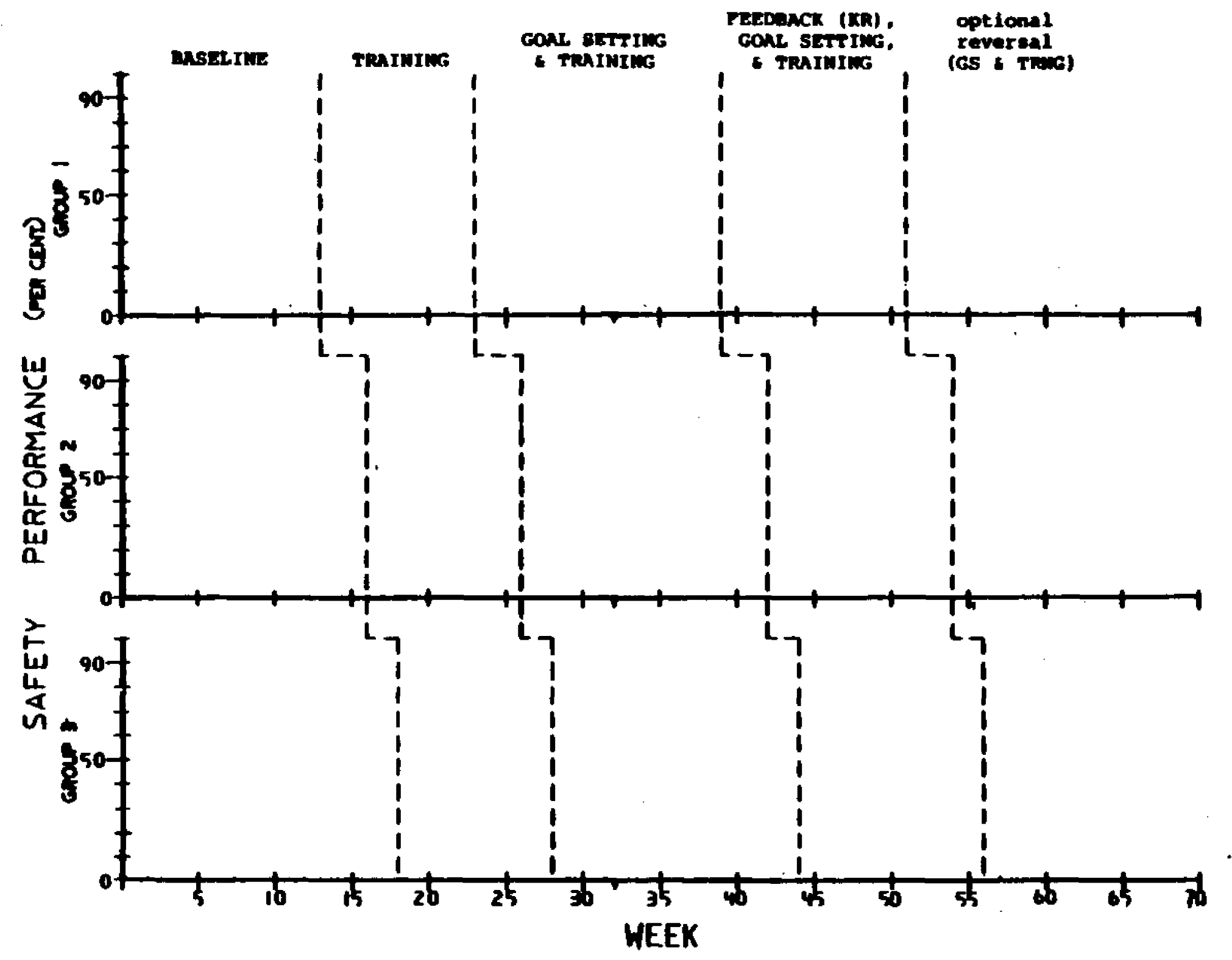


APPENDIX G

Description of Training Slides*

*Note: The following notation by the slide number indicates that the slide was used for a safety quiz:
a - Group 1 quiz
b - Group 2 quiz
c - Group 3 quiz 


\begin{tabular}{|c|c|c|c|}
\hline $\begin{array}{l}\text { SLIDE } \\
\text { NO. }\end{array}$ & $\begin{array}{l}\text { GROUP(S) } \\
\text { VIEWING } \\
\end{array}$ & DESCRIPTION & $\begin{array}{c}\text { OBSERVATIONAL } \\
\text { CODE } \\
\text { REFERENCE } \\
\end{array}$ \\
\hline 1 & A11 & $\begin{array}{l}\text { Unsafe: Horseplay example. } \\
\text { Individual seen riding on a } \\
\text { crane load. }\end{array}$ & TE- 3 \\
\hline 2 & Al1 & $\begin{array}{l}\text { Unsafe: Individual seen running/ } \\
\text { jumping over a stack of metal. }\end{array}$ & GS-7 \\
\hline 3 & & $\begin{array}{l}\text { Safe: Individual seen walking around } \\
\text { the stack of metal. }\end{array}$ & \\
\hline $4^{a}$ & A11 & $\begin{array}{l}\text { Unsafe: Employee using a cheater } \\
\text { pipe on a wrench and in a position } \\
\text { to be hurt if the tool slips. }\end{array}$ & GS- 1, TE- 7 \\
\hline 5 & & $\begin{array}{l}\text { Safe: Shows enployee using proper } \\
\text { wrench and not applying his weight } \\
\text { against the tool. }\end{array}$ & \\
\hline $6^{c}$ & A11 & $\begin{array}{l}\text { Unsafe: Depicts employee using an } \\
\text { improper hand tool to work on a } \\
\text { power tool that is connected to } \\
\text { its energy source. }\end{array}$ & GS- 8, TE- 8 \\
\hline $7^{\mathrm{b}}$ & & $\begin{array}{l}\text { Safe: Power tool clearly disconnected } \\
\text { and proper hand tool is being used. }\end{array}$ & \\
\hline $8^{c}$ & Al1 & $\begin{array}{l}\text { Unsafe: Employee is hamnering (metal } \\
\text { to metal contact) while not wearing } \\
\text { safety glasses. }\end{array}$ & PPE-1 \\
\hline $9^{b}$ & & $\begin{array}{l}\text { Safe: Shows same employee now wearing } \\
\text { safety glasses. }\end{array}$ & \\
\hline $10^{\mathrm{a}}$ & 1 only & $\begin{array}{l}\text { Unsafe: Worker is underneath a combine } \\
\text { but is not wearing safety glasses. }\end{array}$ & PPE-2 \\
\hline 11 & & Safe: Same worker, now wearing glasses. & \\
\hline $12^{\mathrm{b}}$ & Al1 & $\begin{array}{l}\text { Unsafe: Shows a welder not woaring } \\
\text { gloves, long sleeve shirt, or a } \\
\text { welding cap. (Does have face } \\
\text { shield on.) }\end{array}$ & $\begin{array}{l}\text { PPE-5, PPE-7, } \\
\text { PPE-8, PPE-12 }\end{array}$ \\
\hline $13^{a}$ & & $\begin{array}{l}\text { Safe: Welder now wearing proper } \\
\text { protective oquipment: gloves, } \\
\text { long sleeve shirt, and cap. }\end{array}$ & \\
\hline
\end{tabular}




\begin{tabular}{|c|c|c|c|}
\hline $\begin{array}{l}\text { SLIDE } \\
\text { NO. }\end{array}$ & $\begin{array}{l}\text { GROUP (S) } \\
\text { VIEWING }\end{array}$ & DESCRIPTION & $\begin{array}{c}\text { OBSERVATIONAL } \\
\text { CODE } \\
\text { REFERENCE } \\
\end{array}$ \\
\hline $14^{c}$ & 3 on $1 y$ & $\begin{array}{l}\text { Unsafe: Lathe operator has no eye } \\
\text { protection, and has shirtail out. }\end{array}$ & PPE-3, PPE- 10 \\
\hline 15 & & $\begin{array}{l}\text { Safe: Operator now shown with safety } \\
\text { glasses with side shields and shirt } \\
\text { tucked inside his trousers. }\end{array}$ & \\
\hline $16^{b}$ & A11 & $\begin{array}{l}\text { Unsafe: Employee walking in aisle } \\
\text { which has tripping hazards: blocks, } \\
\text { pry bar, welding cable and welding } \\
\text { wans. }\end{array}$ & HK- 3 \\
\hline $17^{\mathrm{ac}}$ & & Safe: Aisle now clear, tools put away. & \\
\hline 18 & A11 & $\begin{array}{l}\text { Unsafe: Material piled by: } \\
\text { electrical substation. }\end{array}$ & HK-4 \\
\hline $19^{c}$ & & fire fighting equipnent & \\
\hline 20 & & crane ladders & \\
\hline $21^{b}$ & A11 & $\begin{array}{l}\text { Unsafe: Individual is bending over to } \\
\text { lift a piced of pipe with his bare } \\
\text { hands grasping the edge. }\end{array}$ & MH- 1, PPE-9 \\
\hline $22^{\mathrm{ac}}$ & & $\begin{array}{l}\text { Safe: Individual demonstrates proper } \\
\text { lifting technique and is wearing } \\
\text { gloves to grasp the sharp edges } \\
\text { of the piece. }\end{array}$ & \\
\hline 23 & 3 only & $\begin{array}{l}\text { Unsafe: Worker is sawing a board } \\
\text { without wearing eye protection. } \\
\text { He is lso cutting between two saw } \\
\text { horses with power circular saw. }\end{array}$ & MH- 3, PPE- 3 \\
\hline 24 & & $\begin{array}{l}\text { Safe: Worker is wearing glasses } \\
\text { with side shields and is cutting } \\
\text { the board across the saw horses. }\end{array}$ & \\
\hline 25 & 3 only & $\begin{array}{l}\text { Unsafe: Employee is not wearing } \\
\text { safety glasses while cutting a } \\
\text { board with circular saw. He is } \\
\text { also balancing the board on one } \\
\text { saw horse. }\end{array}$ & MH- 3, PPE- 3 \\
\hline $26^{c}$ & & $\begin{array}{l}\text { Safe: Enployee now shown wearing } \\
\text { glasses with side shields and has } \\
\text { the board being cut laid across two } \\
\text { saw horses. }\end{array}$ & \\
\hline
\end{tabular}




\begin{tabular}{|c|c|c|c|}
\hline $\begin{array}{l}\text { SLIDE } \\
\text { NO. }\end{array}$ & $\begin{array}{l}\text { GROUP (S) } \\
\text { VIEWING }\end{array}$ & DESCRIPTION & $\begin{array}{c}\text { OBSERVAT IONAL } \\
\text { CODE } \\
\text { REFERENCE } \\
\end{array}$ \\
\hline $27^{a}$ & $\begin{array}{l}1,2, \\
\text { only }\end{array}$ & $\begin{array}{l}\text { Unsafe: Welder is preparing to weld } \\
\text { too close to another employee. } \\
\text { Welder is not wearing a long } \\
\text { sleeve shirt, gloves, or cap } \\
\text { (other enployee is hamering } \\
\text { without eye protection). }\end{array}$ & $\begin{array}{l}\text { GS-3, PPE-5, } \\
\text { PPE-7, PPE-8, } \\
\text { (PPE-1, PPE-6) }\end{array}$ \\
\hline $28^{b}$ & & $\begin{array}{l}\text { Safe: Welder is preparing to weld } \\
\text { with no other workers within a } \\
5 \text { ft. radius. Welder is also } \\
\text { wearing all required personal } \\
\text { protective equipment. }\end{array}$ & \\
\hline 29 & $\begin{array}{l}1,2 \\
\text { only }\end{array}$ & $\begin{array}{l}\text { Unsafe: Shows employee lighting an } \\
\text { acetylene torch with a butane } \\
\text { lighter. }\end{array}$ & TE- 1 \\
\hline 30 & & $\begin{array}{l}\text { Safe: Striker is shown being used } \\
\text { to light torch. }\end{array}$ & \\
\hline $31^{b}$ & All & $\begin{array}{l}\text { Unsafe: Grinder and welder working } \\
\text { within } 5 \mathrm{ft} \text {. of each other: } \\
\text { Grinder: Improper eye } \\
\text { protection, allowing sparks } \\
\text { to hit welder, has scaling gun } \\
\text { still attached, lying at his } \\
\text { feet. }\end{array}$ & $\begin{array}{c}\text { GS-3, PPE-3, } \\
H K-2\end{array}$ \\
\hline & & $\begin{array}{l}\text { Welder: Proper personal } \\
\text { protective equipment but } \\
\text { welding too close to other } \\
\text { without a shield botween them. }\end{array}$ & GS-3, HK-2 \\
\hline $32^{a}$ & & $\begin{array}{l}\text { Safe: Grinder only: wearing face } \\
\text { sheild, sparks directed down, } \\
\text { scaling gun disconnected and removed. }\end{array}$ & $\begin{array}{l}\text { GS-3, PPE-3, } \\
\text { HK-2 }\end{array}$ \\
\hline $33^{\mathrm{B}}$ & A11 & $\begin{array}{l}\text { Unsafe: Worker is using grinder with } \\
\text { one hand, holding the piece of metal } \\
\text { with the other hand. Wearing } \\
\text { glasses only, and has his shirttail } \\
\text { out. }\end{array}$ & $\begin{array}{l}\text { PPE- 3, PPE-10, } \\
\text { MH-2, TE-2 }\end{array}$ \\
\hline $34^{c}$ & & $\begin{array}{l}\text { Safe: Grinder now has piece clamped } \\
\text { to work bench, is wearing a face } \\
\text { shield, and has his shirt tucked in. }\end{array}$ & \\
\hline
\end{tabular}




\begin{tabular}{|c|c|c|c|}
\hline $\begin{array}{c}\text { SLIDE } \\
\text { NO. }\end{array}$ & $\begin{array}{l}\text { GROUP (S) } \\
\text { VIEW ING } \\
\end{array}$ & DESCRIPTION & $\begin{array}{l}\text { OBSERVATIONAL } \\
\text { CODE } \\
\text { REFERENCE } \\
\end{array}$ \\
\hline $35^{b}$ & A11 & $\begin{array}{l}\text { Unsafe: Elployee passing a piece of } \\
\text { material held by a lift-magnet on a } \\
\text { crane, over another employee. He } \\
\text { is also pulling the material } \\
\text { towards himself. An oil spill is } \\
\text { on the floor within } 3 \text { ft. of the } \\
\text { crane operator. }\end{array}$ & $\begin{array}{l}\text { GS-2, GS-6, } \\
\text { HK-1 }\end{array}$ \\
\hline${ }_{36} \mathrm{c}$ & & $\begin{array}{l}\text { Safe: Load is shown being moved at } \\
\text { a lower height, not over anyone; } \\
\text { and the operator is pushing the } \\
\text { part away from his body. The liquid } \\
\text { spill has floor-dri on it. }\end{array}$ & \\
\hline 37 & A11 & $\begin{array}{l}\text { Unsafe: Shows a worker operating a } \\
\text { crane to transport a large load. } \\
\text { Employee is standing on the load } \\
\text { to help balance it. }\end{array}$ & TE- 3 \\
\hline $38^{b}$ & & $\begin{array}{l}\text { Safe: Load is properly balanced. The } \\
\text { crane operator is now standing } \\
\text { beside the load. }\end{array}$ & \\
\hline 39 & A1 1 & $\begin{array}{l}\text { Unsafe: Shows a plate clamp holding } \\
\text { two pieces of sheet netal. The crane } \\
\text { is pulling on the plates at a } 45^{\circ} \\
\text { angle. }\end{array}$ & TE- 4 \\
\hline 40 & & $\begin{array}{l}\text { Safe: Shows plate clamp holding only } \\
\text { one shoet of metal in the middle, } \\
\text { and pulling (lifting) straight up. }\end{array}$ & \\
\hline $41^{a}$ & A11 & $\begin{array}{l}\text { Unsafe: Depicts a worker standing on } \\
\text { the raised forks of a fork lift to } \\
\text { attach a hook on a part. }\end{array}$ & TE- 5 \\
\hline $42^{b}$ & & $\begin{array}{l}\text { Safe: Employee shown standing on a } \\
\text { step ladder to attach the hook. }\end{array}$ & \\
\hline $43^{c}$ & A11 & $\begin{array}{l}\text { Unsafe: Employee is standing on a } \\
\text { bucket and stretching out to } \\
\text { reach a part. }\end{array}$ & TE- 5 \\
\hline $44^{a}$ & & $\begin{array}{l}\text { Safe: Same employee is now shown } \\
\text { standing on a proper work plat form } \\
\text { allowing him to easily reach the } \\
\text { area he needs to work in. }\end{array}$ & \\
\hline
\end{tabular}




\begin{tabular}{|c|c|c|c|}
\hline $\begin{array}{l}\text { SLIDE } \\
\text { NO. }\end{array}$ & $\begin{array}{l}\text { GROUP (S) } \\
\text { VIEW ING }\end{array}$ & DESCRIPTION & $\begin{array}{l}\text { OBSERVATIONAL } \\
\text { CODE } \\
\text { REFERENCE }\end{array}$ \\
\hline 45 & 2 on $1 y$ & $\begin{array}{l}\text { Unsafe: Worker not wearing glasses, } \\
\text { is shown placing his fingers in a } \\
\text { punch press (piranha) to adjust } \\
\text { the position of the material. }\end{array}$ & TE-9, PPE- 1 \\
\hline 46 & & $\begin{array}{l}\text { Safe: Worker, now wearing safety } \\
\text { glasses, is shown using a tool to } \\
\text { align the material to be punched. }\end{array}$ & \\
\hline
\end{tabular}


APPENDIX H

Safety Goal Sign*

-Reduced to 658 of actual size. 


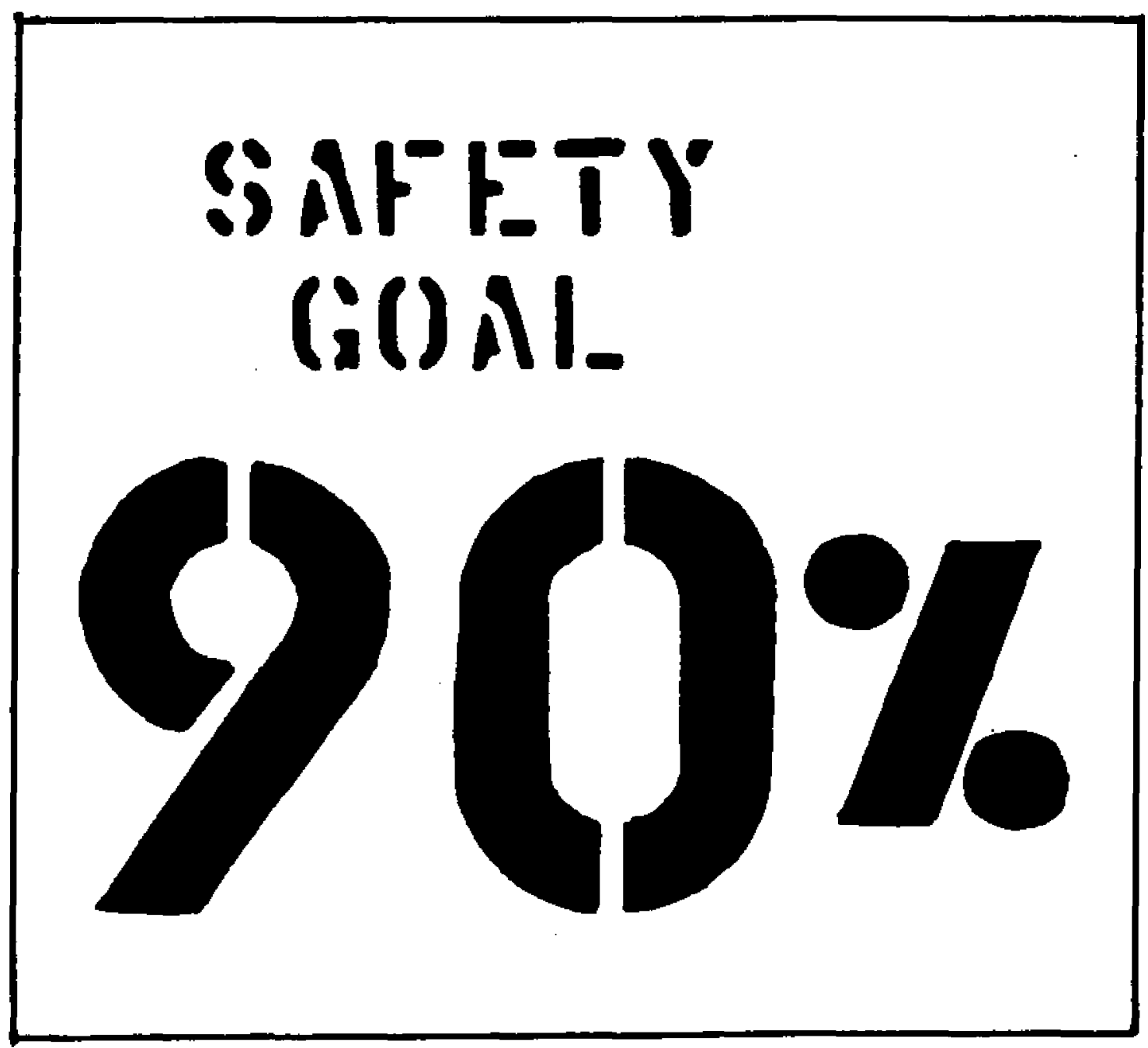


APPENDIX I

Safety Goal Reminder*

*Reduced to 748 of actual size. 


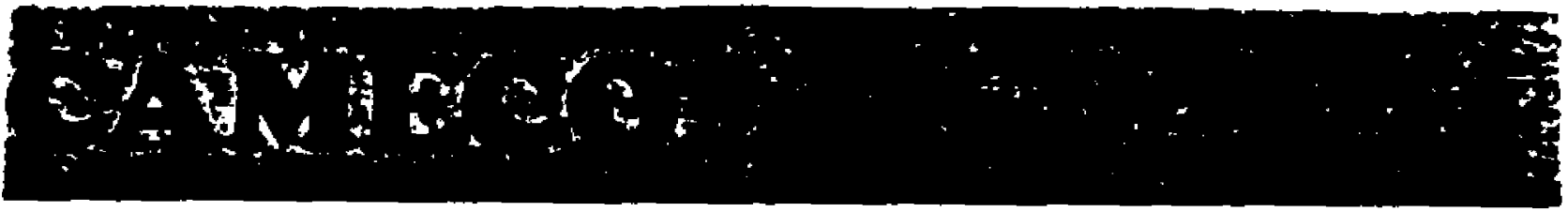

To: (depertent)

Froet infety boprorieor

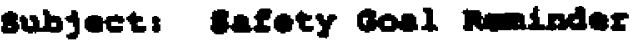

artert cons $=\operatorname{set}$

In an exfort to improw the anfety porformance bere at craces, the eployeen it your departent

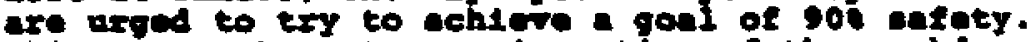
This wan thet et any given time of the workday, et leset oo of all the oployeen in your depert-

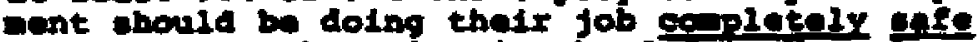
cocording to the roles in the sarety imul. Eefet ebocke will be nde perjodieeliy and

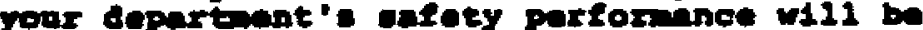
reoseded on a weelely bente. the depertant o provious pertorence indicater thet the 90 eafety gonl w11 bo aifficult to redch, bot if reryone does hig or hor part,

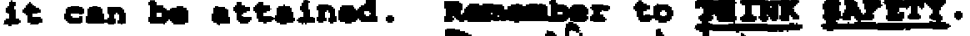
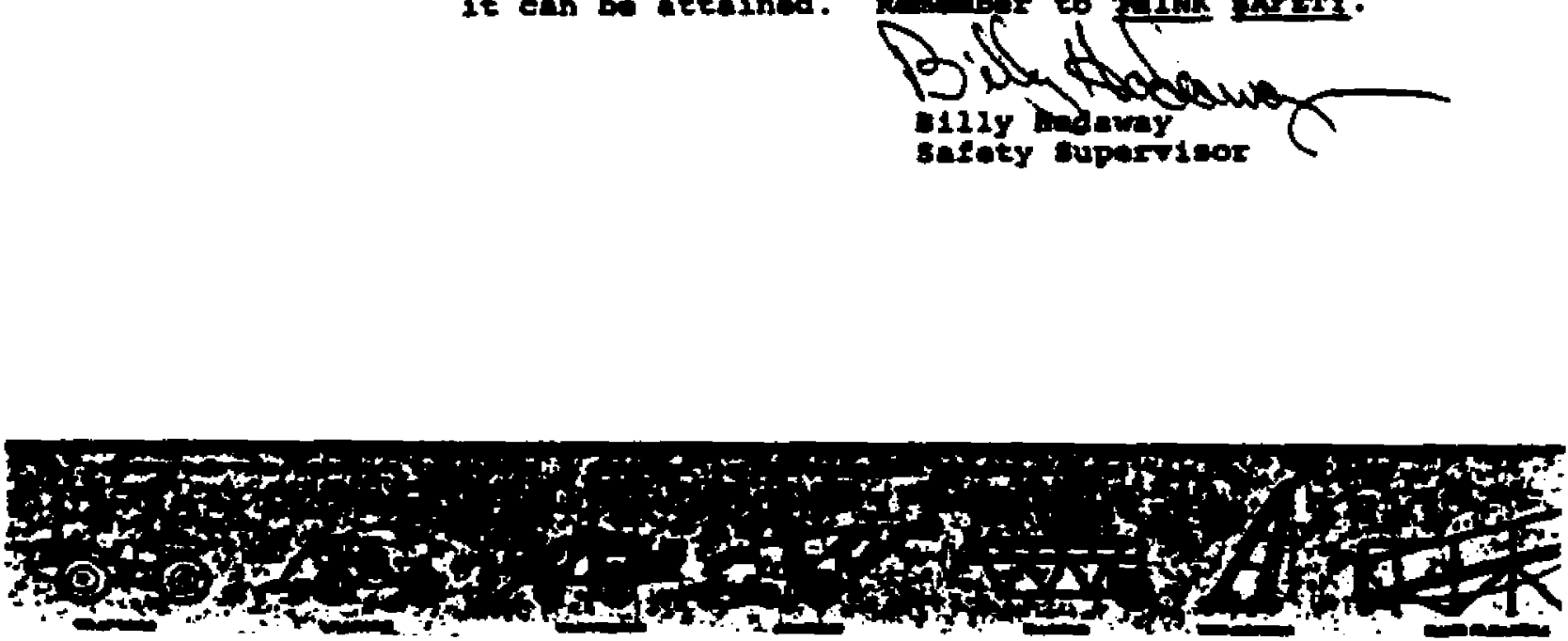


\section{APPENDIX $J$ \\ Questionnai re for Manipulation Checks*}

*Note: The following notation by the questionnaire item indicates which factor it was used to measure:
a - Goa1 Acceptance/Comitment
b - Goal Clarity
c - Goal Difficulty
d - Positive Supervisory Feedback
e - Negative Supervisory Feedback
f - Corrective Supervisory Feedback
8 - Current Level of Safety 
Yod hr work

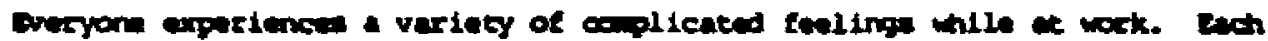

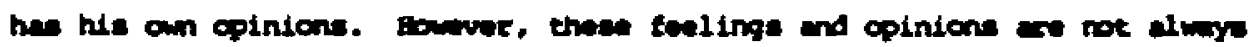

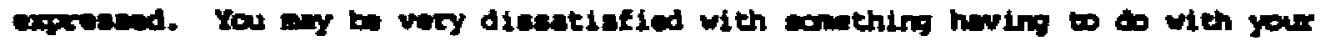

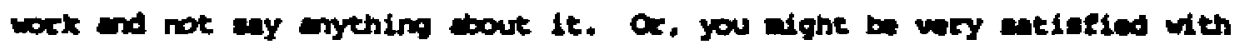

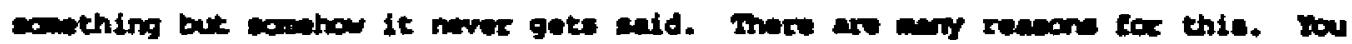

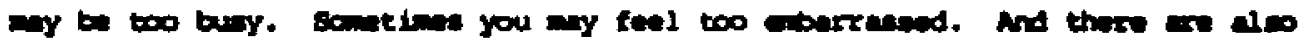

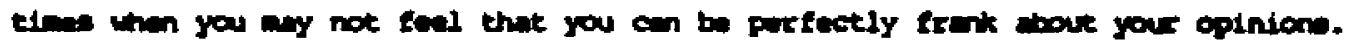

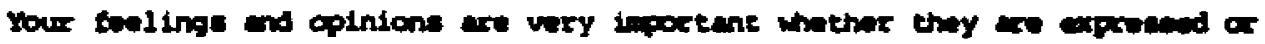

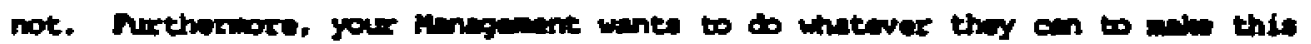
Copany a better place to work. This is a difficult telk eipecially van Dangoment is not coctain bout wat is eatisfying and hat is diseatinfying.

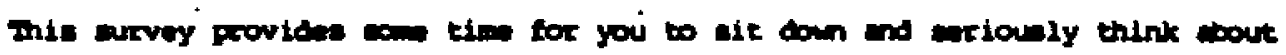
your opinion. It als provides en opportunity w exprese your foelinge, god or bed, whout tor of ebotrevent.

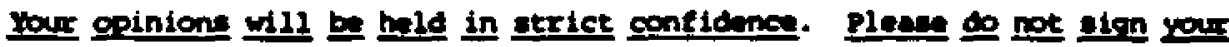
n.w.

Aeter you hwe ofpleted the booklet, plenes drop it in the enied bon a

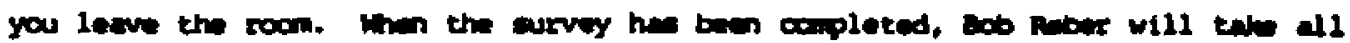

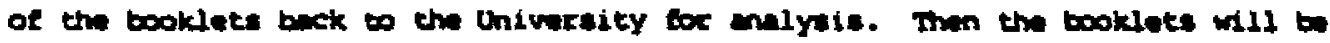
destroyd. Ler, a mpote of the rovulte will be given to you and angmant, but your booklet wil nover bo show to enyone corrieted with the ompany. 


\section{Desmuctias}

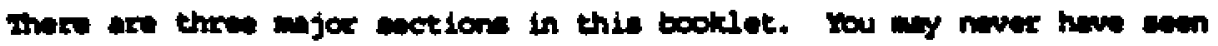
anthing quite like it betor, ov wil give coplete invtruction for ach enction. Plenw do not hasitete to ask quetion at eny tim.

To bain with, whold like for you to 1111 out the blank apese belor.

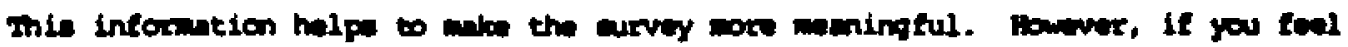

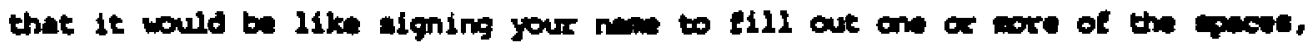
plears lewe the blerk.

1. Aprevisoc's Nuse

2. Depertant or Work Area

3. Job $x \in t$ 을

4. Lenth of Eervice

3.

6.

7. 


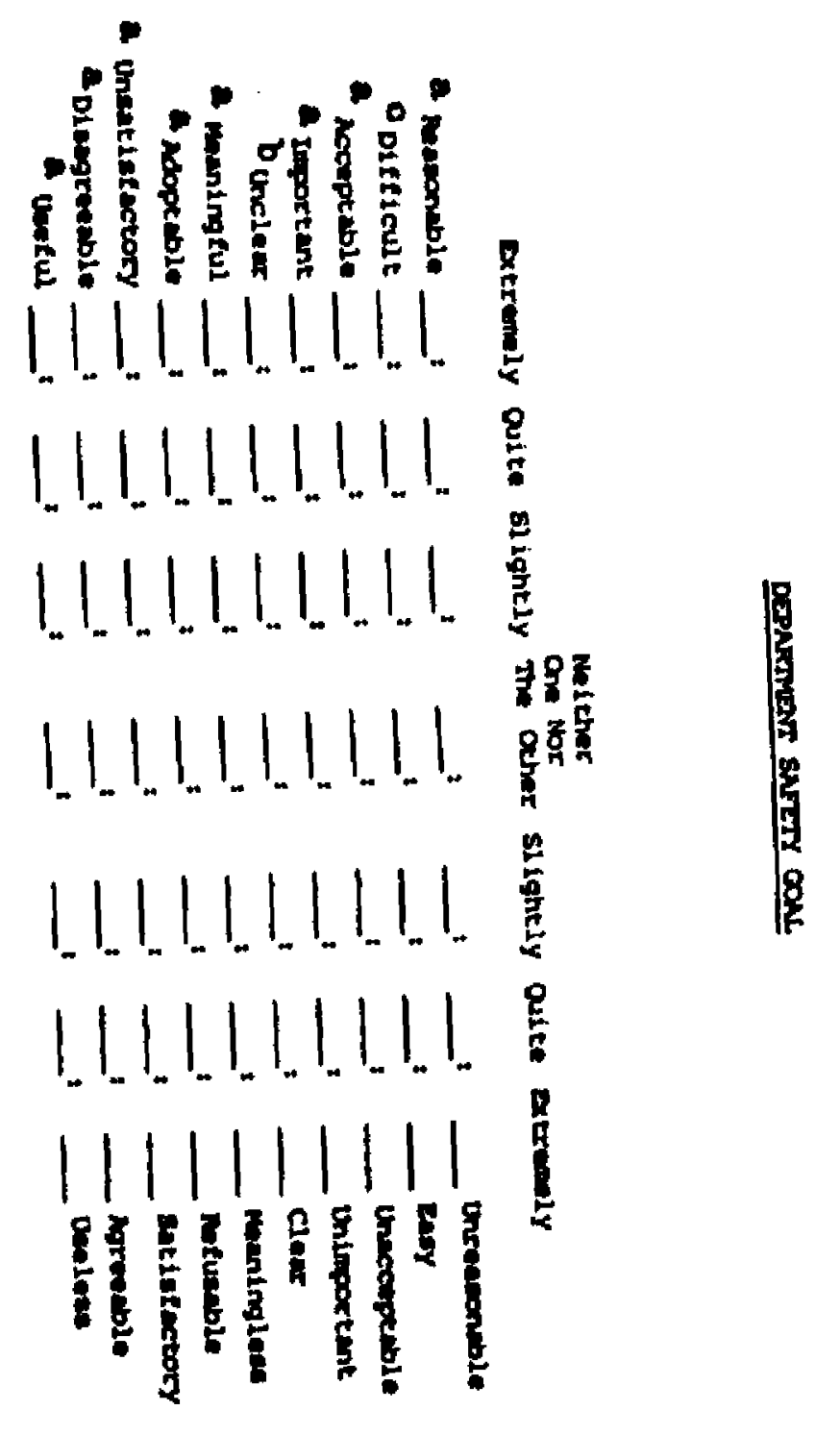




\section{SECTION Tho}

Please reter to the following seale for making your anmes in this coction:

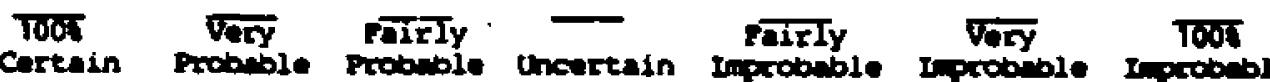

In your opinion, whet is the probability that...

91. Your department will schieve ite enfety goll.

1008

cortein

1004

topcobable

22. Everyone in your depertint is trying to achieve the enfety goel.

1009

certein

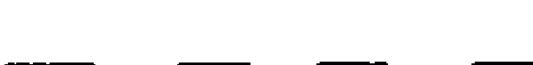

1008

Trobeble

23. You are comitted to achioving the eatety goal.

100

Cortain

1004

ropobale

24. Your apervieor would pereonelly compliment you if you did your fob ately. 100 s

100

Certain

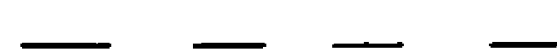

In wobable

25. Your cupervicor would reptimand you if you consistently worked in in uneafo menrex.

1004

1001

Certain

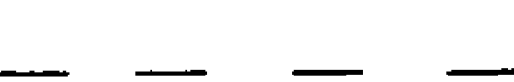

Inpeobuble

626. You will get injured on the job if you continue to work an we wh you do now.

1008

1000

Certain

trecobable

27. Your apmevisor will correct you if you are doing your job unentely. 1001

1005

certain

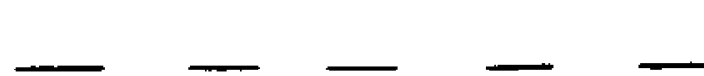

Impobable

2. What of the people in your departunt don't care bout the wafety goel.

1002

Cartain

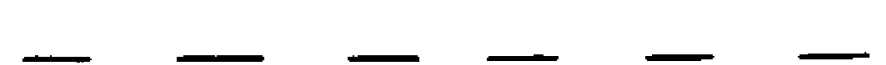

Inpoouble 
In your opinion, whet is the proobility that...

29. Your departunt he reached its safoty goal.

$100 \mathrm{e}$

Cortain
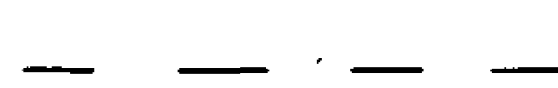

1004

tomobie

6 30. You and your co-workers work en mafe a pasible at all thmes.

Cortain

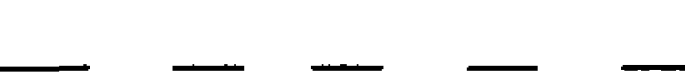

1004

Intobable 
secrias Thines

You heve expessed your toelings bout a nuber of thangs - your job, pry,

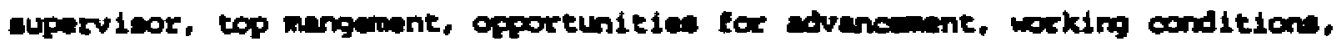
coupeny bonefits, and tellow wokers. Howner, w my hov left out ecmething very inportant to you. Inis section if included for that prpoes. If you would 11ke to chinent bout comthing you would like to th changed, pleses do to. 


\section{APPENDI $X K$}

\section{Feedback Sign*}

\#Reduced to 74t of actual size. 


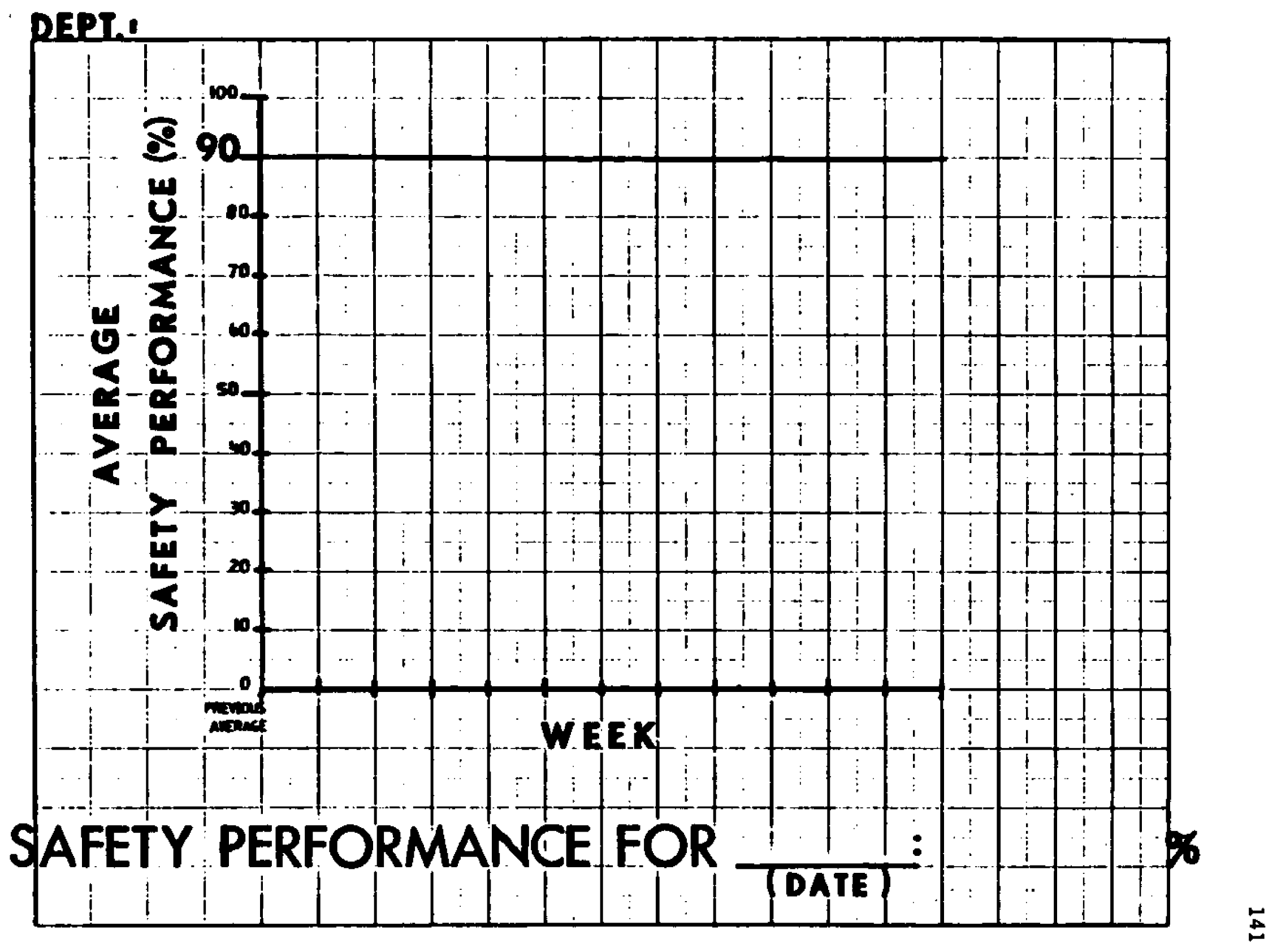


APPENDIX L

Results of Departmental Data Analysis 
RESULTS OF DEPARTMENTAL DATA ANALYSIS

Manipulation Checks:

The mean responses for the variables neasured by the questionnaire completed prior to introducing KR are shown in Table 3.

Insert Table 3 about here

In general, each department perceived the goal to be clear and slightly difficult. Goal acceptance appeared to be high for each department. Further, positive supervisory feedback (i.e., praise) was given infrequent1y. On the other hand, employees indicated that it was quite possible that they would receive negative feedback (reprimand) and/or corrective feedback from their supervisor if thoy were working unsafely. The results also indicated that the employees of each department perceived themselves as generally working safety. Interestingly, the behavioral safety performance was estimated to be less than the 90 goal by all but one of the departments (Welding).

Table 4 depicts the mean response for each department concerning the goals attempted after receiving KR. All but one of the departments indicated a safety goal higher than the assigned goal.

Insert Table 4 about here

Observational Data Analysis:

ARIMA Aralysis--An ARIMA analysis was performed on the timeseries data for each period of the study on a departmental basis. As with the group data, visual inspection of the behavioral performance 
for each department (displayed graphically in Figure 2a-k) indicated marked intervention effects. Therefore, the results of the ARIMA analysis for each period were used to determine the best adel for the time-series for each department.

Insert fiture 2a-k about here

Inspection of the autocorrelations revealed that none of the departmental observational data required differencing, $1 . e .$, corrections for trond or drift. Again, the autocorrelation function and the partial autocorrelation function for each period did not indicate the presence of an autoregressive or moving average component. Therefore, an ARIMA $(0,0,0)$ model was diagnosed. The Q-statistic performed on the residuals of the autocorrelations supported the white noise model for every department and for every period with three isolated exceptions. The time-series analysis for the baseline period for Raw Material Prep, and the Goal Setting period for both the Hydraulics and Machine Shop departments resulted in a significant Q-statistic. However, closer evaluation of the respective autocorrelations and partial autocorrelations failed to identify an ARIMA model other than a stochastic one. The significant residuals checks were assumed to be due to several random (i.e., nonseasonal) lag spikes which appeared in the plot of the autocorrelations for the periods and departments in question.

Repeated Measures ANOVA--Given the aforenentioned implications and the fact that a white noise model was identified for the majority of the departmental time-series, it was decided to analyze the data as 
a repeated measures design with blocking on departments. Table 5 summarizes the data used for this analysis.

Insert Table 5 about here

In concert with the group data analysis, the repeated measures ANOVA for the departmental data resulted in a strong main effect for the study phase or period ( $F=151.50, \mathrm{df}=3, \mathrm{p}<.0001$ ). The Duncan's multiple range test was then performed on the period means. As hypothesized, the mean performance during the KR phase $(X=95.40)$ was significantly greater than the mean performance during the Goal Setting phase $(\bar{X}=77.27)$. Further, performance after Goal setting was significantly better than performance after Training $(\bar{X}=71.09)$; which in turn was better than baseline performance $(\bar{X}=61.57)$. These differences appear for each department as seen in Table 5 and Figures 2a-k.

It may be worth noting that ten of the elevon departments' average performance during the KR phase was above the assigned goal; whereas only two of the departments achieved goal level performance during the Goal Setting period. 
Table 3

Wean Departmental Response for Each Questionnaire Factor

\begin{tabular}{|c|c|c|c|c|c|c|c|c|c|}
\hline \multirow[b]{2}{*}{ Department } & \multirow[b]{2}{*}{$\underline{\mathbf{n}}$} & \multicolumn{7}{|c|}{ Factor $\mathbf{r}^{\mathbf{a}}$} & \multirow[b]{2}{*}{$\begin{array}{c}\text { Estimated } \\
\text { Performance } \\
(\xi)\end{array}$} \\
\hline & & $\begin{array}{c}\text { Goal } \\
\text { Acceptance }\end{array}$ & $\begin{array}{c}\text { Goal } \\
\text { Clarity }\end{array}$ & $\begin{array}{c}\text { Goal } \\
\text { Difficulty }\end{array}$ & $\begin{array}{l}\text { Positive } \\
\text { Feedback }\end{array}$ & $\begin{array}{l}\text { Negative } \\
\text { Feedback }\end{array}$ & $\begin{array}{l}\text { Corrective } \\
\text { Feedback }\end{array}$ & $\begin{array}{l}\text { Current } \\
\text { Safety }\end{array}$ & \\
\hline Final Assembly & 21 & 5.41 & 5.57 & 4.51 & 2.81 & 5.05 & 4.38 & 4.67 & 75.48 \\
\hline Hydraulies & 5 & 6.16 & 6.40 & 5.00 & 3.20 & 5.20 & 4.20 & 5.60 & 77.00 \\
\hline Mechanics & 5 & 6.32 & 6.80 & 5.47 & 3.40 & 6.80 & 5.40 & 4.90 & 87.60 \\
\hline Paint/Sandblast & 4 & 6.05 & 6.25 & 5.00 & 3.25 & 6.25 & 5.00 & 5.63 & 73.75 \\
\hline Heavy Equipment & 9 & 5.92 & 5.67 & 4.59 & 4.00 & 6.00 & 5.33 & 4.72 & 77.22 \\
\hline Raw Material Prep & 14 & 5.88 & 5.93 & 4.40 & 3.14 & 5.71 & 5.00 & 5.54 & 81.71 \\
\hline Sub-Asse-bly & 6 & 5.97 & 5.50 & 4.44 & 4.00 & 6.00 & 5.33 & 5.83 & 86.67 \\
\hline Welding & 3 & 6.33 & 5.67 & 5.33 & 3.67 & 7.00 & 3.67 & 6.33 & 93.67 \\
\hline Crating & $\mathbf{5}$ & 5.76 & 5.40 & 4.53 & 3.60 & 4.60 & 4.80 & 4.90 & 75.00 \\
\hline Machine Shop & 5 & 5.47 & 5.80 & 4.00 & 3.60 & 4.80 & 4.40 & 4.60 & 76.00 \\
\hline Parts & 9 & 5.69 & 6.11 & 3.89 & 2.67 & 4.78 & 4.33 & $\$ .17$ & 79.67 \\
\hline Overal1 & 86 & 5.78 & 5.82 & 4.54 & 3.28 & 5.49 & 4.76 & 5.12 & 79.43 \\
\hline
\end{tabular}


Table 4

Mean Goal for Each Department After

Receiving Feedback (KR)

\begin{tabular}{|c|c|c|}
\hline Department & $\underline{\mathbf{n}}$ & Goal (t) \\
\hline \multicolumn{3}{|l|}{ Group 1} \\
\hline Final Assembly & 16 & 92.63 \\
\hline Hydraulics & $\mathbf{5}$ & 99.00 \\
\hline Mechanics & 4 & 92.50 \\
\hline Painting/Sandblasting & 4 & 95.00 \\
\hline \multicolumn{3}{|l|}{ Group 2} \\
\hline Heavy Equipment & $\mathbf{8}$ & 98.75 \\
\hline Raw Material Prep & 12 & 96.83 \\
\hline Sub-Assembly & 6 & 89.17 \\
\hline Welding & 3 & 100.00 \\
\hline \multicolumn{3}{|l|}{ Group 3} \\
\hline Crating & 6 & 96.67 \\
\hline Machine Shop & $\mathbf{5}$ & 95.00 \\
\hline Parts & 8 & 98.75 \\
\hline Overall & 77 & 95.68 \\
\hline
\end{tabular}


Table 5

Mean Departmental Safety Performance for Each Period

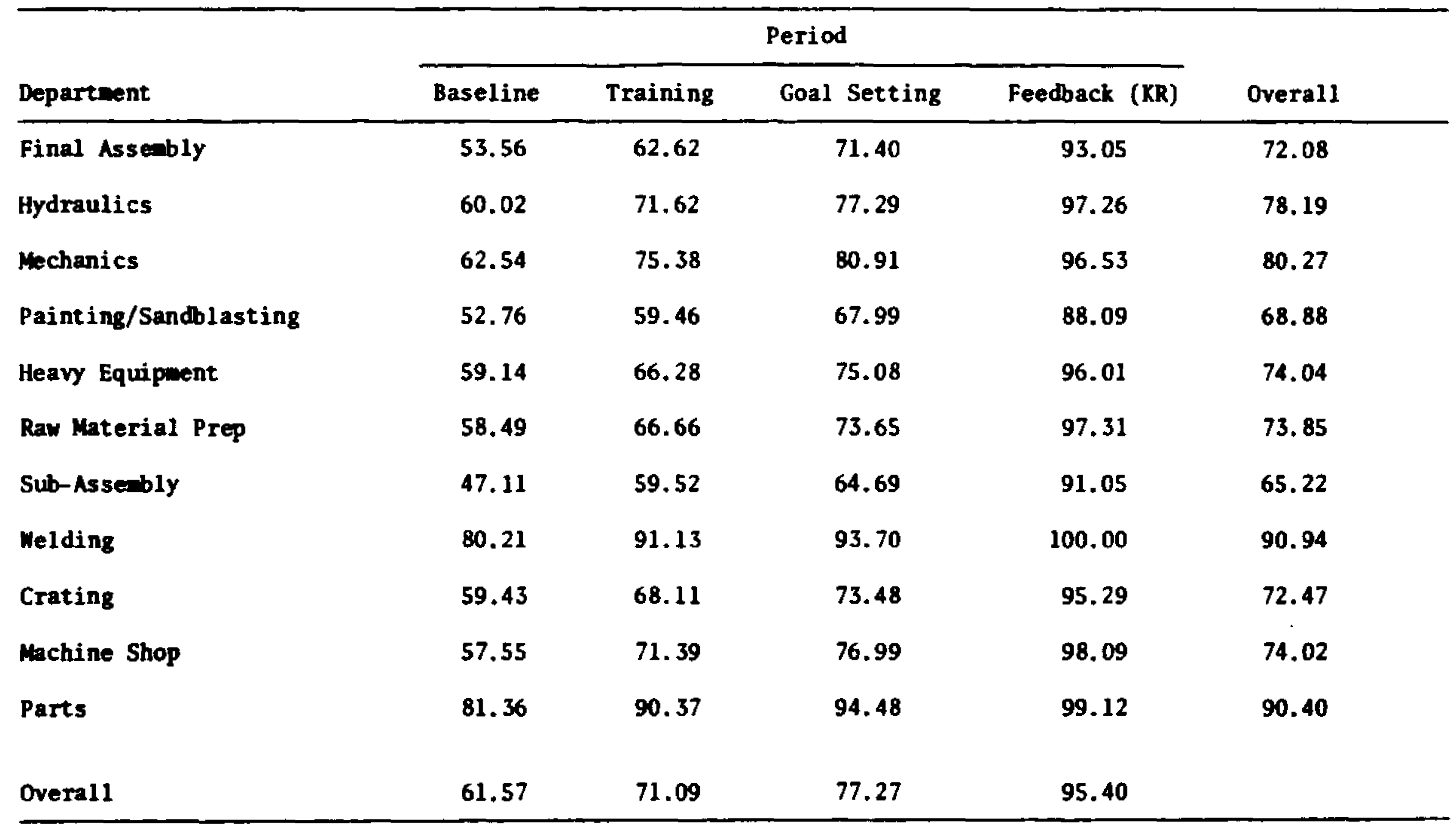

Note. Safety performance refers to the percentage of elployees working in a coupletely safe anner. 


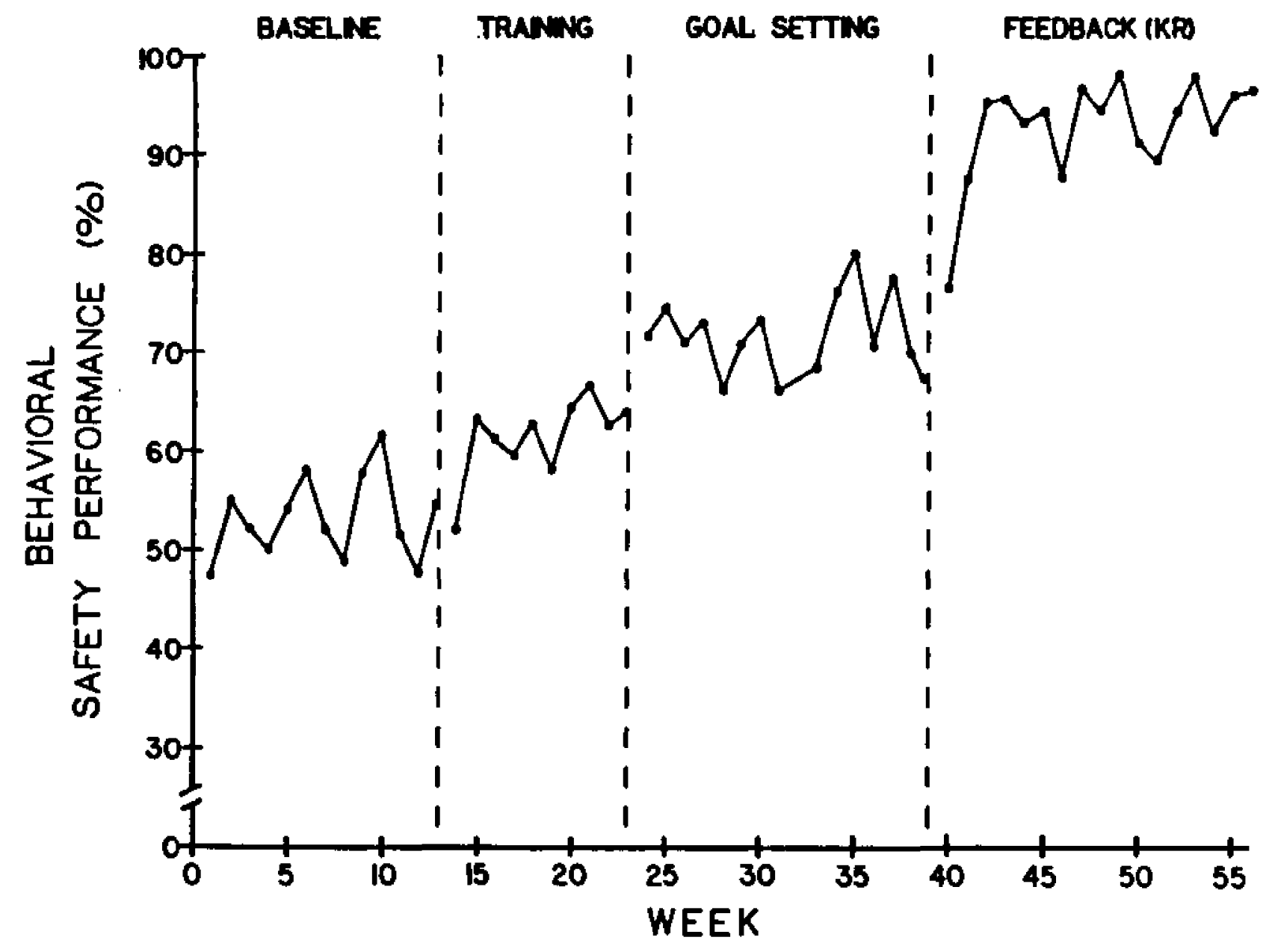

DEPT: FINAL ASSEMBLY

Figure 2a. Average weekly safety performance for final asse-bly. 


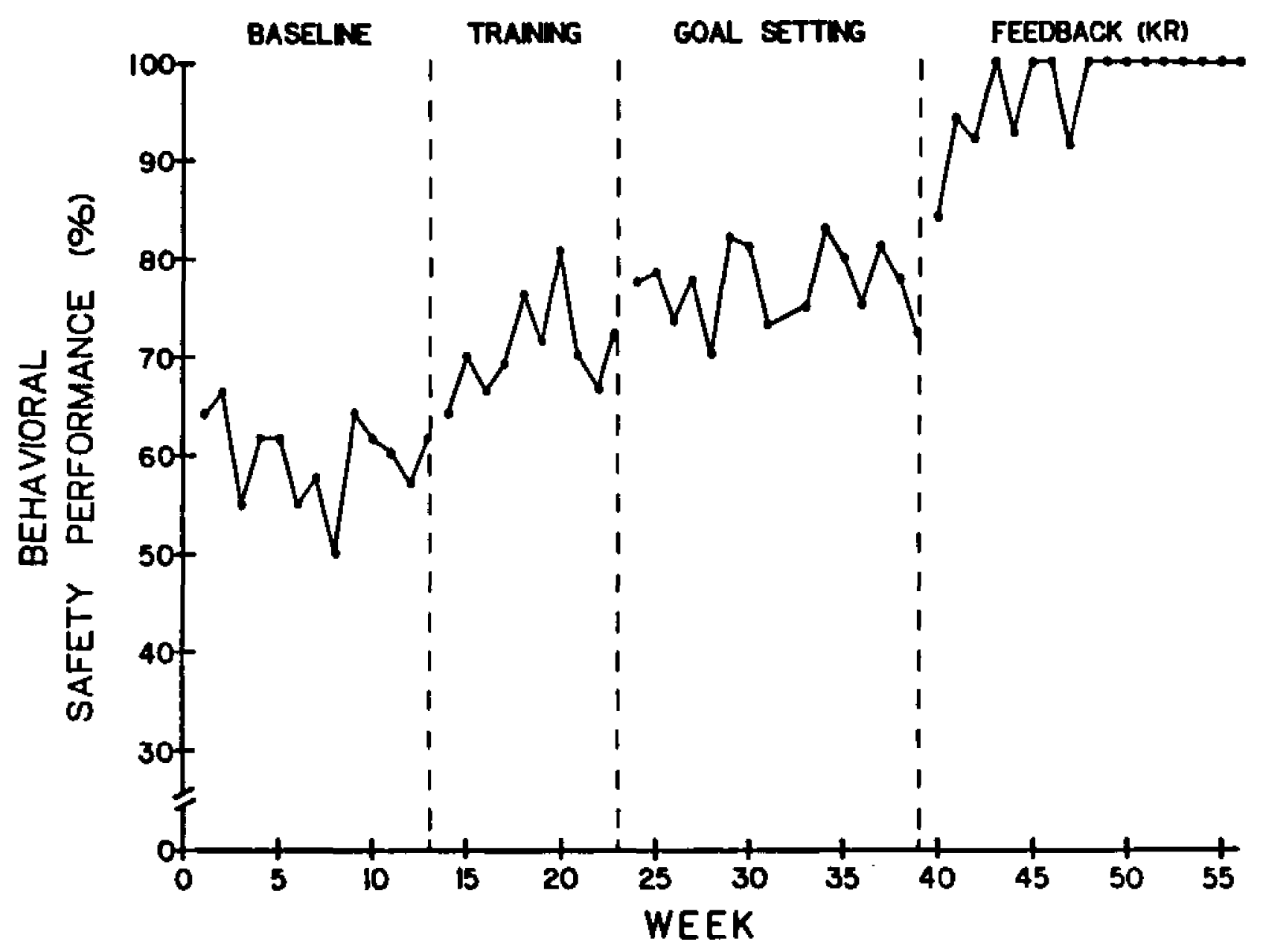

DEPT:: HYDRAULICS

Figure 2b. Average weekly safety performance for hydraulics. 


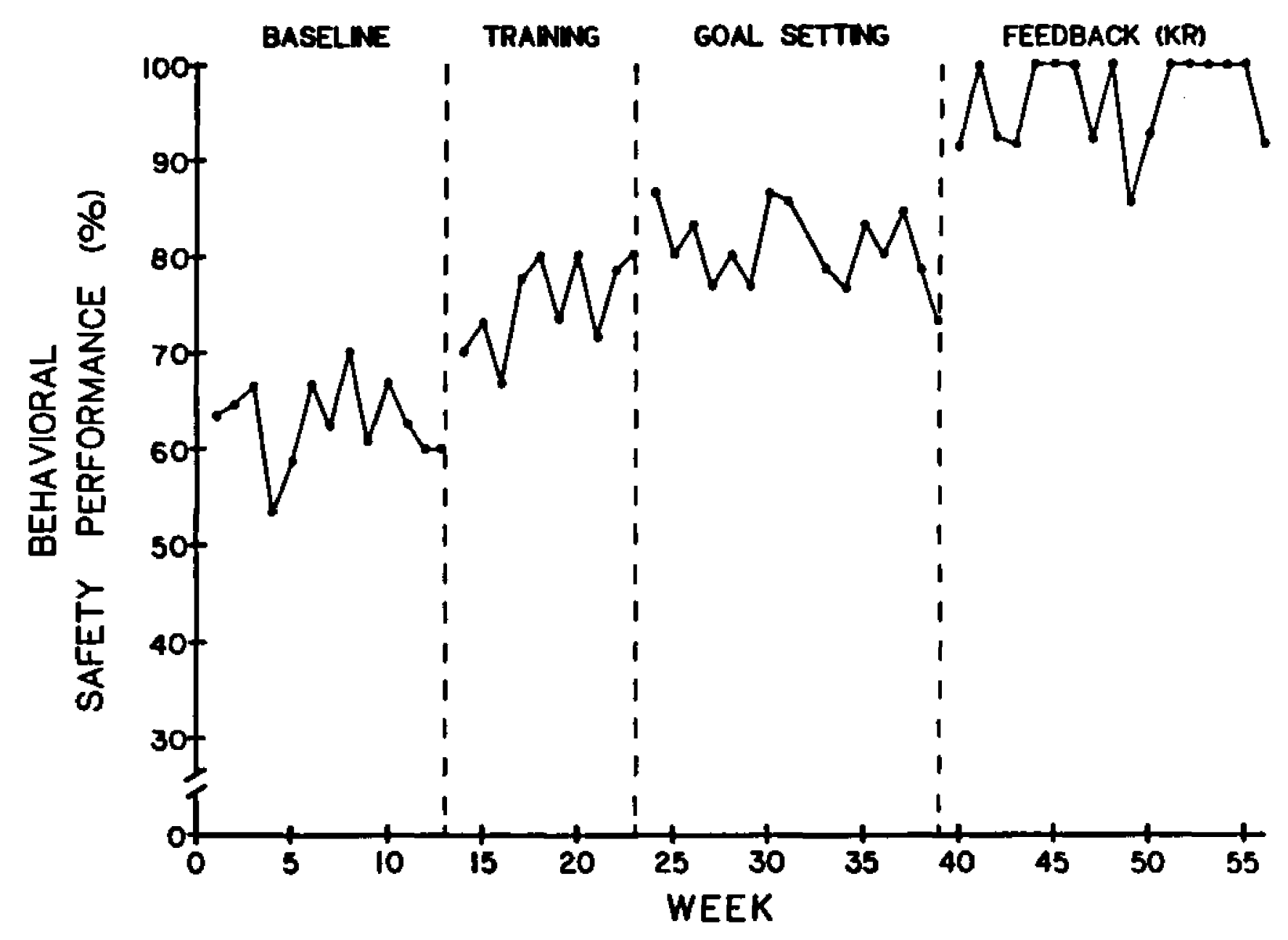

DEPT.: MECHANICS

Figure 2c. Average weekly safety performance for wechanics. 


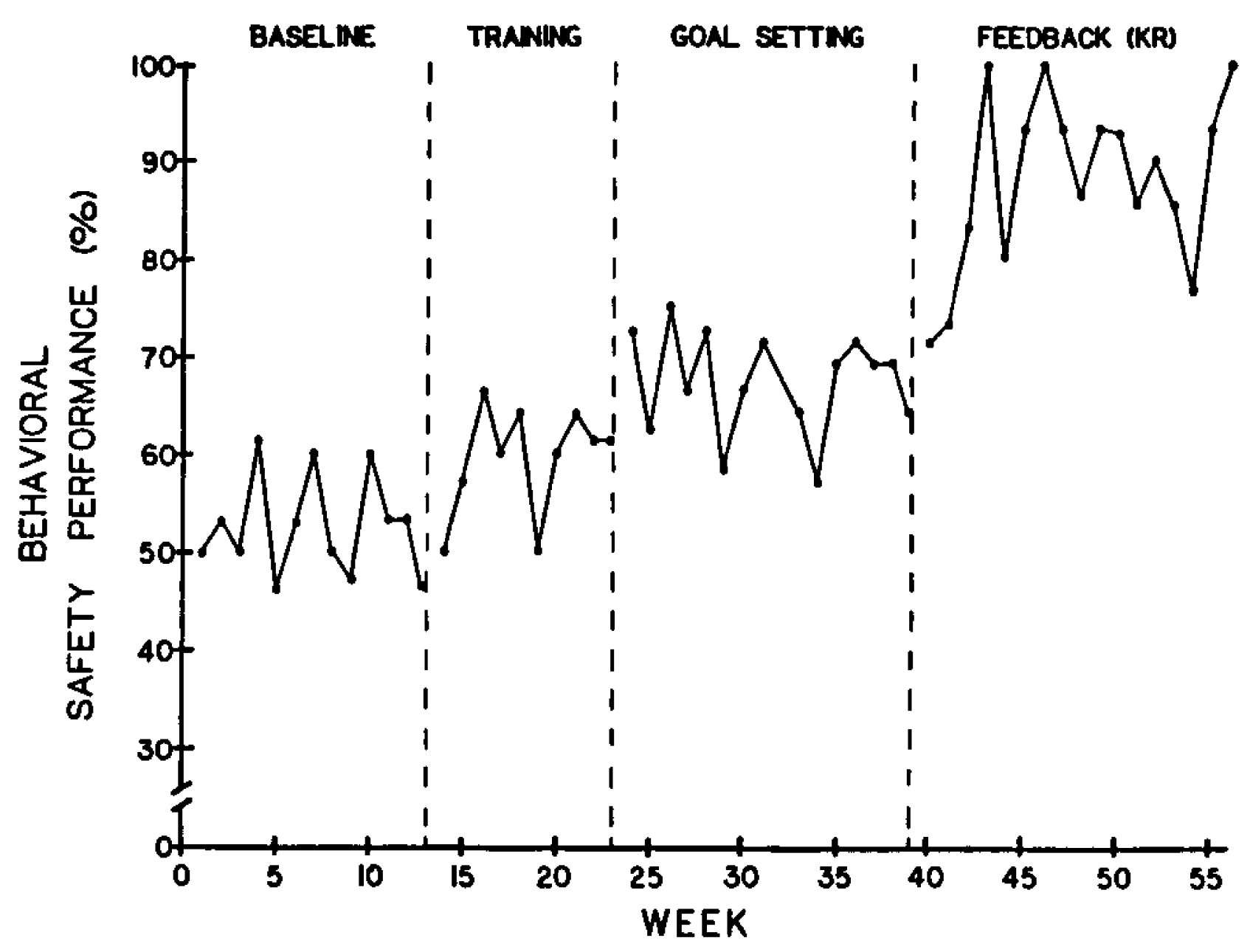

DEPT: PAINTING/SANDBLASTING

Figure 2d. Average weekly safety performance for painting/sandblasting. 


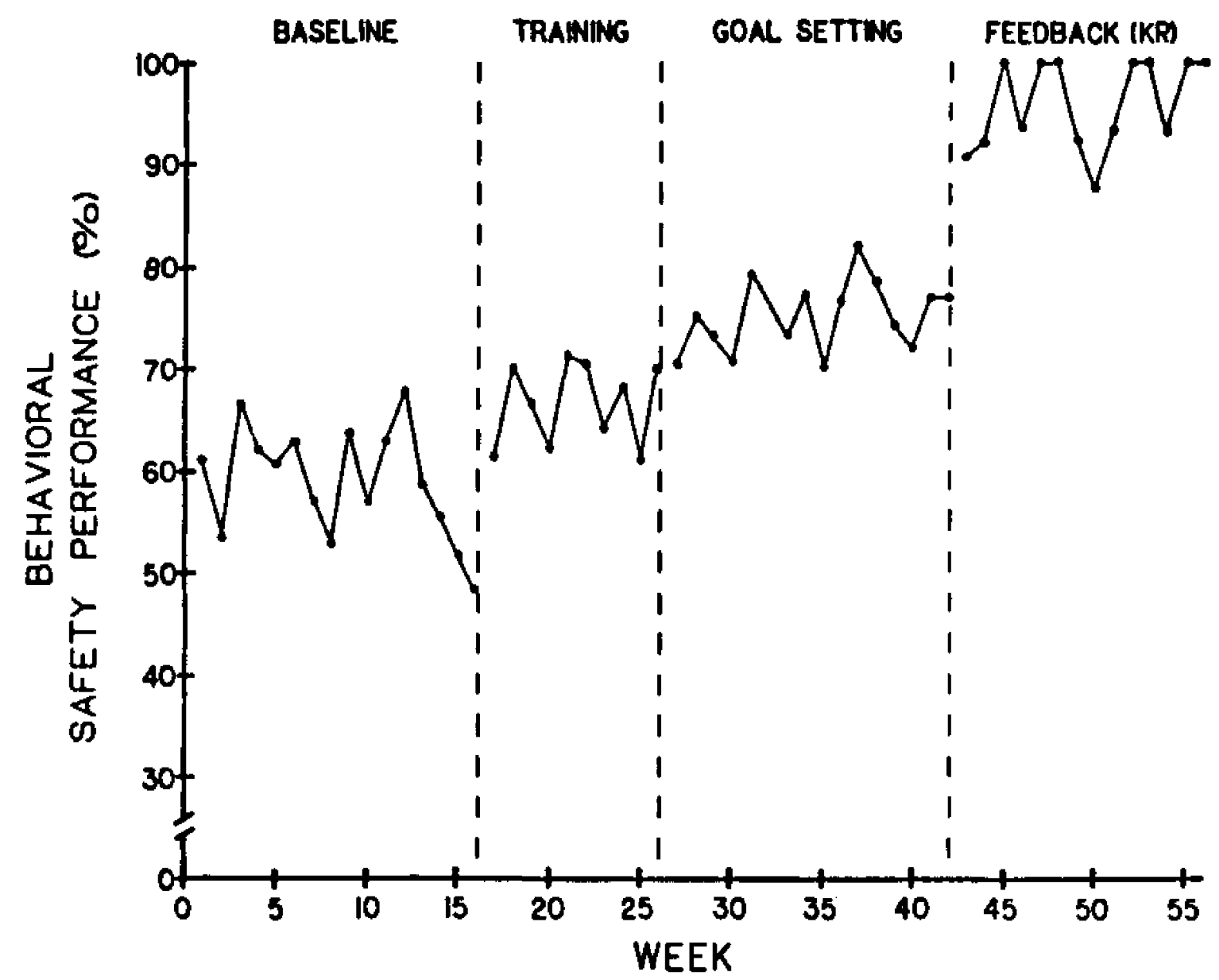

DEPT.: HEAVY EQUIPMENT

Figure 2e. Average weekly safety performance for heavy equipment. 
<smiles>C#C[Al]1CCCCC1</smiles> 


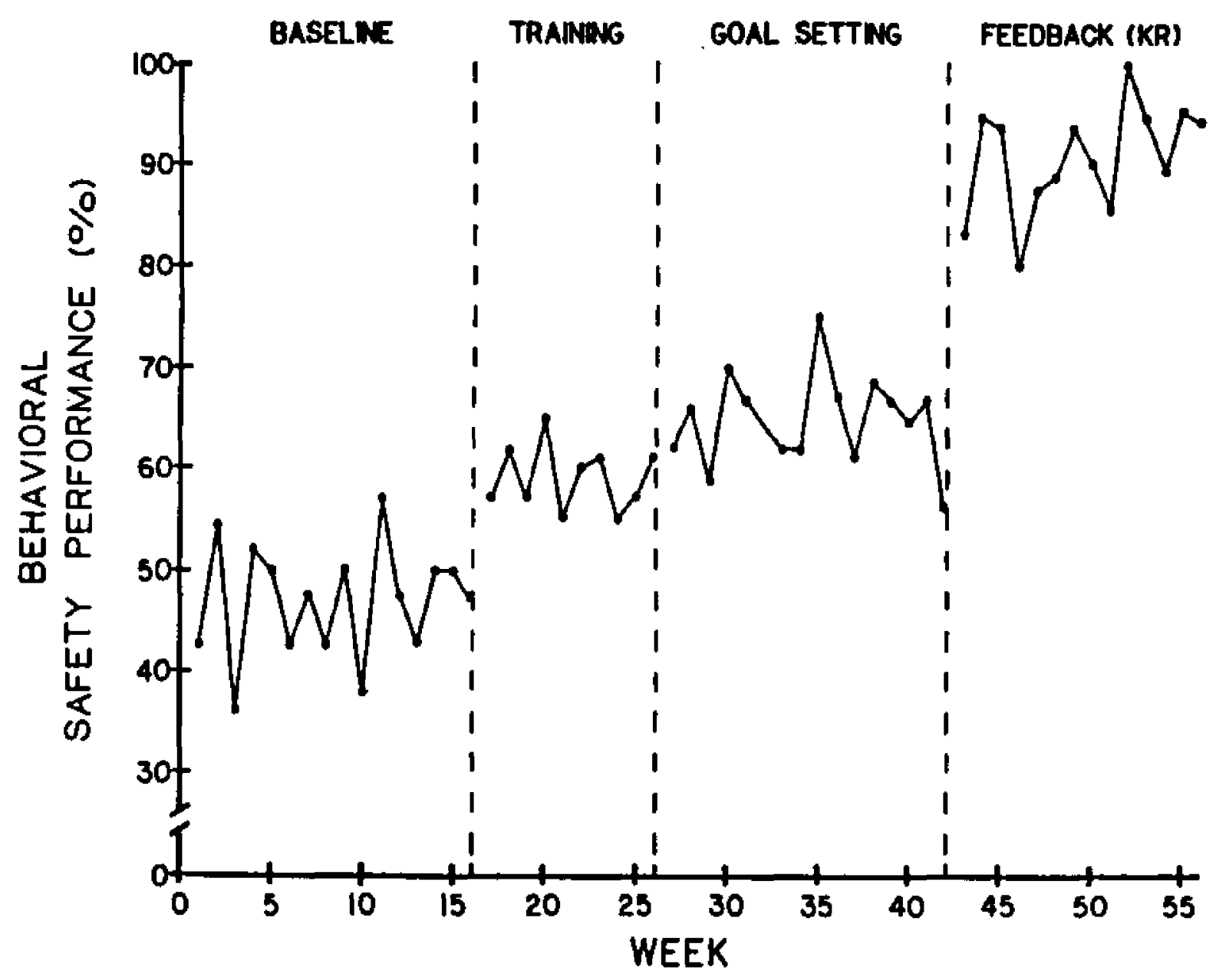

DEPT: SUB-ASSEMBLY

Figure 2g. Average weekly safety perfornance for sub-assembly. 


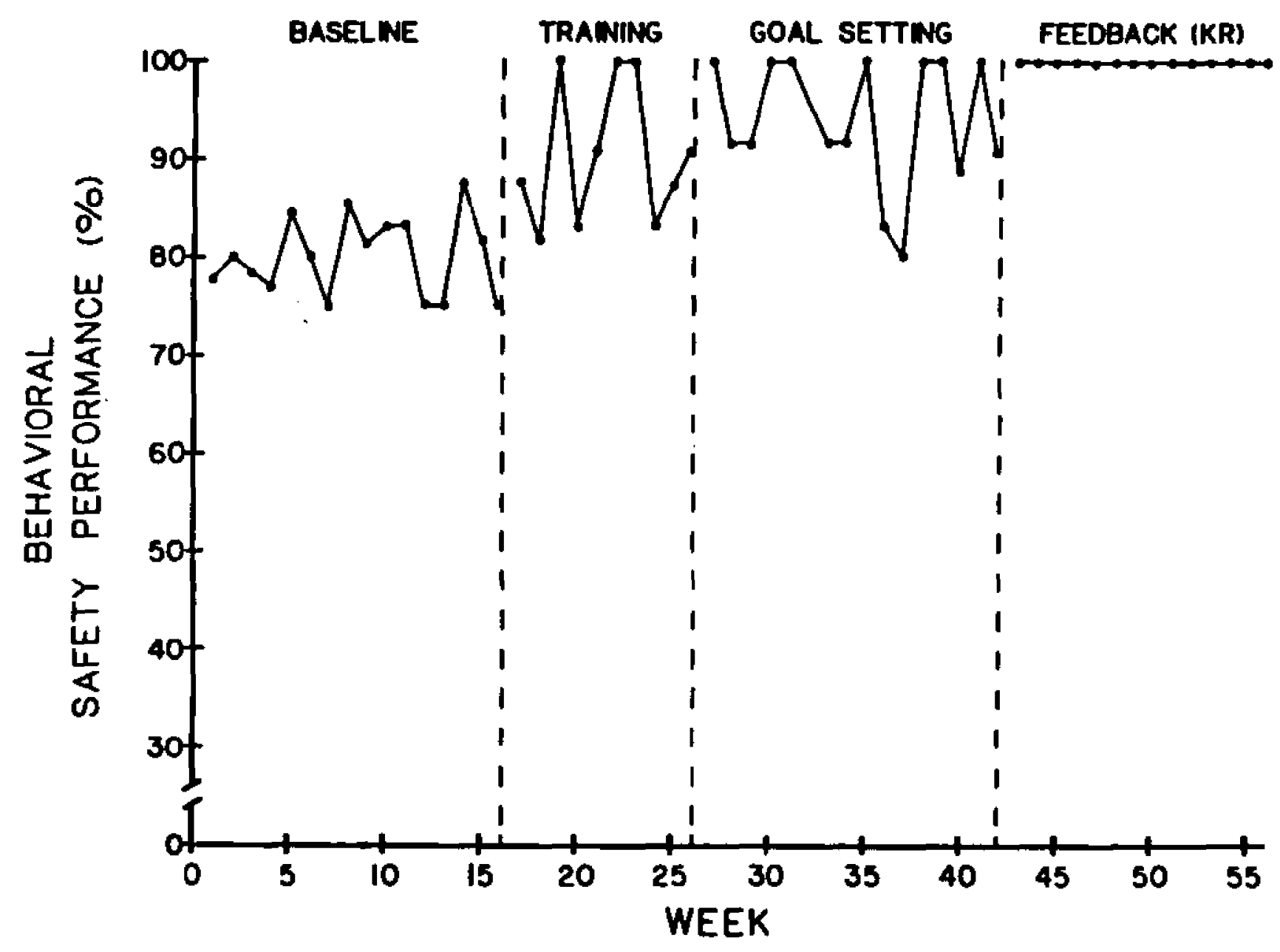

DEPT: WELDING

Figure $2 \mathrm{~h}$. Average weekly safety performance for welding. 


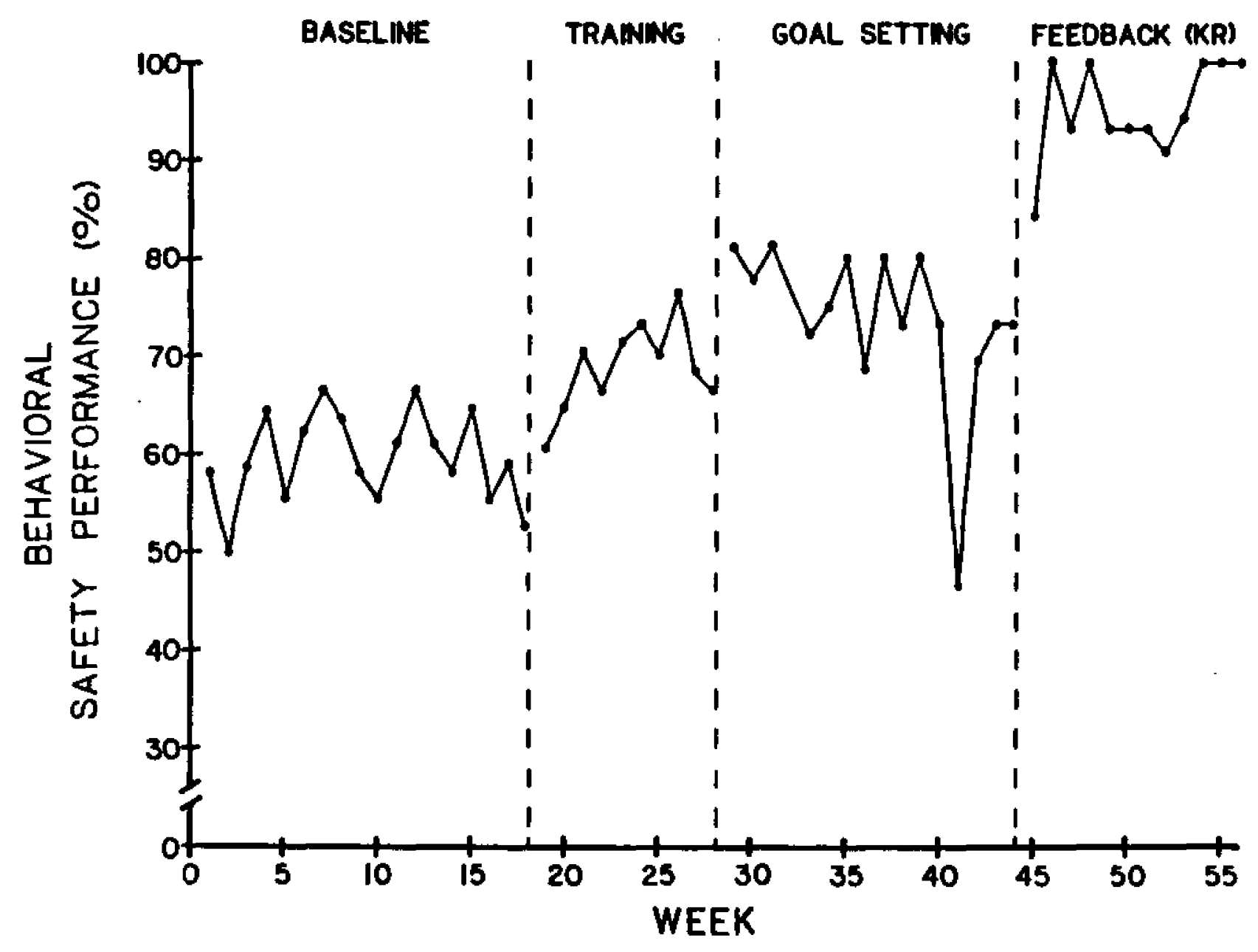

DEPT: CRATING

Figure 2i. Average weekly safety performance for crating. 


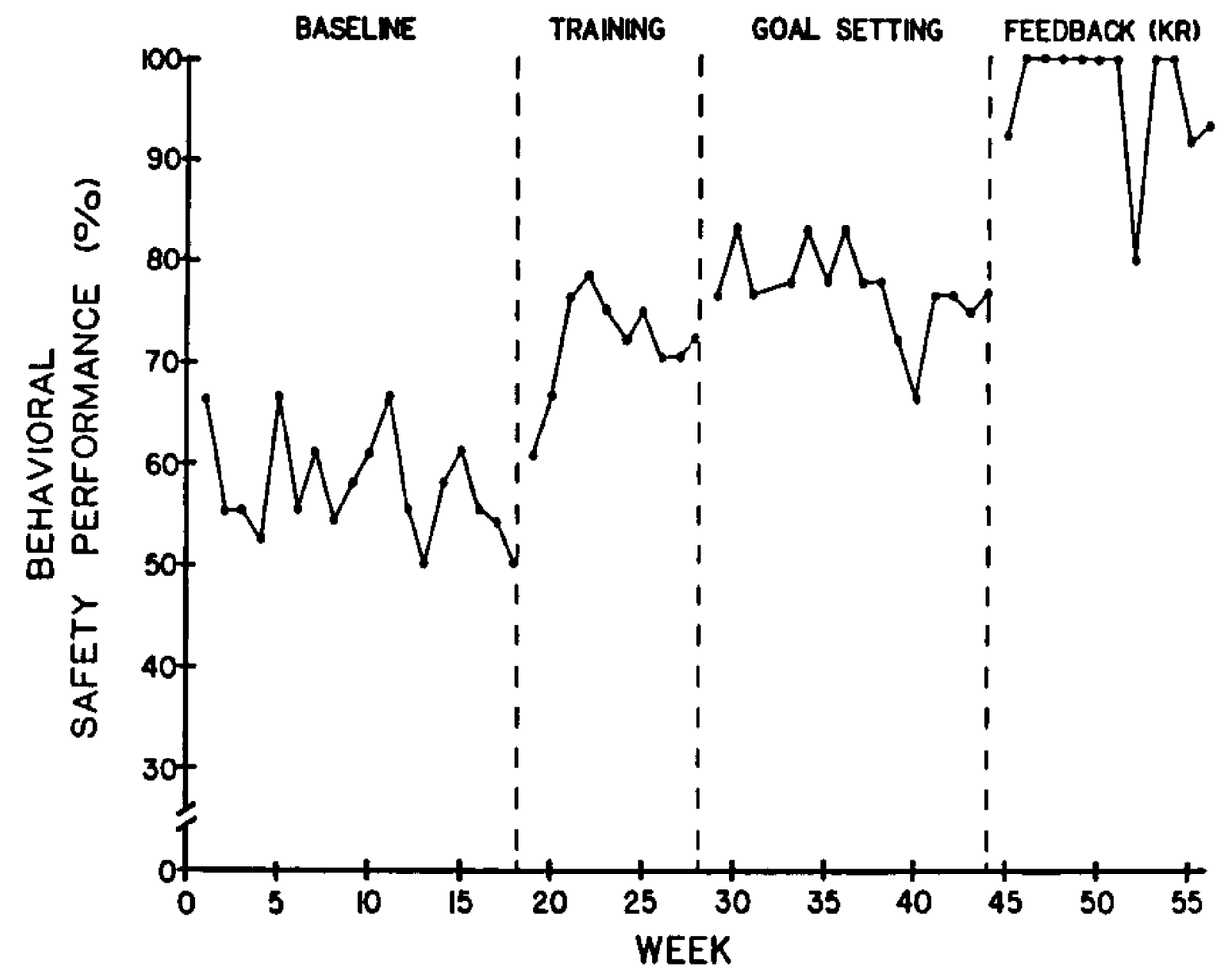

DEPT: MACHINE SHOP

Figure $2 j$. Average weekly safety performance for machine shop. 


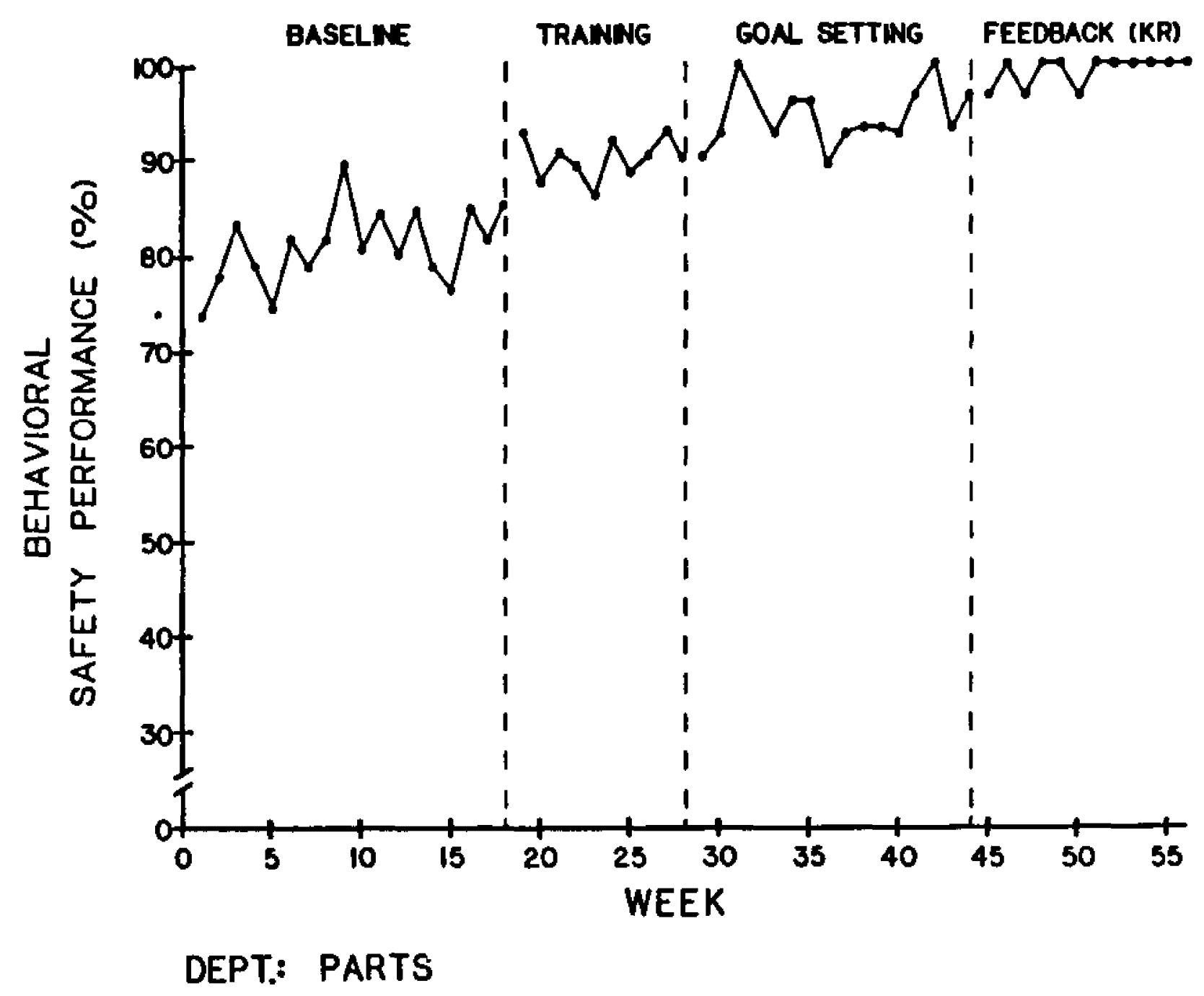

Figure 2k. Average weekly safety performance for parts. 


\section{VITA}

Robert Allen Reber was born in Morgantown, West Virginia on September 15, 1955. After graduating from Parkersburg South High School in 1973, he enrolled in Parkersburg Community College, Parkersburg, West Virginia where he majored in psychology. In the fa11 of 1974 he entered West Virginia University, Morgantown, West Virginia with a double major of psychology and soctology. He received his Bachelor of Arts degree, magna clm laude, in May, 1977. He was also initiated into Phi Beta Kappa and Phi Kappa Phi. In August, 1977, he enrolled in the Graduate School of Louisiana State University, Baton Rouge, Louisiana, majoring in industrialorganizational psychology and minoring in management. He received his Master of Arts degree fron LSU in December, 1979. He is married to the former Debra Lee Hoffman and is a candidate for the Doctor of Philosophy degree at the spring commencement, 1982. 
EXAMINATION AND THESIS REPORT

Candidate: Robert A. Reber

Major Field:

Title of Thesis: The Effects of Training, Goal Setting, and Knowledge of Results on Safe Behavior: A Component Analysis

Approved:
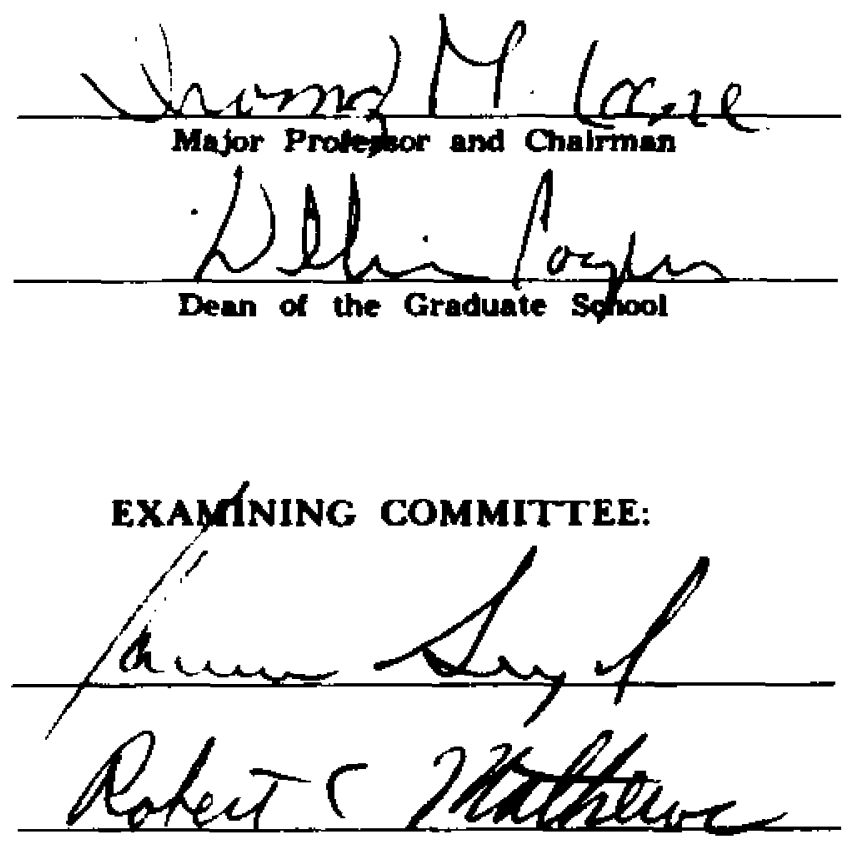

Demy a. Wallis
Donald a. Wilkins

Date of Examination:

Apr11 23, 1982 